\title{
Nursing Students' Understanding and Enactment of Resilience: A Grounded Theory Study
}

Andrew T. Reyes, The University of Western Ontario

Supervisor: Mary-Anne Andrusyszyn, The University of Western Ontario

Joint Supervisor: Carroll Iwasiw, The University of Western Ontario

A thesis submitted in partial fulfillment of the requirements for the Doctor of Philosophy degree

in Nursing

(C) Andrew T. Reyes 2015

Follow this and additional works at: https://ir.lib.uwo.ca/etd

Part of the Nursing Commons

\section{Recommended Citation}

Reyes, Andrew T., "Nursing Students' Understanding and Enactment of Resilience: A Grounded Theory Study" (2015). Electronic Thesis and Dissertation Repository. 2836.

https://ir.lib.uwo.ca/etd/2836

This Dissertation/Thesis is brought to you for free and open access by Scholarship@Western. It has been accepted for inclusion in Electronic Thesis and Dissertation Repository by an authorized administrator of Scholarship@Western. For more information, please contact wlswadmin@uwo.ca. 


\title{
NURSING STUDENTS' UNDERSTANDING AND ENACTMENT OF RESILIENCE: A GROUNDED THEORY STUDY
}

(Thesis Format: Integrated-Article)

$$
\text { by }
$$

Andrew Thomas Reyes

Graduate Program in Nursing

\begin{abstract}
A thesis submitted in partial fulfillment of the requirements for the degree of Doctor of Philosophy
\end{abstract}

The School of Graduate and Postdoctoral Studies

The University of Western Ontario

London, Ontario, Canada

(C) Andrew Thomas Reyes 2015 


\begin{abstract}
The purpose of this study was to explore nursing students' understanding and enactment of resilience. Stress is considered to be a major factor affecting the health, well-being, and academic performance of nursing students. Resilience has been extensively researched as a process that allows individuals to successfully adapt to adversity and develop positive outcomes as a result. However, relatively little is known about the resilience of nursing students. A constructivist grounded theory study design was used. In-depth individual interviews were conducted with 38 nursing students enrolled in a four-year, integrated baccalaureate nursing degree program at a university in Ontario, Canada. Face-to-face interviews were conducted from January to April 2012. The basic social process of pushing through emerged as nursing students' understanding and enactment of resilience. Participants employed this process to withstand challenges in their academic lives. This process was comprised of three main phases: stepping into, staying the course, and acknowledging. Pushing through also included a transient disengaging process in which students were temporarily unable to push through their adversities. The process of pushing through was based on a progressive trajectory, which implied that nursing students enacted the process in order to make progress in their academic lives and to attain goals. Study findings provide important evidence for understanding the phenomenon of resilience as a dynamic, contextual process that can be learned and developed, rather than a static trait or personality characteristic.
\end{abstract}

Keywords: resilience, resiliency, stress, nursing students, constructivist grounded theory, undergraduate students, nursing education, 


\section{Co-Authorship Statement}

Andrew Reyes completed the following work under the supervision of Dr. MaryAnne Andrusyszyn and Dr. Carroll Iwasiw, and advisement of Dr. Cheryl Forchuk and Dr. Yolanda Babenko-Mould. All supervisors and advisors will be co-authors on publications resulting from Chapters Two, Three, and Four of this dissertation. 


\section{Acknowledgments}

I would like to express my heartfelt gratitude to my supervisors, Dr. Mary-Anne Andrusyszyn and Dr. Carroll Iwasiw. Thank you so much for believing in me, for your unwavering support and mentorship, and for your commitment to excellence in nursing education research that is so contagiously inspiring. I also would like to extend a genuine thank you to my advisors Dr. Cheryl Forchuk and Dr. Yolanda Babenko-Mould who provided me valuable insights and feedback for this research. To all four of you, my heart is just overflowing with gratitude for your countless hours of working with my research, providing feedback and support, and expressing encouraging words so I could continue pushing through the challenges that were ahead of me in my doctoral education.

I am also grateful to the Registered Nurses Foundation of Ontario, the Iota Omicron Chapter of the Sigma Theta Tau International, and the Irene E. Nordwich Foundation for financially supporting this work. I also would like to acknowledge the nursing students who participated in this research - may your stories of pushing through inspire current and future nursing students who will also be future leaders of our profession and healthcare.

Finally, I would like to express my gratitude to my family and friends who continually supported me in my doctoral education - special mention to Tatay and Nanay (my parents) and my brother and sisters and their families for their unwavering support and prayers. I am also thankful to my friends, especially Greg, for helping me with proofreading and editing, and being my sounding board. 


\section{Table of Contents}

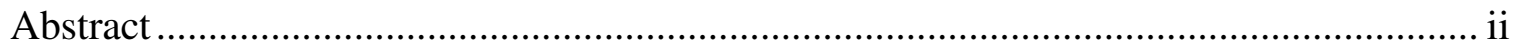

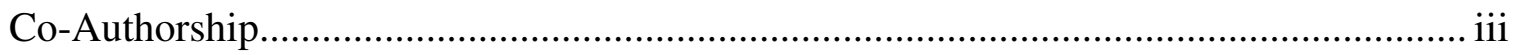

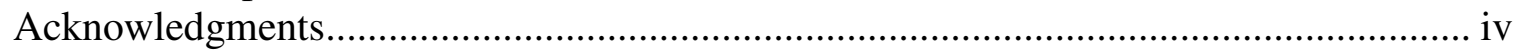

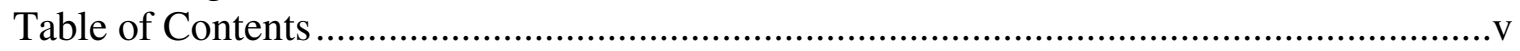

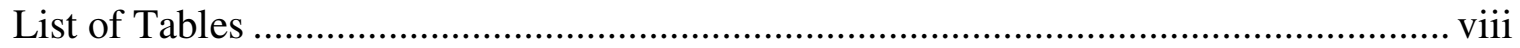

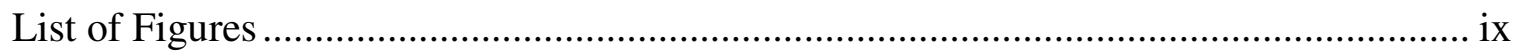

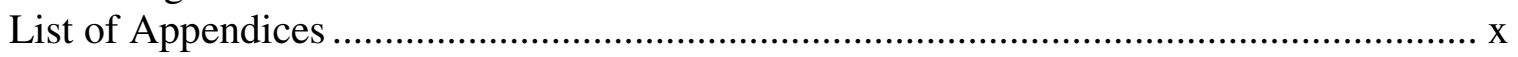

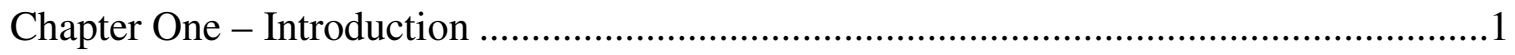

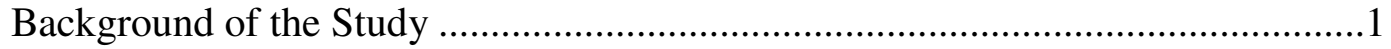

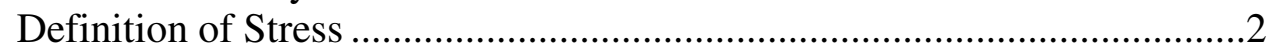

Nursing Student Stressors ..................................................................

Factors that Aggravate Nursing Student Stress .................................... 3

Manifestations of Stress in Nursing Students .........................................4

Resilience as a Stress Mitigator ...........................................................6

Purpose of the Study ................................................................................ 7

Research Questions ...........................................................................

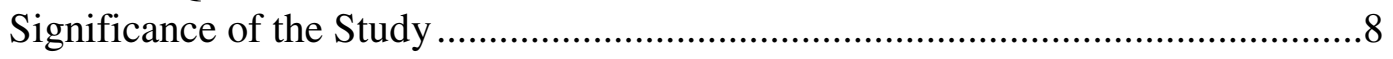

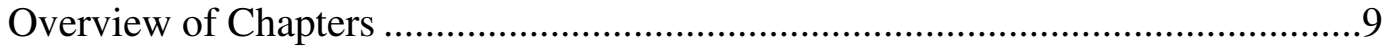

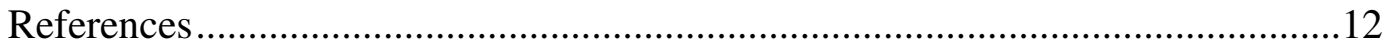

Chapter Two - Resilience in Nursing Education: An Integrative Review .......................22

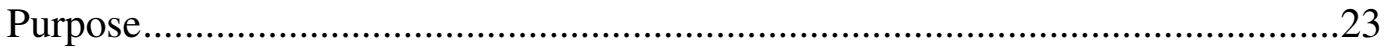

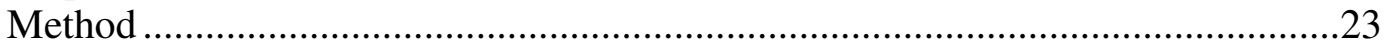

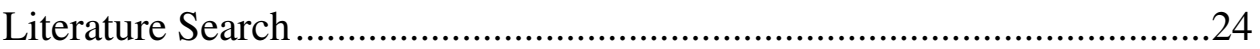

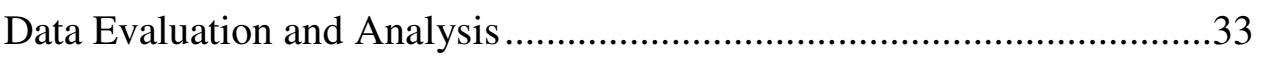

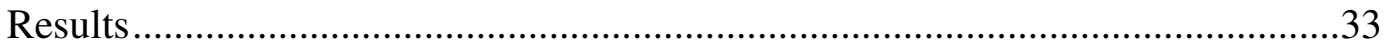

Resilience as Important in Nursing Education....................................33

Resilience as Conceptualized as a Trait or Process .................................35

Resilience as Related to Protective Factors ..............................................36

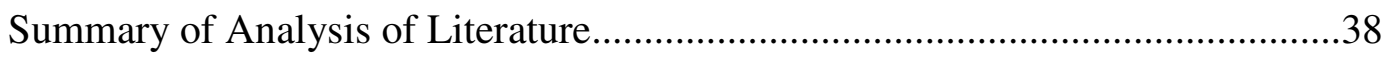

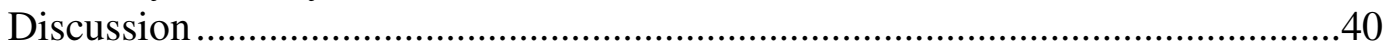

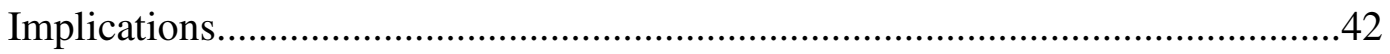

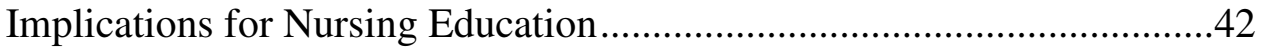

Implications for Nursing Education Research ...................................43

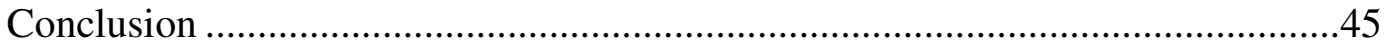

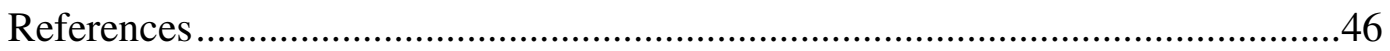

Chapter Three - Nursing Students' Understanding and Enactment of Resilience:

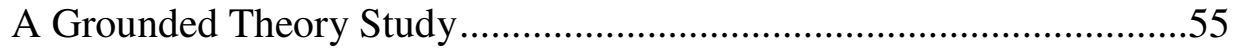

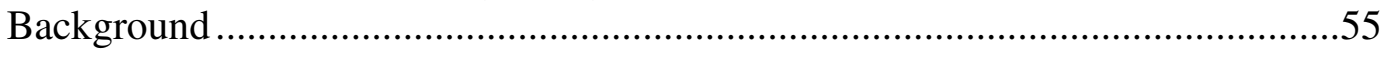

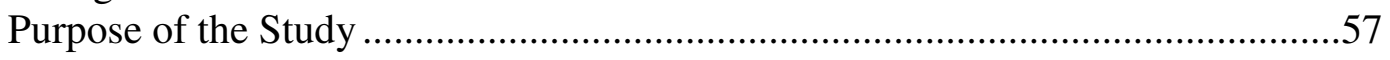

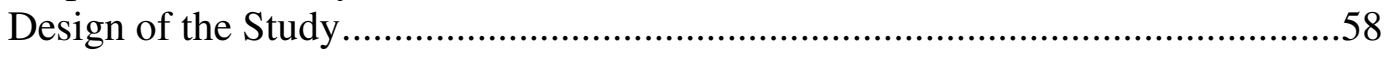

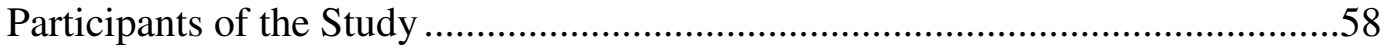




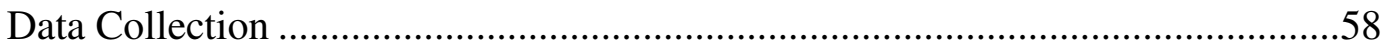

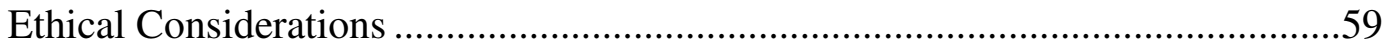

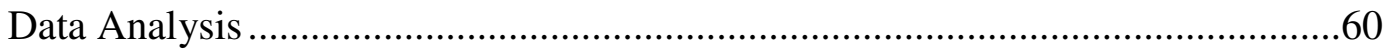

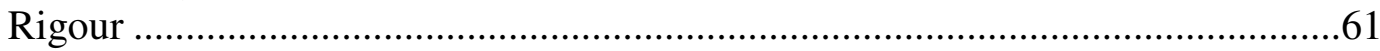

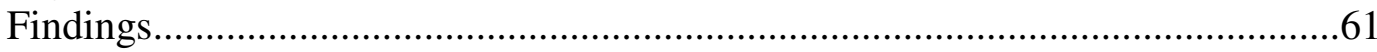

First Phase of Pushing Through: Stepping Into ……………………….....64

Second Phase of Pushing Through: Staying the Course .............................67

Disengaging: An Intersecting Process in the Second Phase of Pushing

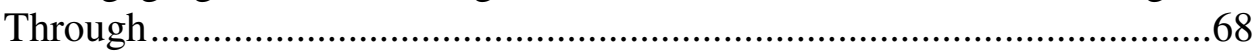

Third Phase of Pushing Through: Acknowledging ....................................69

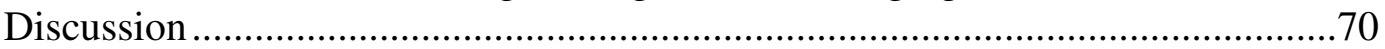

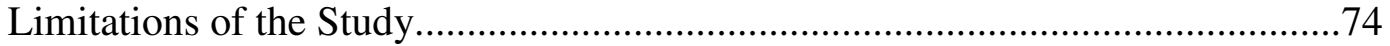

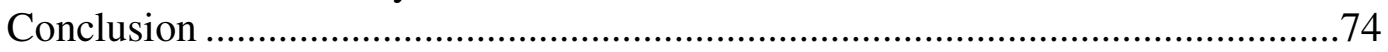

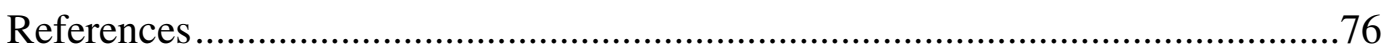

Chapter Four - Exploring Nursing Student Resilience: Rationale, Challenges, and Strengths of Using Constructivist Grounded Theory.........................85

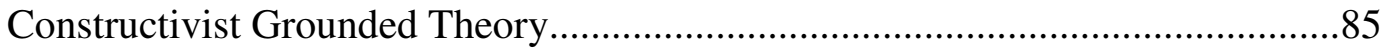

Literature Review of CGT Studies in Nursing Education ....................................87

Summary of a CGT Study on Nursing Students' Resilience ..................................89

Rationale for Using CGT in Exploring Nursing Students' Resilience ...................92

Compatibility of Focus of the Methodology and Purpose of Research .....92

Coherence Between Methodology's Philosophy and the Use of Extant

Concepts ..........................................................................................93

Challenges of Using CGT in Exploring Nursing Students' Resilience .................95

Risk of Forcing Data into Preexisting Concepts........................................95

Risk of Obtaining Insufficient Data ..........................................................98

Advantages of Using CGT in Exploring Nursing Students' Resilience ................99

Recommendations for Using CGT in Nursing Education Research.....................100



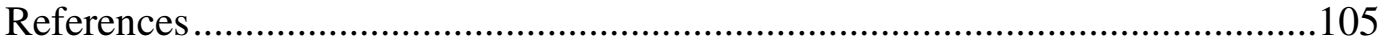

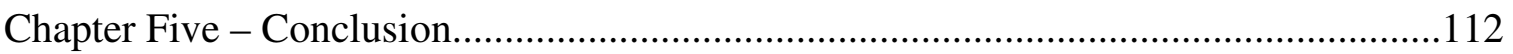

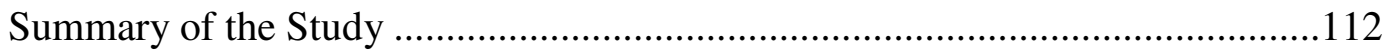

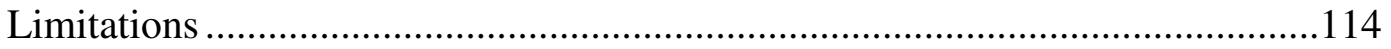

Key Study Findings and Discussion .........................................................115

The Process of Pushing Through .............................................................115

Three Main Phases of Pushing Through ..................................................117

Disengaging Process of Pushing Through ................................................119

Implications for Nursing Education............................................................120

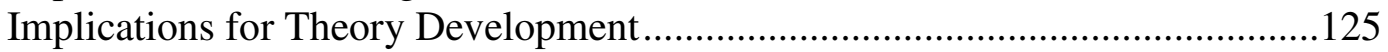

Recommendations for Nursing Students ....................................................128

Recommendations for Nurse Educators.........................................................130

Recommendations for Nursing School Administrators .......................................134

Recommendations for Theory Development ...................................................135 


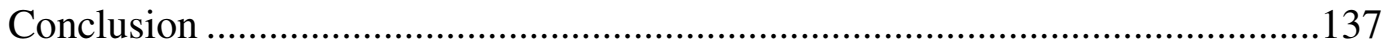

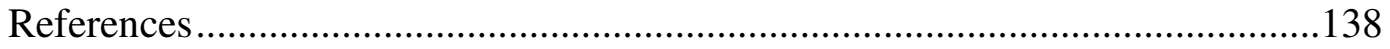



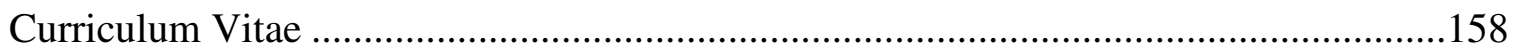




\section{List of Tables}

Table 1: Summary of Empirical Reports on Resilience in Nursing Education ................26

Table 2: Summary of Theoretical Papers on Resilience in Nursing Education.................32

Table 3: Examples of Exemplars Supporting Sub-Processes of Pushing Through ...........65

Table 4: Examples of Classic or Glaserian and Straussian Grounded Theory Studies in

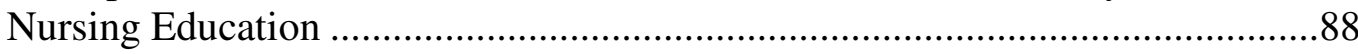




\section{List of Figures}

Figure 1: The Grounded Theory of Pushing Through ..................................................63 


\section{List of Appendices}

Appendix A: Semi-Structured Interview Guide for Participants .................................143

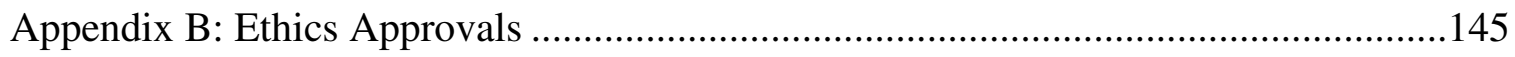

Appendix C: Letter of Permission to Conduct the Study ...........................................147

Appendix D: Letter of Permission to Promote the Study in a Classroom Session ..........149

Appendix E: Letter of Information to Participants ................................................151

Appendix F: Participant Consent Form .............................................................. 153

Appendix G: Demographic Data Questionnaire ...................................................... 154

Appendix H: Recruitment Poster/Flyer for Students ............................................156

Appendix I: Email Communication to Students Forward by the Designated School

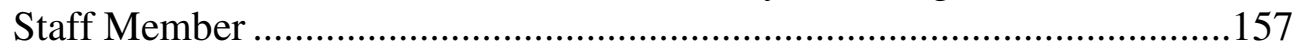




\section{Chapter One - Introduction}

This grounded theory study was conducted to explore nursing students' understanding and enactment of resilience. Background information relevant to the study is presented in this chapter. The purpose and significance of the study as well as an overview of the chapters within this dissertation are described.

\section{Background of the Study}

Stress is a common and potentially debilitating concern for nursing students. Their reactions to stressful situations in their academic lives can negatively affect their physical, mental, and psychological health, and can adversely affect their academic performance. However, resilience can allow nursing students to thrive despite this stress. Resilience is defined as a "human capacity of successful adaptation despite challenging or threatening circumstances” (Masten, Best, \& Garmezy, 1990, p. 426). Resilience pertains to a combination of behaviours, abilities, and characteristics that allow an individual to cope successfully with significant stress or adversity (Rutter, 1993). Resilience is also a dynamic process that enables individuals to demonstrate positive adaptation in the face of significant adversity or difficulty (Luthar, Cicchetti, \& Becker, 2000).

Resilience can be seen as a positive response to stress. Resilient individuals are not only able to buffer the negative impacts of stress (Hodges, Keeley, \& Troyan, 2008; House, 1981; Rutter, 1993), but they bounce back from their challenges and move beyond their adversities (Hodges et al., 2008; Rutter, 1993). They have the capacity to overcome their situations, achieve their goals, and develop mastery of other situations (Dyer \& McGuinness, 1996). Therefore, resilience should be beneficial to nursing students who experience stress and adversities in their academic lives. 


\section{Definition of Stress}

Stress is defined as "a particular relationship between the person and the environment that is appraised by the person as taxing or exceeding his or her resources and endangering his or her wellbeing" (Lazarus \& Folkman, 1984, p. 19). Lazarus and Folkman further explained that an event is perceived as stressful if the person evaluates the event as threatening (such as the possibility of causing harm to the person) and sees that there is a lack of resources and capacity to deal with the threatening situation. Therefore, there are three aspects of the stress process: (a) sources of stress or also called stressors; (b) stress which is considered a set of psychophysiological reactions to stressors; and (c) coping which refers to the person's attempts at dealing with these reactions (Pryjmachuk \& Richards, 2007).

\section{Nursing Student Stressors}

Nursing students are continually faced with different types of stressors (Magnussen \& Amundson, 2003; Pulido-Martos, Augusto-Landa, \& Lopez-Zafra, 2012). These stressors can be academic, clinical, and personal. Some of these academic stressors are perceived stress from examinations and assessments (Evans \& Kelly, 2004; Howard, 2001; Kipping, 2000), fear of failing examinations (Higginson, 2006), increased academic workload (Barboza \& Soares, 2012; Evans \& Kelly, 2004), and disorganized and overwhelming course structure (Gibbons, Dempster, \& Moutray, 2008).

Nursing students' practicum areas have been identified as one of the leading stressors in their academic lives (Thomas, Jack, \& Jinks, 2012). More specifically, the sources of stress in practicum areas involve fear of making mistakes (Kim, 2003; Sharif \& Masoumi, 2005), interpersonal difficulties with health care staff in clinical placements (Crombie, Brindley, Harris, Marks-Maran, \& Thompson, 2013; Howard, 2001; Jackson et al., 2011), 
dealing with death and dying (Timmins \& Kaliszer, 2002), lack of competence (Sheu, Lin, \& Hwang, 2002), and being emotionally involved with care of patients (Gorostidi et al., 2007).

Personal and social stressors of nursing students include financial difficulties (Brown \& Edelmann, 2000; Lo, 2002; Timmins \& Kaliszer, 2002) and the competitive nature of relationships and difficulties of getting along with their peers (Chan, So, \& Fong, 2009; Sheu et al., 2002). It is interesting to note that nursing students are not only distressed about how personal and social aspects of their lives impact their academic performance; they also say that their academic and clinical workload could in turn negatively affect their social and personal lives (Jimenez, Navia-Osorio, \& Diaz, 2010).

\section{Factors that Aggravate Nursing Student Stress}

There are factors within nursing students' educational process that aggravate their stress. For example, due to the nursing faculty shortage, teachers experience role strain, that in turn impacts the level of academic support for nursing students and the stress they are already experiencing (Health Canada, 2006; Oermann, 2004). Additionally, because of the increasing complexity and acuity of patient conditions as well as nursing staff shortages in nursing practice areas, professional nurses who support students in clinical settings are experiencing work-related distress and burnout (Nevidjon \& Erickson, 2006), resulting in students' feelings of inadequacy and insecurity, fear of making mistakes, and the perception

of incompetence in caring for patients (Gibbons et al., 2008; Higginson, 2006; Oermann \& Lukomski, 2001; Shipton, 2002).

With increasing diversity in the cultural and ethnic backgrounds of nursing student populations, it behooves nurse educators to provide constructive and relevant learning environments for students (Bednarz, Schim, \& Doorenbos, 2010; Williams \& Calvillo, 2002). Jeffreys (2006) suggests that the increasing cultural diversity of nursing student 
populations makes supporting nursing students' persistence in their nursing programs and academic success even more complicated. Nursing students from diverse ethnic backgrounds have experienced stress due to lack of support from nursing teachers which in turn affects their academic performance (Amaro, Abriam-Yago, \& Yoder, 2006; Gardner, 2005; Omeri, Malcolm, Ahern, \& Wellington, 2003). Changing demographic characteristics as aggravating factors to nursing students' stress are not only based on cultural backgrounds. Additionally, being married, having children, being employed, and commuting to campus have also been linked with nursing student stress (Gigliotti, 2004; Nicholl \& Timmons, 2005; Yonge, Myrick, \& Haase, 2002; Zeitlin-Ophir, Melitz, Miller, Podoshin, \& Mesh, 2004). Issues such as unstable national and global economies, rising tuition, and the ongoing struggle of balancing school, family, and work also negatively impact the stress nursing students are already encountering (Gigliotti, 2004; Nicholl \& Timmons, 2005; Vanhanen \& Janhonen, 2000; Zeitlin-Ophir et al., 2004).

\section{Manifestations of Stress in Nursing Students}

Stress affects many aspects of nursing students' lives. First, stress influences academic outcomes. High levels of stress among nursing students has been associated with poor academic performance, memory and concentration problems, and deficiencies in problem-solving ability (Al-Kandari \& Vidal, 2007; Higginson, 2006; Oermann \& Lukomski, 2001; Wells, 2007). Continued experiences of stress during the educational process of nursing students can impact their learning and academic performance (Jimenez et al., 2010; Yonge et al., 2002) and even decrease the quality of patient care students provide (Caldwell, 2000). Stress also affects nursing students' persistence in their programs. For example, in a qualitative study involving nursing students who withdrew from their nursing 
program, Wells (2007) reported that one of the main reasons for leaving the program was the ongoing and continued experience of increasing levels of stress from their academic lives.

There are also serious, negative health outcomes of stress among nursing students. Symptoms of depression and anxiety are mental health effects of nursing student stress (Reeve, Shumaker, Yearwood, Crowell, \& Riley, 2013; Ross et al., 2005; Stecker, 2004). It is also documented that nursing students resort to substance-dependence behaviours such as increased use of alcohol and chemical substances and smoking (Freeburn \& Sinclair, 2009; Stecker, 2004; Tully, 2004) as a result of increasing levels of stress. Suicidal tendencies have also been associated with nursing student stress (Stecker, 2004).

Psychological distress is a common but debilitating manifestation of stress among nursing students (Dzurec, Allchin, \& Engler, 2007; Freeburn \& Sinclair, 2009; KlaininYobas et al., 2014; Watson, Deary, Thompson, \& Li, 2008; Watson et al., 2009). In Nolan and Ryan's (2008) study of nursing students' stress, they reported that $48 \%$ of the respondents had stress levels above the threshold score, indicating levels of distress that were not likely to resolve without proper and prompt intervention. Other symptoms of emotional and psychological distress include feelings of being overwhelmed and overloaded, loneliness, and sense of inadequacy (Dzurec et al., 2007); fear of sharing or disclosing their experience of stress (Chipas \& McKenna, 2011); negative self-esteem (Lo, 2002); and exhaustion and lack of control in relation to workload (Nolan \& Ryan, 2008).

Lastly, increased levels of stress are also significantly associated with poor physical health (Freeburn \& Sinclair, 2009; Klainin-Yobas et al., 2014). Some of these physical symptoms include weight gain, nausea and vomiting, chest pain, vertigo, poor sleep (Freeburn \& Sinclair, 2009; Sheu et al., 2002); gastrointestinal disorders (Lee, Mun, Lee, \& Cho, 2011); and lower back pain (Mitchell et al., 2009). Although stress accounts for greater 
variance in psychological distress than in poor physical health (Klainin-Yobas et al., 2014), negative physical health outcomes of stress should be given equal attention to those of psychological and mental health effects of stress. More particularly, Klainin-Yobas et al. reported in their study of nursing student stress that there was a greater mediating effect of coping on physical health than on psychological distress. Therefore, it is imperative that further investigation be conducted to explore factors that ameliorate and mitigate the effects of stress on nursing students.

\section{Resilience as a Stress Mitigator}

Resilience has been described as a dynamic process that mitigates the effects of stress through behaviours that facilitate adaptation in the context of adversity, resulting in the ability to function above the norm in spite of significant stress (Tusaie \& Dyer, 2004). Resilience is also viewed as a preventive strategy that inhibits the debilitating effects of chronic stress (Kelley, 2004; Sedgeman, 2005, 2008).

Because stress is a major part of nursing students' academic lives, resilience may be required for them to buffer the negative impacts of stress. Since stress continues to adversely influence students' academic lives as they progress in their education (Dixon \& RobinsonKurpius, 2008; Misra, McKean, West, \& Russo, 2000), it is paramount for nursing students to develop and enhance their resilience to help them withstand the challenges and adversities within their education.

It is also important to take note that, despite the unrelenting and demanding nature of the educational process for nursing students, many have not succumbed to the pressures of their academic lives but rather have remained effective in attaining their academic goals and completing their educational programs. One of the factors that may account for students' thriving despite challenges and stress is resilience. Resilience allows individuals to reframe, 
adapt, balance, and persist in the face of difficulties and adversities (Wolin \& Wolin, 1994), while being able to experience some insight and growth through their challenges (Richardson, 2002) and develop mastery over other situations (Dyer \& McGuinness, 1996). Many nursing education research studies indicate the benefits of resilience in nursing students' academic lives. Resilience contributed to nursing students' meeting their challenges and academic goals (Carroll, 2011; Crombie et al., 2013; Knight et al., 2012; Peters, 2003; Williamson, Health, \& Proctor-Childs, 2013). However, despite the growing number of studies of nursing students' resilience, there remains limited description of nursing students' resilience, particularly their understanding and enactment of resilience. For this reason, this grounded theory study has focused on exploring nursing students' understanding and enactment of resilience to gain broader knowledge of how nursing students thrive in adversities and produce positive academic outcomes despite challenges and stress. Hence, this grounded theory may extend the limited theoretical explication of nursing students' resilience in the nursing education literature.

\section{Purpose of the Study}

The purpose of this study was to describe nursing students' understanding and enactment of resilience in their academic lives. More specifically, the aim of this study was to generate a grounded theory that represents nursing students' understanding and enactment of resilience. The emerging grounded theory of the study can provide information on how nursing students overcome adversities, thrive in difficult academic situations, and develop positive adaptation despite challenging circumstances. Furthermore, the results of this study may offer a strength-based perspective in nursing education research regarding nursing student stress, in which attention is given to students' capacities, resources, and strengths rather than weaknesses and deficits. 


\section{Research Questions}

Two research questions were addressed in this study. 1) How do nursing students understand resilience in the context of their academic lives? 2) How do nursing students enact resilience in the context of their academic lives?

\section{Significance of the Study}

Nursing students experience stress throughout their higher education. It does not stop after their first year. Rather, their stress levels, use of negative coping mechanisms, and psychological morbidities continue to increase as they progress in their education (Deary, Watson, \& Hogston, 2003). Undergraduates are generally experiencing more pronounced levels of stress these days (Gallagher, 2009). Additionally, there is an increasing number of students arriving on college and university campuses with severe psychological issues (Gallagher, 2009; Storrie, Ahern, \& Tuckett, 2010) that may compromise how they cope with the challenges of their education. Continued ineffective coping with stress has been documented to produce deleterious effects on the well-being and academic performance of nursing students, and has resulted in their leaving their programs (Wells, 2007). For most of these students, dealing with stress in their academic lives is almost inevitable. Hence, it is imperative to support students in the development of resilience to adapt, persist, and overcome adversities.

Many experts claim that resilience can be taught (Seligman, Ernst, Gillham, Reivich, \& Linkins, 2009) and developed (Bernard, 2004; Hodges et al., 2008; Reivich \& Shattè, 2002), which then implies that resilience can be fostered through various strategies and processes. Therefore, it behooves nurse educators and researchers to further explore the phenomenon of resilience in the context of nursing education. With increased understanding of the complex phenomenon of resilience as it applies to nursing education, nurse educators 
and administrators in academic settings can implement evidence-based pedagogical interventions that will engender the resilience of nursing students.

To date there is little description of resilience within the context of nursing education. Additionally, studies that examine the resilience of nursing students are scarce. There is also very limited description in nursing education research that explains nursing students' perceptions of resilience and how resilience is enacted in their academic lives.

If a goal of nursing education programs is to produce academically excellent students who can thrive as professional, competent, and knowledgeable nurses in stressful and rapidly changing work environments, then it is imperative that nursing students develop resilience and positively adapt to challenges during their education. Therefore, this study is important because the findings can provide significant contributions to the limited, existing evidence of nursing student resilience.

\section{Overview of Chapters}

This dissertation has been prepared in the integrated-article format containing five chapters. Three chapters (chapters 2, 3, and 4) within this dissertation are created as manuscripts for selected journals. Each manuscript represents a stand-alone journal article to be submitted for publication. Therefore, some repetition is evident among chapters. Furthermore, the advantage of an integrated-article format is that it allows timely dissemination of the dissertation research.

This Chapter (Chapter One) contains the introduction, which sets the stage for the importance of conducting the research study. Chapter One includes the background of the study, such as the definitions of resilience and stress, an overview of nursing students' sources of stress or stressors, aggravating factors and manifestations of stress among nursing students, resilience as a stress mitigator, and the purpose and significance of the study. 
Chapter Two is an integrative review of past research studies and theoretical papers about resilience in nursing education. The purpose of this integrative review was to evaluate the current state of knowledge of resilience in nursing education. Whittemore and Knafl's (2005) integrated review method was used to analyze and synthesize literature on resilience in nursing education. Results of this integrative review provide implications for understanding the importance of fostering resilience in nursing students and the significance of further research of resilience within the specific context of nursing education.

Chapter Three consists of the key findings of the study. The focus of this chapter is the emerging grounded theory of pushing through, as the main result of the study. The grounded theory of pushing through represents nursing students' understanding and enactment of resilience. In this chapter, the three different phases of the process of pushing through are discussed: (1) stepping into; (2) staying the course; and (3) acknowledging. Specific responses in each of these phases are explained and illustrated with key participant quotations. Moreover, a process called disengaging, which is a distinct process within the staying the course (second phase of pushing through), is explored as an emerging aspect of nursing students' experience of resilience to indicate that the grounded theory of pushing through is not a straight-forward, linear, and unhindered process. Implications of the study findings and recommendations for nurse educators, nursing administrators, and nursing education researchers are provided within this chapter.

Chapter Four is a methodological paper, in which the usefulness of constructivist grounded theory (CGT) is examined as a research methodology in exploring the resilience of nursing students. The focus of this manuscript is to explore the rationales, challenges, and advantages of using constructivist grounded theory methodology in investigating the phenomenon of resilience. This chapter provides philosophical and methodological 
implications for researchers interested in employing constructivist grounded theory in resilience research and in nursing education research.

Finally, Chapter Five, which is the conclusion of the dissertation, consists of the summary and limitations of the study. Key findings of the study are also presented. This chapter also includes a discussion of the major findings as they relate to existing conceptualizations of resilience in the literature and as to how the findings contribute to the current state of knowledge of resilience in nursing education research. In-depth exploration of key implications of the study findings and recommendations for nursing students, nurse educators, nursing education program administrators, and theory development are also included. This chapter concludes with a brief discussion of the unique contribution of the emerging grounded theory to the current state of knowledge of the resilience of nursing students. 


\section{References}

Al-Kandari, F., \& Vidal, V. (2007). Correlation of the health-promoting lifestyle, enrollment level, and academic performance of College of Nursing students in Kuwait. Nursing and Health Sciences, 9, 112-119. doi: 10.1111/j.1442-2018.2007.00311.x

Amaro, D. J., Abriam-Yago, K., \& Yoder, M. (2006). Perceived barriers for ethnically diverse students in nursing programs. Journal of Nursing Education, 45, 247-254.

Barboza, M. C., \& Soares, M. H. (2012). Analysis of stress-causing factors in the final undergraduate year of the nursing course. Acta Scientiarum. Health Sciences, 34, 177183. doi: 10.4025/actascihealthsci.v34i2.9209

Bednarz, H., Schim, S., \& Doorenbos, A. (2010). Cultural diversity in nursing education: Perils, pitfalls, and pearls. Journal of Nursing Education, 49, 253-260. doi: 10.3928/01484834-20100115-02

Bernard, B. (2004). Resilience: What we have learned. San Francisco, CA: West Ed.

Brown, H., \& Edelmann, R. (2000). Project 2000: A study of expected and experienced stressors and support reported by students and qualified nurses. Journal of Advanced Nursing, 31, 857-864. doi: 10.1046/j.1365-2648.2000.01344.x

Caldwell, R. (2000) Quality nursing care: An exploration of student nurses' perspectives. Retrieved from ProQuest Dissertations and Theses database. (UMI No. 9976850)

Carroll, S. (2011). Resilience as a factor in the successful completion of a California community college based associate degree in nursing program (Doctoral dissertation). Retrieved from ProQuest Dissertations and Theses database. (UMI No. 3454870) 
Chan, C. K. L., So, W. K. W., \& Fong, D. Y. T. (2009). Hong Kong baccalaureate nursing students' stress and their coping strategies in clinical practice. Journal of Professional Nursing, 25, 307-313. doi: 10.1016/j.profnurs.2009.01.018

Chipas, A., \& McKenna, D. (2011). Stress and burnout in nurse anesthesia. AANA Journal, 79, 122-128. Retrieved from http://www.aana.com/Documents/stress_0411_ p122-128.pdf

Crombie, A., Brindley, J., Harris, D., Marks-Maran, D., \& Thompson, T. M. (2013). Factors that enhance rates of completion: What makes students stay? Nurse Education Today, 33, 1282-1287. doi: 10.1016/j.nedt.2013.03.020

Deary, I. J, Watson, R., \& Hogston, R. (2003). Longitudinal cohort study of burnout and attrition in nursing students. Journal of Advanced Nursing, 43, 71-81. doi: 10.1046/j.1365-2648.2003.02674.x

Dixon, S. K., \& Robinson-Kurpius, S. E. (2008). Depression and college stress among university undergraduates: Do mattering and self-esteem make a difference? Journal of College Student Development, 49, 412-424. doi: 10.1353/csd.0.0024

Dyer, J. G., \& McGuinness, T. M. (1996). Resilience: Analysis of the concept. Archives of Psychiatric Nursing, 5, 276-282. doi: 10.1016/S0883-9417(96)80036-7

Dzurec, L. C., Allchin, L., \& Engler, A. J. (2007). First-year nursing students' accounts of reasons for student depression. Journal of Nursing Education, 46, 545-451.

Evans, W., \& Kelly, B. (2004). Pre-registration diploma student nurse stress and coping measures. Nurse Education Today, 24, 473-482. doi: 10.1016/j.nedt.2004.05.004

Freeburn, M., \& Sinclair, M. (2009). Mental health nursing students' experience of stress: Burdened by a heavy load. Journal of Psychiatric and Mental Health Nursing 16, 335-342. doi: 10.1111/j.1365-2850.2008.01376.x 
Gallagher, R. (2009). National survey of counseling center directors, 2009. Retrieved from http://www .education.pitt.edu /survey/nsccd/archive/2009/monograph.pdf.

Gardner, J. (2005). Barriers influencing the success of racial and ethnic minority students in nursing programs. Journal of Transcultural Nursing, 16, 155-162. doi: $10.1177 / 1043659604273546$

Gibbons, C., Dempster, M., \& Moutray, M. (2008). Stress and eustress in nursing students. Journal of Advanced Nursing, 61, 282-290. doi: 10.1111/j.1365-2648.2007.04497.x

Gigliotti, E. (2004). Types and sources of social support and maternal-student role stress in married associate degree nursing students. Issues in Mental Health Nursing, 25, 415432. doi: $10.1080 / 01612840490432943$

Gorostidi, X. Z., Egilegor, X. H., Erice, M. J. A., Iturriotz, M. J. U., Garate, I. E., Lasa, M. B., \& Cascante, X. S. (2007). Stress sources in nursing practice. Evolution during nursing training. Nurse Education Today, 27, 777-787. doi:

10.1016/j.nedt.2006.10.017

Health Canada (November 2006). Nursing issues: Education. Retrieved from http://www.hcsc.gc.ca/hcs-sss/pubs/nurs-infirm/onp-bpsi-fs-if/2006-educ-eng.php

Higginson, R. (2006). Fears, worries and experiences of first-year pre-registration nursing students: A qualitative study. Nurse Researcher, 13(3), 32-49. doi: $10.7748 / \mathrm{nr} 2006.04 \cdot 13.3 .32 . c 5977$

Hodges, H. F., Keeley, A. C., \& Troyan, P. J. (2008). Professional resilience in baccalaureate-prepared acute care nurses: First steps. Nursing Education Perspectives, 29, 80-89. doi: 10.1043/1094-2831(2008)29[80:PRIBAC]2.0.CO;2 
House, J. (1981). Work, stress, and social support. Reading, MA: Addison-Wesley.

Howard, D. A. (2001). Student nurses' experience of Project 2000. Nursing Standard, 15(48), 33-38. doi: 10.7748/ns2001.08.15.48.33.c3071

Jackson, D., Hutchinson, M., Everett, B., Mannix, J., Peters, K., Weaver, R., \& Salamonson, Y. (2011). Struggling for legitimacy: Nursing students' stories of organisational aggression, resilience, and resistance. Nursing Inquiry, 18, 102-110. doi:

10.1111/j.1440-1800.2011.00536.x

Jeffreys, M. R. (2006). Teaching cultural competence in nursing and health care: Inquiry, action, and innovation. New York: Springer.

Jimenez, C., Navia-Osorio, P. M. \& Diaz, C. V. (2010) Stress and health in novice and experienced nursing students. Journal of Advanced Nursing, 66, 442-455. doi:

10.1111/j.1365-2648.2009.05183.x

Kelley, T. M. (2004). Positive psychology and adolescent mental health: False Promise or True Breakthrough? Adolescence, 39, 257-277. Retrieved from http://www.threeprinciplesmovies.com/threeprinciplesmovies/cache/file/CE43362E1B07-4EE7-B67D1C5316A0AF75.pdf

Kim, K. H. (2003). Baccalaureate nursing students' experiences of anxiety producing situations in the clinical setting. Contemporary Nurse: A Journal for the Australian Nursing Profession, 14, 145-155. doi: 10.5172/conu.14.2.145

Kipping, C. J. (2000). Stress in mental health nursing. International Journal of Nursing Studies, 37, 207-218. doi: 10.1016/S0020-7489(00)00006-7 
Klainin-Yobas, P., Keawkerd, O., Pumpuang, W., Thunyadee, C., Thanoi, W., \& He, H. G. (2014). The mediating effects of coping on the stress and health relationships among nursing students: a structural equation modeling approach. Journal of Advanced Nursing 70, 1287-1298. doi: 10.1111/jan.12283

Knight, J., Corbett, A., Smith, C., Watkins, B., Hardy, R., \& Jones, G. (2012). What made me stay? A review of the reasons student nurses enrolled in a bachelor of nursing programme completed their studies: A descriptive phenomenological study. Nurse Education Today, 32, e62-65. doi: 10.1016/j.nedt.2012.03.007

Lazarus, R., \& Folkman, S. (1984). Stress, appraisal, and coping. New York, NY: Springer. Lee, E. Y., Mun, M. S., Lee, S. H., \& Cho, H. S. M. (2011). Perceived stress and gastrointestinal symptoms in nursing students in Korea: A cross-sectional survey. BMC Nursing, 10, Article 22. doi: 10.1186/1472-6955-10-22

Lo, R. (2002). A longitudinal study of perceived level of stress, coping and self-esteem of undergraduate nursing students: An Australian case study. Journal of Advanced Nursing, 39, 119-126. doi: 10.1046/j.1365-2648.2000.02251.x

Luthar, S. S., Cicchetti, D., \& Becker, B. (2000). The construct of resilience: A critical evaluation and guidelines for future work. Child Development, 71, 543-562. doi: $10.1111 / 1467-8624.00164$

Magnussen, L., \& Amundson, M. J. (2003). Undergraduate nursing student experience. Nursing and Health Sciences, 5, 261-267. doi: 10.1046/j.1442-2018.2003.00158.x Masten, A. S., Best, K. M., \& Garmezy, N. (1990). Resilience and development: Contributions from the study of children who overcome adversity. Development and Psychopathology, 2, 425-444. doi: 10.1017/S0954579400005812 
Misra, R., McKean, M., West, S., \& Russo, T. (2000). Academic stress of college students: Comparison of student and faculty perceptions. College Student Journal, 34, 236245.

Mitchell, T., O’Sullivan, P. B., Smith, A., Burnett, A. F., Straker, L., Thornton, J., \& Rudd, C. J. (2009). Biopsychosocial factors are associated with low back pain in female nursing students: A cross-sectional study. International Journal of Nursing Studies, 46, 678-688. doi: 10.1016/j.ijnurstu.2008.11.004

Nevidjon, B., \& Erickson, J. I. (2006). The nursing shortage: Solutions for the short and long term. In L. C. Andrist, P. K. Nicholas, K. A. Wolf, \& K. Wolf (Eds.), A history of nursing ideas (pp. 461-469). Sudbury, MA: Jones \& Bartlett Publishers.

Nicholl, H., \& Timmons, F. (2005). Programme-related stressors among part-time undergraduate nursing students. Journal of Advanced Nursing, 50, 93-100. doi: 10.1111/j.1365-2648.2004.03352.x

Nolan, G., \& Ryan, D. (2008). Experience of stress in psychiatric nursing students in Ireland. Nursing Standard, 22(43), 35-43. doi: 10.7748/ns2008.07.22.43.35.c6583

Oermann, M. H. (2004). Reflections on undergraduate nursing education: A look to the future. International Journal of Nursing Education Scholarship, 1, Article 5. doi: 10.2202/1548-923X.1011

Oermann, M. H., \& Lukomski, A. P. (2001). Experiences of students in pediatric nursing clinical courses. Journal for Specialists in Pediatric Nursing, 6, 65-72. doi: 10.1111/j.1744-6155.2001.tb00123.x

Omeri, A., Malcolm, P., Ahern, M., \& Wellington, B. (2003). Meeting the challenges of cultural diversity in the academic setting. Nurse Education in Practice, 3, 5-22. doi: $10.1016 / \mathrm{S} 1471-5953(02) 00026-4$ 
Peters, J. M. (2003). A qualitative study of registered nurses returning to school for a baccalaureate degree in nursing (Doctoral dissertation). Retrieved from ProQuest Dissertations and Theses database. (UMI No. 30282499)

Pryjmachuk, S., \& Richards, D. A. (2007). Predicting stress in pre-registration nursing students. British Journal of Health Psychology, 12, 125-144. doi: $10.1348 / 135910706 \times 98524$

Pulido-Martos, M., Augusto-Landa, J. M., \& Lopez-Zafra, E. (2012). Sources of stress in nursing students: A systematic review of quantitative studies. International Nursing Review, 59, 15-25. doi: 10.1111/j.1466-7657.2011.00939.x

Reeve, K. L., Shumaker, C. J., Yearwood, E. L., Crowell, N. A., \& Riley, J. B. (2013). Perceived stress and social support in undergraduate nursing students' educational experiences. Nurse Education Today, 33, 419-424. doi: 10.1016/j.nedt.2012.11.009

Reivich, K., \& Shattè, A. (2002). The resilience factor: 7 keys to finding your inner strength and overcoming life's hurdles. New York: Broadway Books.

Richardson, G. E. (2002). The metatheory of resilience and resiliency. Journal of Clinical Psychology, 58, 307-321. doi: 10.1002/jclp.10020

Ross, R., Zeller, R., Srisaeng, P., Yimmee, S., Somchid, S., \& Sawatphanit, W. (2005). Depression, stress, emotional support, and self-esteem among baccalaureate nursing students in Thailand. International Journal of Nursing Education Scholarship, 2, Article 25. doi: 10.2202/1548-923X.1165

Rutter, M. (1993). Resilience: Some conceptual considerations. Journal of Adolescent Health, 14, 626-631. doi: 10.1016/1054-139X(93)9016-V 
Sedgeman, J. A. (2005). Health Realization/Innate Health: Can a quiet mind and a positive feeling state be accessible over the lifespan without stress-relief techniques? Medical Science Monitor, 11(12), HY47-52.

Sedgeman, J. A. (2008). Effects of a Mind-Consciousness-Thought (MCT) intervention on stress and well-being in freshmen nursing students. (Doctoral thesis). Retrieved from ProQuest Dissertations and Theses. (Accession Order No. AAT 3326919).

Seligman, M. P., Ernst, R., Gillham, J., Reivich, K, \& Linkins, M. (2009). Positive education: Positive psychology and classroom interventions. Oxford Review of Education, 35, 293-311. doi: 10.1080/03054980902934563

Sharif, F., \& Masoumi, S. (2005). A qualitative study of nursing student experiences of clinical practice. BMC Nursing, 4, Article 6. doi: 10.1186/1472-6955-4-6

Sheu, S., Lin, H. W., \& Hwang, S. L. (2002). Perceived stress and physio-psycho-social status of nursing students during their initial period of clinical practice: the effect of coping behaviors. International Journal of Nursing Studies, 39, 165-175. doi: 10.1016/S0020-7489(01)00016-5

Shipton, S. P. (2002). The process of seeking stress-care: Coping as experienced by senior baccalaureate nursing students in response to appraised clinical stress. Journal of Nursing Education, 41, 243-256.

Stecker, T. (2004). Well-being in an academic environment. Medical Education, 38, 465-478. doi: 10.1046/j.1365-2929.2004.01812.x

Storrie K., Ahern, K., \& Tuckett, A. (2010). A systematic review: Students with mental health problems - A growing problem. International Journal of Nursing Practice, 16, 1-6. doi: 10.1111/j.1440-172X.2009.01813.x 
Thomas, J., Jack, B. A., \& Jinks, A. M. (2012). Resilience to care: A systematic review and meta-synthesis of the qualitative literature concerning the experiences of student nurses in adult hospital settings in the UK. Nurse Education Today, 32, 657-664. doi:10.1016/j.nedt.2011.09.005

Timmins, F., \& Kaliszer, M. (2002). Aspects of nurse education programmes that frequently cause stress to nursing students - fact-finding sample survey. Nurse Education Today, 22, 203-211. doi: 10.1054/nedt.2001.0698

Tully, A. (2004). Stress, sources of stress and ways of coping among psychiatric nursing students. Journal of Psychiatric and Mental Health Nursing, 11, 43-47. doi: 10.1111/j.1365-2850.2004.00682.x

Tusaie, K., \& Dyer, J. (2004). Resilience: A historical review of the construct. Holistic Nursing Practice, 18, 3-8.

Vanhanen, L., \& Janhonen, S. (2000). Factors associated with students' orientations to nursing. Journal of Advanced Nursing, 31, 1054-1062. doi: 10.1046/j.13652648.2000.01390.x

Watson, R., Deary, I., Thompson, D., \& Li, G. (2008). A study of stress and burnout in nursing students in Hong Kong: A questionnaire survey. International Journal of Nursing Studies, 45, 1534-1542. doi: 10.1016/j.ijnurstu.2007.11.003

Watson, R., Gardiner, E., Hogston, R., Gibson, H., Stimpson, A., Wrate, R., \& Deary, I. (2009). A longitudinal study of stress and psychological distress in nurses and nursing students. Journal of Clinical Nursing, 18, 270-278. doi: 10.1111/j.13652702.2008.02555.x 
Wells, M. I. (2007). Dreams deferred but not deterred: A qualitative study on undergraduate nursing student attrition. Journal of College Student Retention: Research, Theory, and Practice, 8, 439-456. doi: 10.2190/17K2-5847-6637-L70P

Whittemore, R., \& Knafl, K. (2005). The integrative review: Updated methodology. Journal of Advanced Nursing, 52, 546-553. doi: 10.1111/j.1365-2648.2005.03621.x

Williams, R. P., \& Calvillo, E. R. (2002). Maximizing learning among students from culturally diverse backgrounds. Nurse Educator, 27, 222-226.

Williamson, G. R., Health, V., \& Proctor-Childs, T. (2013). Vocation, friendship, and resilience: A study exploring nursing student and staff views on retention and attrition. The Open Nursing Journal, 7, 149-156. doi: 10.2174/1874434601307010149

Wolin, S. J., \& Wolin, S. (1994). Survivor's pride: Building resilience in youth at risk. Verona, WI: Attainment Co.

Yonge, O., Myrick, F., \& Haase, M. (2002). Student nurse stress in the preceptorship experience. Nurse Educator, 27, 84-88. Retrieved from http://www.chw.org/ /media/Files/Medical\%20Professionals/Nursing\%20Students/stu dent\%20stress\%20in\%20preceptorship.pdf

Zeitlin-Ophir, I., Melitz, O., Miller, R., Podoshin, P., \& Mesh, G. (2004). Variables affecting the academic and social integration of nursing students. Journal of Nursing Education, 43, 326-329. 


\section{Chapter Two - Resilience in Nursing Education: An Integrative Review}

Stress, which involves a person's appraisal of the environment as threatening to his or her well-being (Lazarus \& Folkman, 1984), can adversely affect the education of nursing students and the work life of nurse educators. Continued ineffective coping with stress has been documented to produce deleterious effects on the well-being and academic performance of nursing students, and has resulted in their leaving their programs (Wells, 2007). Although nursing students may be dealing with the same academic challenges as most post-secondary students (including increased academic workload, stress at examination times, and social integration into different learning communities), they face unique stressors. Their practicum areas have been identified as one of the leading stressors in their academic lives (Thomas, Jack, \& Jinks, 2012). Students deal with culture shock from the realities of their clinical workload (Brennan \& McSherry, 2007); unwelcoming and negative attitudes of clinical staff (Hoel, Giga, \& Davidson, 2007; Pearcey \& Elliott, 2004); death and other social issues and concerns (Mackintosh, 2006; McGowan, 2005); and anxiety about making clinical errors (Levett-Jones \& Lathlean, 2008; Sharif \& Masoumi, 2005). They also grapple with faculty incivility that increases their stress and negatively influences their learning and selfconfidence (Clark, 2008).

Nurse educators are also subjected to high levels of stress in their workplaces. Growing numbers of nursing faculty members are stressed, emotionally exhausted, and without a sense of personal accomplishment (Sarmiento, Laschinger, \& Iwasiw, 2004; Talbot, 2000). Many nurse academics lack readiness for faculty work expectations, such as being a researcher, mentor, and educator (Siler \& Kleiner, 2001; Tartavoulle, Manning, \& Fowler, 2011). Educators are also stressed from pressure to maintain both clinical and educational expertise (Hinshaw, 2001); increasing complexity of the nursing faculty role 
(Disch, Edwardson, \& Adwan, 2004); rapidly changing educational technology (Burke, 2009); faculty-to-faculty incivility (Clark, Olender, Kensi, \& Cardoni, 2013); student aggression and incivility (Luparell, 2007); and role overload, conflict, and ambiguity, particularly for clinical faculty (Whalen, 2008; Wiens, Babenko-Mould, \& Iwasiw, 2014).

Because nursing students and nurse educators are coping with stress and adversities on a daily basis, it is paramount for them to develop resilience. The phenomenon of resilience has been widely researched and is known to buffer the effects of stress, thereby facilitating adaptation to adversities (Tusaie \& Dyer, 2004). Although there is a growing number of studies about resilience in nursing, there remains limited description of resilience in the nursing education literature.

\section{Purpose}

There were two purposes of this integrative review. The first was to analyze and synthesize empirical and theoretical reports on resilience in nursing education. The second was to deduce implications from the findings of this review for nursing education practice and research. The overall research question that guided this review was: What is the current state of knowledge about resilience in the context of nursing education?

\section{Method}

Whittemore and Knafl's (2005) integrative review method was used to analyze and synthesize literature on resilience in nursing education. This method allows the use of empirical (both quantitative and qualitative studies) and theoretical reports. There are five stages in Whittemore's and Knafl's framework for data collection, analysis, and synthesis: (a) problem identification, (b) literature search, (c) data evaluation, (d) data analysis, and (e) presentation. Problem identification as the first stage of the method has been applied in the 
introduction of this paper. The last four stages are discussed in the following sections of this article.

\section{Literature Search}

The literature search was undertaken by conducting computer searches of the following databases: Cumulative Index for Nursing and Allied Health Literature (CINAHL), Scopus, Educational Resources Information Center (ERIC), PsychINFO, PubMed, and ProQuest. The key words entered in the search included the terms resilience, resiliency, and hardiness along with each of the following four terms: nursing education, nursing students, nurse educator, and nursing faculty. To be included in this review, papers had to be (a) published between 1990 and 2014; (b) written in English; (c) research or theoretical reports on resilience; and (d) focused on resilience in nursing education. The last criterion pertained to literature related to the resilience of nursing students (both undergraduate and graduate) and/or nurse educators in the academic setting. The exclusion criteria of the search were the following: (a) studies focused on resilience of new nursing graduates, school nurses in elementary and secondary schools, and nurse educators supporting nursing staff professional development, and (b) research that did not include resilience as an outcome of the study. The second exclusion criterion pertained to research studies that had discussions of resilience as an implication rather than part of the study findings. Unpublished master's theses and doctoral dissertations derived from the electronic search were also included in the review if they met the inclusion criteria. A manual search of articles that were missed from the electronic search was also conducted by examining the references in relevant articles, and those further sources that met the inclusion criteria were included in the review.

A total of 1,165 records were retrieved. Abstracts were reviewed to determine their relevance to nursing education and duplicate articles were removed. The large number of 
articles from the initial search result involved discussions of resilience as an implication rather than part of the study findings; hence, these were excluded from the review. Altogether, three theoretical papers and 16 research papers related to resilience met the criteria and were included in the data analysis of the integrative review. Detailed characteristics of the literature sample are included in Table 1 for research studies and Table 2 for theoretical papers. 
Table 1

Summary of Empirical Reports on Resilience in Nursing Education

\begin{tabular}{|c|c|c|c|c|}
\hline Author(s)/Country & Purpose & Participants & Design & Relevant Findings \\
\hline $\begin{array}{l}\text { Beauvais et al. (2014) } \\
\text { (U.S.A.) }\end{array}$ & $\begin{array}{l}\text { To determine the } \\
\text { relationship between } \\
\text { emotional intelligence, } \\
\text { psychological } \\
\text { empowerment, resilience, } \\
\text { spiritual well-being, and } \\
\text { academic success }\end{array}$ & $\begin{array}{l}124 \text { baccalaureate ( } 2 \text { nd } \\
\text { year to } 4 \text { th year) and } \\
\text { graduate (master's and } \\
\text { doctoral) nursing students }\end{array}$ & $\begin{array}{l}\text { Quantitative, descriptive, } \\
\text { correlational }\end{array}$ & $\begin{array}{l}\text { The relationship between } \\
\text { resilience and academic } \\
\text { success was weak but } \\
\text { statistically significant } \\
(r=.243, p=.007) .\end{array}$ \\
\hline $\begin{array}{l}\text { Carroll (2011) } \\
\text { (U.S.A.) }\end{array}$ & $\begin{array}{l}\text { To explore the role of } \\
\text { resiliency in students' } \\
\text { completion of their } \\
\text { nursing program }\end{array}$ & $\begin{array}{l}11 \text { college-based associate } \\
\text { degree in nursing students } \\
\text { who were within } 2 \text { months } \\
\text { of graduation }\end{array}$ & $\begin{array}{l}\text { Qualitative, } \\
\text { phenomenological }\end{array}$ & $\begin{array}{l}\text { Nine themes emerged } \\
\text { from a reductionary } \\
\text { coding process: support, } \\
\text { perseverance, autonomy, } \\
\text { empathy, high } \\
\text { expectations, sense of } \\
\text { purpose, optimism, } \\
\text { honesty, and critical } \\
\text { thinking. }\end{array}$ \\
\hline $\begin{array}{l}\text { Connolly et al. (2000) } \\
\text { (U.S.A.) }\end{array}$ & $\begin{array}{l}\text { To investigate the cultural } \\
\text { adaptability of teachers } \\
\text { from } 4 \text { health sciences }\end{array}$ & $\begin{array}{l}40 \text { faculty members in } \\
\text { nursing, dental hygiene, } \\
\text { medical laboratory } \\
\text { sciences, and physical } \\
\text { therapy }\end{array}$ & Quantitative, descriptive & $\begin{array}{l}\text { All } 4 \text { faculty groups } \\
\text { indicated high average } \\
\text { Cross-Cultural } \\
\text { Adaptability Inventory } \\
\text { scores. No statistically } \\
\text { significant difference in } \\
\text { emotional resilience } \\
\text { dimension between } \\
\text { faculty groups ( } F=.4671 \text {, } \\
p=0.7070) \text { was found. }\end{array}$ \\
\hline
\end{tabular}


Table 1 Continued

\begin{tabular}{|c|c|c|c|c|}
\hline Author(s)/Country & Purpose & Participants & Design & Relevant Findings \\
\hline $\begin{array}{l}\text { Crombie et al. (2013) } \\
\text { (U.K.) }\end{array}$ & $\begin{array}{l}\text { To investigate the factors } \\
\text { that influence attrition and } \\
\text { completion of a nursing } \\
\text { program }\end{array}$ & $\begin{array}{l}28 \text { second-year students } \\
\text { from a university adult } \\
\text { nursing program }\end{array}$ & $\begin{array}{l}\text { Qualitative, ethnographic } \\
\text { case study }\end{array}$ & $\begin{array}{l}\text { Resilience was a } \\
\text { motivational factor for } \\
\text { completing the program. }\end{array}$ \\
\hline $\begin{array}{l}\text { Glass (2001) } \\
\text { (Australia) }\end{array}$ & $\begin{array}{l}\text { To develop a critical } \\
\text { understanding of the lived } \\
\text { experience of women } \\
\text { nurse academics }\end{array}$ & $\begin{array}{l}20 \text { female nursing faculty } \\
\text { members from } 3 \\
\text { Australian universities }\end{array}$ & $\begin{array}{l}\text { Qualitative, postmodern } \\
\text { feminist ethnography }\end{array}$ & $\begin{array}{l}\text { Emotional resilience was } \\
\text { imperative in the face of } \\
\text { vulnerability and distress } \\
\text { related to the subtleties of } \\
\text { power and control within } \\
\text { and out of academia. }\end{array}$ \\
\hline $\begin{array}{l}\text { Glass (2007) } \\
\text { (International) }\end{array}$ & $\begin{array}{l}\text { To explore the cultural, } \\
\text { sociopolitical, and } \\
\text { interpersonal workplace } \\
\text { contexts of women nurse } \\
\text { academics }\end{array}$ & $\begin{array}{l}53 \text { nursing faculty } \\
\text { members of universities } \\
\text { from Australia, New } \\
\text { Zealand, UK, and US }\end{array}$ & $\begin{array}{l}\text { Qualitative, postmodern } \\
\text { feminist ethnography }\end{array}$ & $\begin{array}{l}\text { Work context of women } \\
\text { nurse academics was } \\
\text { described as male- } \\
\text { dominated, competitive, } \\
\text { lacking support and } \\
\text { recognition, and intolerant } \\
\text { to novice faculty. } \\
\text { Academics articulated the } \\
\text { necessity of resilience in } \\
\text { their workplace. }\end{array}$ \\
\hline
\end{tabular}


Table 1 Continued

\begin{tabular}{|c|c|c|c|c|}
\hline Author(s)/Country & Purpose & Participants & Design & Relevant Findings \\
\hline $\begin{array}{l}\text { Jackson et al. (2011) } \\
\text { (Australia) }\end{array}$ & $\begin{array}{l}\text { To understand student } \\
\text { experiences of negative } \\
\text { behaviours in the clinical } \\
\text { learning setting }\end{array}$ & $\begin{array}{l}105 \text { students of a } 3 \text {-year } \\
\text { Bachelor of Nursing } \\
\text { program }\end{array}$ & $\begin{array}{l}\text { Qualitative, content } \\
\text { analysis of open-ended } \\
\text { questions of an online } \\
\text { survey }\end{array}$ & $\begin{array}{l}\text { Clinical learning settings } \\
\text { were described as hostile. } \\
\text { Students were treated as } \\
\text { the 'Other.' They resisted } \\
\text { these exclusionary } \\
\text { practices through } \\
\text { confrontational behaviours } \\
\text { which indicated that they } \\
\text { possessed enhanced } \\
\text { resilience and professional } \\
\text { identity. }\end{array}$ \\
\hline $\begin{array}{l}\text { Knight et al. (2012) } \\
\text { (New Zealand) }\end{array}$ & $\begin{array}{l}\text { To examine the reasons } \\
\text { students stay and } \\
\text { complete their nursing } \\
\text { program }\end{array}$ & $\begin{array}{l}18 \text { graduating } \\
\text { baccalaureate nursing } \\
\text { students and } 13 \text { students } \\
\text { who graduated the } \\
\text { previous year }\end{array}$ & $\begin{array}{l}\text { Qualitative, } \\
\text { phenomenology }\end{array}$ & $\begin{array}{l}\text { Personal resilience was } \\
\text { one theme that emerged as } \\
\text { a contributor to staying in } \\
\text { 'and completing the } \\
\text { program. Resilience was } \\
\text { related to being } \\
\text { determined to finish } \\
\text { school. }\end{array}$ \\
\hline $\begin{array}{l}\text { Mott }(2013) \\
\text { (U.S.A.) }\end{array}$ & $\begin{array}{l}\text { To understand students' } \\
\text { lived experience of faculty } \\
\text { bullying }\end{array}$ & $\begin{array}{l}5 \text { associate degree and } 1 \\
\text { baccalaureate nursing } \\
\text { students }\end{array}$ & $\begin{array}{l}\text { Qualitative, descriptive } \\
\text { phenomenology }\end{array}$ & $\begin{array}{l}\text { Students used resilience in } \\
\text { overcoming the emotional } \\
\text { response to bullying. } \\
\text { Resilience was } \\
\text { demonstrated through } \\
\text { behaviours such as } \\
\text { persisting to remain in the } \\
\text { program and overcoming } \\
\text { bullying. }\end{array}$ \\
\hline
\end{tabular}


Table 1 Continued

\begin{tabular}{|c|c|c|c|c|}
\hline Author(s)/Country & Purpose & Participants & Design & Relevant Findings \\
\hline $\begin{array}{l}\text { Peters (2003) } \\
\text { (U.S.A.) }\end{array}$ & $\begin{array}{l}\text { To describe registered nurses' } \\
\text { realities of returning for a } \\
\text { baccalaureate degree in nursing }\end{array}$ & $\begin{array}{l}15 \text { RNs enrolled in a } \\
\text { baccalaureate degree in } \\
\text { nursing }\end{array}$ & $\begin{array}{l}\text { Qualitative, constructivist } \\
\text { grounded theory }\end{array}$ & $\begin{array}{l}\text { Stress/coping/adaptation } \\
\text { process was the emerging } \\
\text { theory that explained } \\
\text { participants' realities. } \\
\text { Resilience was conceptualized } \\
\text { as personal characteristics of } \\
\text { students that modified their } \\
\text { coping with stressors, resulting } \\
\text { in successful adaptation. }\end{array}$ \\
\hline $\begin{array}{l}\text { Pines et al. (2012) } \\
\text { (U.S.A.) }\end{array}$ & $\begin{array}{l}\text { To investigate the relationships } \\
\text { between stress resiliency, } \\
\text { psychological empowerment, } \\
\text { and conflict management styles }\end{array}$ & $\begin{array}{l}166 \text { baccalaureate } \\
\text { nursing students }\end{array}$ & $\begin{array}{l}\text { Quantitative, descriptive, } \\
\text { correlational }\end{array}$ & $\begin{array}{l}\text { Stress Resiliency Profile (SRP) } \\
\text { scores were significantly } \\
(p<0.01) \text { related to } \\
\text { empowerment, except for the } \\
\text { deficiency subscale of the SRP. } \\
\text { Accommodating as a conflict } \\
\text { management style was related } \\
\text { to the skill recognition subscale } \\
\text { of the SRP }(\beta=-0.21, p<0.05) \text {. }\end{array}$ \\
\hline $\begin{array}{l}\text { Pines et al. (2014) } \\
\text { (U.S.A.) }\end{array}$ & $\begin{array}{l}\text { To examine effects of an } \\
\text { educational intervention on } \\
\text { resiliency, empowerment, and } \\
\text { conflict management styles }\end{array}$ & $\begin{array}{l}60 \text { baccalaureate } \\
\text { nursing students }\end{array}$ & $\begin{array}{l}\text { Quantitative, pretest, } \\
\text { posttest, quasi- } \\
\text { experimental }\end{array}$ & $\begin{array}{l}\text { Only one subscale of the } \\
\text { resiliency scale (necessitating) } \\
\text { was statistically significant } \\
\text { after the intervention }(t=2.527 \text {, } \\
p=.014) \text {. Significant decrease } \\
\text { in accommodating }(t=2.835, p \\
\leq .006) \text { and increase in } \\
\text { compromising ( } t=2.388, p \\
\leq .02) \text { as conflict management } \\
\text { styles after the intervention } \\
\text { were found. }\end{array}$ \\
\hline
\end{tabular}


Table 1 Continued

\begin{tabular}{|c|c|c|c|c|}
\hline Author(s)/Country & Purpose & Participants & Design & Relevant Findings \\
\hline $\begin{array}{l}\text { Pitt et al. (2014) } \\
\text { (Australia) }\end{array}$ & $\begin{array}{l}\text { To explore the } \\
\text { relationships between } \\
\text { students' personal } \\
\text { attributes and their } \\
\text { academic and clinical } \\
\text { performance, } \\
\text { behaviours, and } \\
\text { progression }\end{array}$ & $\begin{array}{l}138 \text { students of a } 3 \text {-year } \\
\text { Bachelor of Nursing program }\end{array}$ & $\begin{array}{l}\text { Quantitative, descriptive, } \\
\text { longitudinal, } \\
\text { correlational }\end{array}$ & $\begin{array}{l}\text { Resilience was positively } \\
\text { related to GPA in the first year } \\
\text { only ( } r=.214, p<.05 \text { ), and with } \\
\text { the clinical nursing course } \\
\text { grade in the third year ( } r=.252 \text {, } \\
p<.05 \text { ). Resilience was a weak } \\
\text { predictor of completing the } \\
\text { nursing program (with an odds } \\
\text { ratio of } 0.970) \text {. }\end{array}$ \\
\hline $\begin{array}{l}\text { Stephens (2012) } \\
\text { (U.S.A.) }\end{array}$ & $\begin{array}{l}\text { To investigate the } \\
\text { effectiveness of an } \\
\text { educational intervention } \\
\text { designed to increase } \\
\text { resilience }\end{array}$ & $\begin{array}{l}70 \text { junior-level baccalaureate } \\
\text { nursing students }\end{array}$ & $\begin{array}{l}\text { Quantitative, } \\
\text { experimental }\end{array}$ & $\begin{array}{l}\text { In a quadratic model }(p=0.46) \\
\text { resilience scores in the } \\
\text { experimental group increased } \\
\text { from Time } 1 \text { (pre-test) to } \\
\text { Time } 2 \text { (post-test) by } 1.29 \text { but } \\
\text { unexpectedly decreased from } \\
\text { Time } 2 \text { to Time } 3 \text { (follow-up) } \\
\text { by } 2.85 \text {. }\end{array}$ \\
\hline $\begin{array}{l}\text { Taylor \& Reyes (2012) } \\
\text { (U.S.A.) }\end{array}$ & $\begin{array}{l}\text { To determine the } \\
\text { relationship between } \\
\text { self-efficacy, resilience, } \\
\text { and test grades }\end{array}$ & $\begin{array}{l}136 \text { baccalaureate in nursing } \\
\text { students }\end{array}$ & $\begin{array}{l}\text { Quantitative, pretest, } \\
\text { posttest, quasi- } \\
\text { experimental }\end{array}$ & $\begin{array}{l}\text { There was no significant } \\
\text { difference in overall resilience } \\
\text { score (RS) between first and } \\
\text { last week of semester ( } t=-.024 \text {, } \\
p=.981) \text {. No significant } \\
\text { correlations between } \\
\text { resilience and test scores were } \\
\text { found. }\end{array}$ \\
\hline
\end{tabular}


Table 1 Continued

\begin{tabular}{|c|c|c|c|c|}
\hline Author(s)/Country & Purpose & Participants & Design & Relevant Findings \\
\hline $\begin{array}{l}\text { Williamson et al. } \\
\text { (2013) } \\
\text { (U.K.) }\end{array}$ & $\begin{array}{l}\text { To gain insights into } \\
\text { students' and staff } \\
\text { concerns about their } \\
\text { nursing program and } \\
\text { placements }\end{array}$ & $\begin{array}{l}6 \text { staff members and } 8 \text { third- } \\
\text { year students from an } \\
\text { university adult nursing } \\
\text { program, and } 4 \text { former } \\
\text { students who left the } \\
\text { program } \\
\text { early }\end{array}$ & $\begin{array}{l}\text { Qualitative, content } \\
\text { analysis }\end{array}$ & $\begin{array}{l}\text { Resilience as a characteristic } \\
\text { of personality was a reason } \\
\text { described by participants in } \\
\text { persevering through } \\
\text { challenges and staying in the } \\
\text { program. }\end{array}$ \\
\hline
\end{tabular}


Table 2

Summary of Theoretical Papers on Resilience in Nursing Education

\begin{tabular}{|c|c|c|c|}
\hline Author(s)/Country & Purpose & Theoretical Framework & Summary \\
\hline $\begin{array}{l}\text { Chen }(2011) \\
\text { (Taiwan) }\end{array}$ & $\begin{array}{l}\text { To describe how problem-based learning } \\
\text { (PBL) influences development of resilience } \\
\text { of nursing students }\end{array}$ & Problem-based learning & $\begin{array}{l}\text { The benefits of PBL could facilitate } \\
\text { development of student resilience. } \\
\text { Educators could help build resilience of } \\
\text { students by increasing student } \\
\text { engagement in self-reflection. }\end{array}$ \\
\hline $\begin{array}{l}\text { Hodges et al. } \\
(2005) \\
\text { (U.S.A.) }\end{array}$ & $\begin{array}{l}\text { To articulate Parse's Theory as a framework } \\
\text { for teaching-learning in fostering } \\
\text { professional resilience in undergraduate } \\
\text { nursing education }\end{array}$ & $\begin{array}{l}\text { Parse's (1988) Theory of } \\
\text { Human Becoming }\end{array}$ & $\begin{array}{l}\text { Fostering professional resilience of } \\
\text { nursing students could be achieved } \\
\text { through engaging students in intentional } \\
\text { reflections within student-faculty dyads. }\end{array}$ \\
\hline $\begin{array}{l}\text { Stephens }(2013) \\
\text { (U.S.A.) }\end{array}$ & $\begin{array}{l}\text { To clarify the concept of resilience for the } \\
\text { nursing student population }\end{array}$ & $\begin{array}{l}\text { Norris's (1982) method of } \\
\text { concept clarification }\end{array}$ & $\begin{array}{l}\text { Resilience of nursing students is defined } \\
\text { as the process of using personal } \\
\text { protective factors to effectively cope } \\
\text { with setbacks, resulting in cumulative } \\
\text { successes which further enhance coping } \\
\text { and adaptive abilities. }\end{array}$ \\
\hline
\end{tabular}




\section{Data Evaluation and Analysis}

Records included in the final sample were evaluated for methodological rigor and relevance of findings to the research question. As suggested by Whittemore and Knafl (2005), all reports in the final sample were retained in the data analysis stage regardless of outcome of data evaluation. The four steps of data analysis (data reduction, data display, data comparison, and conclusion drawing/verification) as explicated by Whittemore and Knafl (2005) were used to arrive at common themes and patterns.

\section{Results}

Three main themes emerged from the data analysis: resilience is important in nursing education, is conceptualized as a trait or process, and is related to protective factors.

\section{Resilience is Important in Nursing Education}

Studies included in the review suggest that resilience is necessary in the academic lives of nursing students and work of nurse academics. As described in the studies, nursing students and nurse educators faced significant challenges that required them to have resilience. For example, resilience was demonstrated through students' perseverance with their challenges, which then was a contributing factor in facilitating success in their nursing education and in the completion of their degrees (Carroll, 2011; Crombie, Brindley, Harris, Marks-Maran, \& Thompson, 2013; Knight et al., 2012; Peters, 2003; Williamson, Health, \& Proctor-Childs, 2013). Carroll (2011) found that students described resilience as having the determination to succeed rather than retreating in the face of challenges. In Mott's (2013) study, students reported that resilience was a facilitating factor in persisting with the challenges of faculty bullying. Resilience was a major contributing factor to nursing students' assertiveness in dealing with aggressive behaviours of clinical staff in their clinical 
placements (Jackson et al., 2011). School staff members attributed resilience to students' ability to remain in the program (Williamson et al., 2013).

Resilience is also important because it contributes to the hope and optimism of students and educators. Hope and optimism pertained to having a positive outlook on the adversities nursing students were facing (Carroll, 2011). For nurse educators, hope and optimism were influencing factors in their ability to reframe their future in their challenging workplace (Glass, 2007). Furthermore, as nurse educators became more hopeful and optimistic, they became more resilient in dealing with workplace challenges by expressing their concerns and vulnerability (Glass, 2007).

Findings from three quantitative studies (Beauvais, Stewart, DeNisco, \& Beauvais, 2014; Pitt, Powis, Levett-Jones, \& Hunter, 2014; Taylor \& Reyes, 2012) also demonstrated the importance of resilience in the academic lives of nursing students. In these studies, there was a statistically significant (albeit weak) relationship between students' academic success and their resilience. Pines et al. $(2012,2014)$ suggested the significance of resilience in nursing students' management of conflicts. Students who had cognitive habits that predisposed them to acute or chronic stress (rather than being resilient) used conflict management styles that were less assertive and more neglectful of their personal concerns (Pines et al., 2012). Students also demonstrated an increase in assertive and a decrease in unassertive conflict management styles after a resilience educational intervention conducted over two semesters (Pines et al., 2014). Quantitative studies demonstrating the relationship between resilience and psychological empowerment also indicated the importance of resilience in nursing students' lives. For example, Beauvais et al. (2014) demonstrated a statistically significant (albeit weak) correlation between resilience and empowerment. Pines et al. (2012) showed that empowerment was associated with skill recognition on the Thomas 
and Tymon's (1992) Stress Resiliency Profile, which means that resilient students recognize that their success depends on their competence and abilities (internal resources) rather than external forces.

Finally, one quantitative study (Connolly, Darby, Tolle-Watts, \& Thomson-Lakey, 2000) that focused on the resilience of nurse academics indicated that resilience is necessary, particularly in teaching students from diverse cultures. In this study, the emotional resilience of faculty members (nursing, dental hygiene, medical laboratory sciences, and physical therapy) was tested as a subscale of a construct called cultural adaptability. This group of faculty members had higher cultural adaptability scores (including the subscale of emotional resilience) than a larger cohort group that was previously tested on the instrument. This finding suggests that emotional resilience is imperative as faculty members interact with students from diverse cultures.

\section{Resilience is Conceptualized as a Trait or Process}

It was evident in the studies reviewed that resilience was conceptualized as either a trait or a process. In four quantitative studies on the resilience of nursing students, resilience was presented as a personal trait (Beauvais et al., 2014; Pitt et al., 2014; Stephens, 2012; Taylor \& Reyes, 2012). Resilience was also viewed as a trait in a study of cultural adaptability of educators from nursing and other disciplines (Connolly et al., 2000). In six qualitative studies, resilience was viewed as a trait or personal capacity. For example, Williamson et al. (2013) suggested that resilience was a characteristic of students' personality that allowed them to adapt, withstand challenges, and stay in the nursing program. Peters (2003) identified resilience as a personal characteristic that modifies students' ways of coping with stressors, hence changing their way of thinking and resulting in successful adaptation. Jackson et al. (2011) reported that nursing students who are able to 
confront hostile behaviour of staff in clinical learning settings have well-developed personal resilience. Qualitative studies by Crombie et al. (2013) and Glass $(2001,2007)$ also indicated resilience as a trait or personal capacity.

Four studies and a concept clarification paper suggested resilience as a process. Descriptions of resilience related to actions such as "struggling through" bullying behaviours (Mott, 2013), and "making it through" (Carroll, 2011) signify that the experience of resilience occurs in phases; thus, indicating resilience as a process. Knight et al. (2012) described resilience as strategies used by students to remain and succeed in the program, which denotes that resilience is a process. Stephens (2013), in her concept clarification of the resilience of nursing students, described resilience as a process of applying personal protective factors in coping with adversities. An intervention study that suggests resilience as a process was that of Stephens (2012) in which she investigated the effects of a 4-week educational program on resilience. Stephens' study was also based on her concept clarification of resilience as a process that can be learned and taught. In summary, the conceptualization of resilience as a process suggests resilience as a dynamic and changeable phenomenon involving growth and development (Carroll, 2011; Stephens, 2013).

\section{Resilience is Related to Protective Factors}

A prominent theme in the integrative review was that resilience was a phenomenon related to protective factors. Through concept clarification, Stephens (2013) described resilience as a process of development resulting from the use of protective factors. According to Stephens (2013), protective factors generally refer to resources, attributes, and skills that minimize the debilitating effects of stress. Protective factors are better explained in contrast to risk factors which pertain to individuals' internal characteristics and external conditions and events that exacerbate or maintain a problem (Fraser \& Terzian, 2005) or that increase 
the probability for more negative outcomes to occur (Masten \& Reed, 2002). Stephens (2013) further categorized protective factors as both internal (such as personal characteristics of hope, optimism, and self-efficacy) and external (such as supportive relationships).

More on protective factors from the review, Pines et al. $(2012,2014)$ conceptualized resilience, using the Neuman System Model (Neuman \& Fawcett, 2011), as a construct pertaining to the use of an individual's protective lines of defense to maintain stability and balance. In Carroll's (2011) phenomenological study of nursing students' experience of resilience, nine themes emerged that resonated with the protective factors of resilience. These nine themes included support, perseverance, autonomy, empathy, high expectations, sense of purpose, optimism, honesty, and critical thinking. Perseverance as a protective factor of resilience was a common theme among several studies of attrition and retention of nursing students (Crombie et al., 2013; Knight et al., 2012; Peters, 2003; Williamson et al., 2013). Other internal protective factors of nursing students evident in the studies included: selfefficacy (Taylor \& Reyes, 2012) and psychological empowerment (Beauvais et al., 2014; Pines et al., 2012). Hope and optimism were internal protective factors that enhanced resilience of nurse academics (Glass, 2007).

Social support was evident as an external protective factor of nursing students' resilience in many studies (Crombie et al., 2013; Jackson et al., 2011; Knight et al., 2012; Mott, 2013; Williamson et al., 2013). Hodges, Keeley, and Grier (2005) and Chen (2011) also suggested that supportive relationships with teachers who are willing to engage with students could promote the development of student resilience. In relation to external protective factors for nurse educators, Glass (2007) articulated that as teachers sought support through colleagues by sharing their experiences, their resilience was further developed. In summary, the explication of protective factors as related to resilience is 
important because the enhancement of protective factors facilitate further development of resilience (Stephens, 2013).

\section{Summary of Analysis of Literature}

In nine of the 10 qualitative studies about resilience in nursing education, examination of resilience was not a study purpose, yet resilience was a theme that emerged from the data analysis (Table 1). Only Carroll's (2011) study had the exploration of the concept of resilience as the study purpose. Seven of 16 studies reviewed were quantitative research studies (Table 1) and authors recommended study replication. For example, the relationship of resilience to other variables (i.e., academic success, conflict management styles, effects of educational interventions, and empowerment) remains inconclusive. More testing is required using larger samples and alternate indicators of selected variables. Common limitations articulated in the studies were small sample sizes, short intervention periods, lack of generalizability, and use of a single site cohort. Three studies in the review did not explicitly refer to study limitations (Glass, 2001, 2007; Peters, 2003).

Three main resilience measurement tools were used in the studies in the review: (1) The Connor-Davidson Resilience Scale (CD-RISC, Connor \& Davidson, 2003); (2) The Resilience Scale (Wagnild \& Young, 1990, 1993); and the (3) Stress Resiliency Profile (SRP, Thomas \& Tymon, 1992). Stephens (2012) used the CD-RISC to measure the effectiveness of an educational intervention aimed to promote resilience of nursing students. Beauvais et al. (2014) and Taylor and Reyes (2012) tested the Resilience Scale (RS) to explore the relationship of resilience and academic success of nursing students. Pines et al. $(2012,2014)$ applied the Stress Resiliency Profile (SRP) to determine the relationship of resilience to psychological empowerment and conflict management styles of nursing students.

Furthermore, Pitt et al. (2014) and Connolly et al. (2000) measured resilience through the 
subscales of the Personal Qualities Assessment (PQA, Bore, Munro, \& Powis, 2009; Powis, Bore, Munro, \& Lumsden, 2005) and the Cross-Cultural Adaptability Inventory (CCAI, Kelley \& Meyers, 1992), respectively. Both subscales were used to measure the emotional aspects of resilience, such as resilience reflecting emotional stability in the PQA and emotional resilience pertaining to the degree educators can rebound from and react constructively to new cultural experiences in the CCAI. Construct validity of the above instruments has been confirmed. The SRP yielded average internal consistency with Cronbach's alpha of .81 and .74 (Thomas \& Tymon, 1994, 1995) while the other instruments had been reported to have good internal consistency (Cronbach's alpha ranging from .83 to $.94)$.

The CD-RISC and the Resilience Scale have been tested in a wide range of population and age groups (Stephens, 2012; Wagnild, 2009); therefore they may be appropriate measurement instruments to use with nursing student populations. These two instruments also capture the cognitive, emotional, and behavioural characteristics of resilience. The SRP has been used in certain populations such as US naval officers, MBA students, and engineers (Thomas \& Tymon, 1994, 1995) as well as among nurses (Larrabee et al., 2010; Simoni, Larrabee, Birkhimer, Mott, \& Gladden, 2004). Therefore, the SRP may also have applicability for use with nursing students. The focus of the SRP is on the mental habits for coping with stress. In the intervention study by Pines et al. (2014), the particular focus on the cognitive aspects of resilience in the SRP could be one of the attributing factors explaining the lack of statistically significant differences between pre and post conditions of two aspects of the SRP (deficiency focusing and skill recognition) in the intervention study by Pines et al. (2014). A more global resilience instrument such as the CD-RISC or the Resilience Scale could be additionally used to measure other aspects of resilience. 
In studies by Pitt et al. (2014) and Connolly et al. (2000), only the emotional aspect of resilience was measured. Pitt et al. found resilience to be a weak predictor in nursing students' completing the educational program. Connolly et al. concluded that there was no statistically significant difference in emotional resilience among faculty groups. Nuanced significant differences could be yielded if a resilience instrument measuring other aspects of resilience (such as cognitive and behavioural) were used.

In summary, common to all studies are recommendations to replicate the research with larger sample sizes, multiple sites, and longer study durations, particularly for intervention studies. Furthermore, many research articles excluded from the integrative review had implications about the importance of resilience but did not have direct descriptions of resilience in the findings of the study. This suggests that researchers are aware of the importance of resilience in nursing education but have yet to investigate it fully.

\section{Discussion}

The current state of knowledge about resilience in nursing education addresses three main areas: the importance of resilience, the conceptualization of resilience as a trait or process, and the protective factors related to resilience. The results of the integrative review reveal that a) resilience is important in nursing students' academic lives and nurse educators' work life because they continually face and respond to setbacks and adversities, and b) resilience is a key contributing factor in their successful adaptation to these challenges. The findings of the studies in the integrative review also included the conceptualization of resilience as a trait/personal characteristic or as a process. Finally, resilience in the context of nursing education is related to different protective factors that facilitate mitigation of the effects of stress in the lives of nursing students and nurse educators. 
The context of resilience in this review was the daily traumatic experiences of stress, burnout, and oppression. The obstacles and problems nursing students were experiencing were pervasive across their academic lives. The challenges nurse educators faced were ongoing, daily experiences of struggle and distress (Glass, 2001, 2007). Masten (2001) posits that resilience is often observed in common aspects of daily living. Therefore, the chronic and ongoing nature of students' and educators' difficult circumstances suggests that resilience is not only important to successfully adapt to adversities but is also required for them.

In this integrative review, resilience was conceptualized as either a trait or a process. Although resilience was described as a trait in some studies, resilience was not demonstrated as a static trait or characteristic but a phenomenon that changed over time (Beauvais et al., 2014; Pitt et al., 2014; Stephens, 2012; Taylor \& Reyes, 2012). Resilience as a process was more evident in qualitative studies (Carroll, 2011; Knight et al., 2012). This dynamic nature of resilience suggests that resilience is a changeable phenomenon (Tusaie \& Dyer, 2004). This also indicates that resilience can be learned or taught (Gillespie, Chaboyer, \& Wallis, 2007). Therefore, conceptualization of resilience as something that can be learned or taught implies that there are strategies and approaches that can be best applied to develop resilience.

The third main area of the results of the integrative review is based on the conceptualization of resilience as a construct related to different protective factors. Protective factors are those that empower an individual to rebound from stress (Olsson, Bond, Burns, Vella-Brodrick, \& Sawyer, 2003). Identification of related protective factors is important because fostering the development of resilience can be achieved through enhancing protective factors (Haase, 2004; Luthar, Cicchetti, \& Becker, 2000). More importantly, protective factors do not function independently but rather interdependently in order to buffer 
or mitigate the risk factors (Luthar, Doernberger, \& Zigler, 1993). Therefore, comprehensive explorations of related protective factors and subsequent application of strategies for enriching identified protective factors are imperative.

In summary, the results of the integrative review highlight the current state of knowledge about resilience in the context of nursing education. Resilience is important in nursing education because nursing students and nurse educators are dealing with challenges on an ongoing basis. Resilience in current nursing education research literature is conceptualized as either a trait or a process. Finally, the various related protective factors of resilience underscores that resilience development can be achieved through enhancement of protective factors.

\section{Implications}

\section{Implications for Nursing Education}

Findings of the review suggest that nursing students and nurse educators must continually develop and enhance their resilience to positively adapt to the challenges of their school and work environments. In fostering students' resilience, teachers are a valuable source of support (Carroll, 2011). An approach to facilitating students' resilience is through increased engagement between the teacher and the student (Hodges et al., 2005). This individual approach involves more purposeful support to students rather than generic ways that may be ineffective in addressing the unique circumstances of students.

As for nurse educators' resilience, it was evident from the integrative review that nurse educators also require resilience in dealing with the challenges of their workplace. The results of Glass's $(2001,2007)$ studies demonstrate that providing opportunities for teachers to voice their concerns in safe conditions without repercussions is therapeutic, freeing, and a 
healing experience. Therefore, fellow nurse educators have a critical role in collectively creating safe spaces for colleagues who are facing distress and oppression.

The findings of the integrative review also denote that resilience must be viewed in a holistic perspective when consideration is given to fostering students' and educators' resilience. Review findings indicating resilience as a process and as related to protective factors suggest that resilience involves both a stage of disruption or acute phase and reintegration (Fine, 1991; Richardson, 2002). Findings also connote that resilience is an interactional process between protective and risk factors (Dyer \& McGuinness, 1996). Therefore, a holistic view of resilience involves a broader framework of examining strengths and capacities as well as weaknesses and vulnerabilities. From a holistic view, the interactions of protective factors are also considered. Using a holistic framework in enhancing the resilience of students and educators takes into account other variables and contexts. Therefore, listening to stories of both thriving and struggling, exploring strengths and weaknesses, determining capacities and deficits, and addressing problems and solutions are essential in facilitating students' and educators' resilience.

\section{Implications for Nursing Education Research}

The integrative review includes results that require further exploration. For example, the weak correlation between academic success and resilience needs to be further studied because academic success in the studies included in the review were limited to measuring grade point average (GPA) and test grades only. More evidence-based understanding of the role of resilience in academic success is helpful in developing strategies and programs that promote retention of nursing students (Taylor \& Reyes, 2012). A specific area for further exploration includes determining the moderating variables that influence the relationship between academic success and resilience. Measures of academic success that capture not 
only the cognitive aspects of learning should also be considered. For example, the psychological and emotional aspects of clinical learning can be assessed in relation to resilience because clinical learning is a major aspect of students' education and negative clinical learning experiences affect student attrition (Eick, Williamson, \& Heath, 2012; Thomas et al., 2012). Another area for further investigation is more testing of educational interventions that promote resilience. Quantitative studies in the review indicated a lack of significant difference between resilience levels before and after educational interventions. Additionally, the increasing diversity of the nursing student population (such as diversity in age and cultural groups) and the proliferation of technology-based forms of teaching-learning methods (such as the use of online formats of instruction) imply the need for further research on effective educational interventions geared to fostering resilience. Therefore, further analysis of the design of interventions is required to determine effective educational content, learning conditions, and delivery processes that facilitate development of resilience.

More qualitative studies are required because there is a lack of description of how resilience is manifested and enacted in the academic lives of students. Further exploration of this research area can provide a better understanding of effective approaches and strategies for fostering the resilience of students. Expanded knowledge in this area can also contribute to the design of educational interventions geared to promoting and fostering student resilience.

In terms of nurse educators' resilience, there were only three studies (Connolly et al., 2000; Glass, 2001, 2007) related to the resilience of nurse educators. The limited research on educators' resilience suggests the need for more research on the relationship between educator resilience and other variables and the exploration of resilience in other workplace contexts of nurse educators such as clinical settings. In-depth investigation of resilience in 
these areas can provide the theoretical groundwork for future research on understanding educators' resilience and evidence-based strategies for promoting the resilience of nurse educators.

\section{Conclusion}

From a nursing education perspective, the three themes derived from this integrative review (resilience is important, is conceptualized as trait or process, and is related to protective factors) suggest that the teacher-student relationship is key to students' development of resilience. Hodges et al. (2005) posit that teachers' engagement and connection with students is foundational to students' development of professional resilience. Novotny (2011) advocates that teachers engage with their students on an individual basis to purposefully and effectively support them. The findings also imply that nurse educators' safe expression of their concerns contributes to their own resilience development (Glass 2001, 2007). Furthermore, the results of the integrative review highlight the need for more resilience research in the context of nursing education. In the current state of knowledge of resilience in nursing education, little is known about evidence-based processes that promote the development and enhancement of resilience of nursing students and nurse educators. Therefore, more research is required in this area. If this area of resilience research is explored, there may be a better understanding of effective strategies and approaches that foster the experience of resilience among nursing students and educators. 


\section{References}

Beauvais, A. M., Stewart, J. G., DeNisco, S., \& Beauvais, J. E. (2014). Factors related to academic success among nursing students: A descriptive correlational research study, Nurse Education Today, 34, 918-923. doi: 10.1016/j.nedt.2013.12.005

Bore, M., Munro, D., \& Powis, D. (2009). A comprehensive model for the selection of medical students. Medical Teacher, 31, 1066-1072. doi: 10.3109/01421590903095510

Brennan, G., \& McSherry, R. (2007). Exploring the transition and professional socialisation from healthcare assistant to student nurse. Nurse Education in Practice, 7, 206-214. doi:10.1016/j.nepr.2006.08.006

Burke, M.S. (2009). The incidence of technological stress among baccalaureate nurse educators using technology during course preparation and delivery. Nurse Education Today, 29, 57-64. doi: 10.1016/j.nedt.2008.06.008

Carroll, S. (2011). Resilience as a factor in the successful completion of a California community college based associate degree in nursing program (Doctoral dissertation). Retrieved from ProQuest Dissertations and Theses database. (UMI No. 3454870)

Chen, J. Y. (2011). Problem-based learning: Developing resilience in nursing students. Kaohsiung Journal of Medical Sciences, 27, 230-233. doi: 10.1016/j.kjms.2010.11.005

Clark, C.M. (2008). Student voices on faculty incivility in nursing education: A conceptual model. Nursing Education Perspectives, 29, 284-289.

Clark, C. M., Olender, L., Kensi, D., \& Cardoni, C. (2013). Exploring and addressing faculty-to-faculty incivility: A national perspective and literature review. Journal of Nursing Education, 52, 211-218. doi: 10.3928/01484834-20130319-01

Connolly, I. M., Darby, M. L., Tolle-Watts, L., \& Thomson-Lakey, E. (2000). The cultural adaptability of health sciences faculty. The Journal of Dental Hygiene, 74, 102-109. 
Connor, K., \& Davison, J. R. T. (2003). Development of a new resilience scale: The ConnorDavidson Resilience Scale (CD-RISC). Depression and Anxiety, 18, 76-82. doi: 10.1002/da. 10113

Crombie, A., Brindley, J., Harris, D., Marks-Maran, D., \& Thompson, T. M. (2013). Factors than enhance rates of completion: What makes students stay? Nurse Education Today, 33, 1282-1287. doi: 10.1016/j.nedt.2013.03.020

Disch, J., Edwardson, S., \& Adwan, J. (2004). Nursing faculty satisfaction with individual, institution, and leadership factors. Journal of Professional Nursing, 20, 323-332. doi: 10.1016/j.profnurs.2004.07.011

Dyer, J. G., \& McGuinness, T. M. (1996). Resilience: Analysis of the concept. Archives of Psychiatric Nursing, 5, 276-282. doi: 10.1016/S0883-9417(96)80036-7

Eick, S. A., Williamson, G. R., \& Heath, V. (2012). A systematic review of placementrelated attrition in nurse education. International Journal of Nursing Studies, 49, 12991309. doi: 10.1016/j.ijnurstu.2011.12.004

Fine, S. B. (1991). Resilience and human adaptability: Who rises above adversity? The American Journal of Occupational Therapy, 45, 493-503. doi: 10.5014/ajot.45.6.493

Fraser, M., \& Terzian, M. (2005). Risk and resilience in child development: Principles and strategies of practice. In G. P. Mallon \& P. McCartt Hess (Eds.), Child welfare for the 21st century: A handbook of practices, policies, and programs (pp. 55-71). New York, NY: Columbia University Press.

Gillespie, B. M., Chaboyer, W., \& Wallis, M. (2007). Development of a theoretically derived model of resilience through concept analysis. Contemporary Nurse, 25, 124-135. doi: 10.5172/conu.2007.25.1-2.124 
Glass, N. (2001). The dis-ease of nursing academia: Putting the vulnerability 'out there' (Part 2). Contemporary Nurse, 10, 178-186. doi: 10.5172/conu.10.3-4.178

Glass, N. (2007). Investigating women nurse academics' experiences in universities: The importance of hope, optimism, and career resilience for workplace satisfaction. Annual Review of Nursing Education, 5, 111-136.

Haase, J. E. (2004). The adolescent resilience model as a guide to interventions. Journal of Pediatric Oncology Nursing, 21, 289-299. doi: 10.1177/1043454204267922

Hinshaw, A. S. (2001). A continuing challenge: The shortage of educationally prepared nursing faculty. OJIN: Online Journal of Issues in Nursing, 6, Manuscript 1. Retrieved from: http://www.nursingworld.org/MainMenuCategories/ ANAMarketplace/ANAPeriodicals/OJIN/TableofContents/Volume62001/No1Jan01/Sh ortageofEducationalFaculty.aspx

Hodges, H. F., Keeley, A. C., \& Grier, E. C. (2005). Professional resilience, practice longevity, and Parse's theory for baccalaureate education. Journal of Nursing Education, 44, 548-554.

Hoel, H., Giga, S. I., \& Davidson, M. J. (2007). Expectations and realities of student nurses' experiences of negative behaviour and bullying in clinical placement and the influences of socialization processes. Health Services Management Research, 20, 270278. doi: 10.1258/095148407782219049

Jackson, D., Hutchinson, M., Everett, B., Mannix, J., Peters, K., Weaver, R., \& Salamonson, Y. (2011). Struggling for legitimacy: Nursing students' stories of organisational aggression, resilience, and resistance. Nursing Inquiry, 18, 102-110. doi: 10.1111/j.1440-1800.2011.00536.x 
Kelley, C., \& Meyers, J. (1992). The Cross-Cultural Adaptability Inventory. Yarmouth, MA: Intercultural Press.

Knight, J., Corbett, A., Smith, C., Watkins, B., Hardy, R., \& Jones, G. (2012). What made me stay? A review of the reasons student nurses enrolled in a bachelor of nursing programme completed their studies: A descriptive phenomenological study. Nurse Education Today, 32, e62-e65. doi: 10.1016/j.nedt.2012.03.007

Larrabee, J. H., Wu, Y., Persily, C. A., Simoni, P. S., Johnston, P. A., Marcischak, T. L., . . . Gladden, S. D. (2010). Influence of stress resiliency on RN job satisfaction and intent to stay. Western Journal of Nursing Research, 32, 81-102. doi:

$10.1177 / 0193945909343293$

Lazarus, R. S., \& Folkman, S. (1984). Stress, appraisal, and coping. New York: Springer. Levett-Jones, T., \& Lathlean, J. (2008). Belongingness: A prerequisite for nursing student experiences of clinical practice. Nurse Education in Practice, 8, 103-111. doi: 10.1016/j.nepr.2007.04.003

Luparell, S. (2007). The effects of student incivility on nursing faculty. Journal of Nursing Education, 46, 15-19.

Luthar, S. S., Cicchetti, D., \& Becker, B. (2000). The construct of resilience: A critical evaluation and guidelines for future work. Child Development, 71, 543- 562. doi: $10.1111 / 1467-8624.00164$

Luthar, S. S., Doernberger, C. H., \& Zigler, E. (1993). Resilience is not a unidimensional construct: Insights from a prospective study of inner-city adolescents. Development and Psychopathology, 5, 703-717. doi: 10.1017/S0954579400006246 
Mackintosh, C. (2006). Caring: The socialisation of pre-registration student nurses: A longitudinal qualitative descriptive study. International Journal of Nursing Studies, 43, 953-962. doi: 10.1016/j.ijnurstu.2005.11.006

Masten, A. S. (2001). Ordinary magic: Resilience processes in development. American Psychologist, 56, 227-238. doi: 10.1037/0003-066X.56.3.227

Masten, A. S., \& Reed, M. J. (2002). Resilience in development. In C. R. Snyder \& S. J. Lopez (Eds.), Handbook of positive psychology (pp. 74-88). New York: Oxford.

McGowan, B. (2005). Who do they think they are? Undergraduate perceptions of the definition of supernumerary status and how it works in practice. Journal of Clinical Nursing, 15, 1099-1105. doi: 10.1111/j.1365-2702.2005.01478.x

Mott, J. D. (2013). Undergraduate nursing student experiences with faculty bullying (Doctoral dissertation). Retrieved from ProQuest Dissertations and Theses database. (UMI No. 3565596)

Neuman, B., \& Fawcett, J. (2011). The Neuman Systems Model (5th ed.). Upper Saddle River, NJ: Pearson Education.

Norris, C. M. (1982). Concept clarification in nursing. Rockville, MD: Aspen.

Novotny, J. S. (2011). Academic resilience: Academic success as a possible compensatory mechanism of experienced adversities and various life disadvantages. The New Educational Review, 23, 91-101.

Olsson, C. A., Bond, L., Burns, J. M., Vella-Brodrick, D. A., \& Sawyer, S. M. (2003). Adolescent resilience: A concept analysis. Journal of Adolescence, 26, 1-11. doi:10.1016/S0140-1971(02)00118-5

Parse, R. R. (1998). The human becoming school of thought: A perspective for nurses and other health professionals. Thousand Oaks, CA: Sage. 
Pearcy, P. A., \& Elliot, B. E. (2004). Student impressions of clinical nursing. Nurse Education Today, 24, 382-387. doi: 10.1016/j.nedt.2004.03.007

Peters, J. M. (2003). A qualitative study of registered nurses returning to school for a baccalaureate degree in nursing (Doctoral dissertation). Retrieved from ProQuest Dissertations and Theses database. (UMI No. 30282499)

Pines, E. W., Rauschhuber, M. L., Cook, J. L., Norgan, G. H., Canchola, L., Richardson, C., \& Jones, M. E. (2014). Enhancing resilience, empowerment, and conflict management among baccalaureate students. Nurse Educator, 39, 85-90. doi: 10.1097/ NNE.0000000000000023

Pines, E. W., Rauschhuber, M. L., Norgan, G. H., Cook, J. D., Canchola, L., Richardson, C., \& Jones, M. E. (2012). Stress resiliency, psychological empowerment and conflict management style among baccalaureate nursing students. Journal of Advanced Nursing, 68, 1482-1493. doi: 10.1111/j.1365-2648.2011.05875.x

Pitt, V., Powis, D., Levett-Jones, T., \& Hunter, S. (2014). The influence of personal qualities on performance and progression in a pre-registration nursing programme. Nurse Education Today, 34, 866-871. doi: 10.1016/j.nedt.2013.10.011

Powis, D., Bore, M., Munro, D., \& Lumsden, M. A. (2005). Development of the Personal Qualities Assessment as a tool for selecting medical students. Journal of Adult and Continuing Education, 11, 3-14.

Richardson, G. E. (2002). The metatheory of resilience and resiliency. Journal of Clinical Psychology, 58, 307-321.doi: 10.1002/jclp.10020

Sarmiento, T. P., Laschinger, H. K., \& Iwasiw, C. (2004). Nurse educators' workplace empowerment, burnout, and job satisfaction: Testing Kanter's theory. Journal of Advanced Nursing, 46, 134-143. doi: 10.1111/j.1365-2648.2003.02973.x 
Sharif, F., \& Masoumi, S. (2005). A qualitative study of nursing student experiences of clinical practice. BMC Nursing, 4, Article 6. doi: 10.1186/1472-6955-4-6

Siler, B., \& Kleiner, C. (2001). Novice faculty: Encountering expectations in academia. Journal of Nursing Education, 40, 398-403.

Simoni, P. S., Larrabee, J. H., Birkhimer, T. L., Mott, C. L., \& Gladden, S. D. (2004). Influence of interpretive styles of stress resiliency on registered nurse empowerment. Nursing Administration Quarterly, 28, 221-224.

Stephens, T. M. (2012). Increasing resilience in adolescent nursing students. (Doctoral dissertation). Retrieved from http://trace/tennessee.edu/utk_graddiss/1351

Stephens, T. M. (2013). Nursing student resilience: A concept clarification. Nursing Forum, 48, 125-133. doi: 10.1111/nuf.12015

Talbot, L. A. (2000). Burnout and humor usage among community college nursing faculty members. Community College Journal of Research and Practice, 25, 359-373. doi: $10.1080 / 106689200263962$

Tartavoulle, T., Manning, J., \& Fowler, L. (2011). Smoothing the transition from bedside to classroom. American Nurse Today, 6, 45-46.

Taylor, H., \& Reyes, H. (2012). Self-efficacy and resilience in baccalaureate nursing students. International Journal of Nursing Education Scholarship, 9, Article 2. doi: 10.1515/1548-923X.2218

Thomas, J., Jack, B. A., \& Jinks, A. M. (2012). Resilience to care: A systematic review and meta-synthesis of the qualitative literature concerning the experiences of student nurses in adult hospital settings in the UK. Nurse Education Today, 32, 657-664. doi:10.1016/j.nedt.2011.09.005

Thomas, K., \& Tymon, W. (1992). Stress Resiliency Profile. Tuxedo, NY: Xicom. 
Thomas, K., \& Tymon, Jr., W. (1994). Does empowerment always work? Understanding the role of intrinsic motivation and personal interpretation. Journal of Management Systems, 6(2), 1-13.

Thomas, K., \& Tymon, Jr., W. (1995). Interpretive styles that contribute to job-related stress: Two studies of managerial and professional employees. Anxiety, Stress, and Coping, 8, 235-250. doi: 10.1080/10615809508249376

Tusaie, K., \& Dyer, J. (2004). Resilience: A historical review of the construct. Holistic Nursing Practice, 18, 3-8.

Wagnild, G. M. (2009). The Resilience Scale User's Guide for the US English version of the Resilience Scale and the 14-item Resilience Scale (R-14). Worden, MT: Resilience Center.

Wagnild, G. M., \& Young, H. (1990). Resilience among older women. Image: Journal of Nursing Scholarship, 22, 252 - 255. doi: 10.1111/j.1547-5069.1990.tb00224.x

Wagnild, G. M., \& Young, H. (1993). Development and psychometric evaluation of the Resilience Scale. Journal of Nursing Measurement, 1, 165-178.

Wells, M. I. (2007). Dreams deferred but not deterred: A qualitative study on undergraduate nursing student attrition. Journal of College Student Retention: Research, Theory, and Practice, 8, 439-456. doi: 10.2190/17K2-5847-6637-L70P

Whalen, K. S. (2008). Impact of work-related stressors associated with part-time clinical affiliate status on role strain among nursing faculty in baccalaureate nursing education (Doctoral dissertation). Retrieved from ProQuest Dissertations and Theses database. (UMI No. 3318415)

Whittemore, R., \& Knafl, K. (2005). The integrative review: Updated methodology. Journal of Advanced Nursing, 52, 546-553. doi: 10.1111/j.1365-2648.2005.03621.x 
Wiens, S., Babenko-Mould, Y., \& Iwasiw, C. (2014). Clinical instructors' perceptions of structural and psychological empowerment in academic nursing environments. Journal of Nursing Education, 53, 265-270. doi:10.3928/01484834-20140421-01

Williamson, G. R., Health, V., \& Proctor-Childs, T. (2013). Vocation, friendship, and resilience: A study exploring nursing student and staff views on retention and attrition. The Open Nursing Journal, 7, 149-156. doi: 10.2174/1874434601307010149 


\section{Chapter Three - Nursing Students' Understanding and Enactment of Resilience: A Grounded Theory Study}

Resilience is described as a dynamic process that mitigates the effects of stress through behaviours that facilitate adaptation in the context of adversity, resulting in the ability to function above the norm in spite of significant stress (Masten, 2001; Tusaie \& Dyer, 2004). Resilience is also viewed as a preventive strategy that inhibits the potentially debilitating effects of chronic stress (Kelley, 2004). Because stress is a major part of nursing students' academic lives and is experienced throughout their nursing education programs (Deary, Watson, \& Hogston, 2003; Magnussen \& Amundson, 2003), resilience may be required for them to buffer the negative impact of stress.

\section{Background}

Nursing students inevitably deal with stress in their education. Continued stress negatively affects nursing students' academic performance (Al-Kandari \& Vidal, 2007, Jimenez, Navia-Osorio, \& Diaz, 2010). Serious negative health outcomes have also been associated with continued stress of students such as depression and anxiety (Ross et al., 2005), substance-dependence behaviours (Freeburn \& Sinclair, 2009; Tully, 2004), suicidal tendencies (Stecker, 2004), psychological distress (Klainin-Yobas et al., 2014), and other physical symptoms (Lee, Mun, Lee, \& Cho, 2011; Mitchell et al., 2009). Studies have also shown that nursing students use less functional coping behaviours (Deary et al., 2003; Shikai, Shono, \& Kitamura, 2009). Consequently, students' ongoing stress causes some to withdraw from the program (Glossop, 2002; Wells, 2007).

In a meta-synthesis of qualitative studies of nursing students' stress in the clinical setting, Thomas, Jack, and Jinks (2012) conclude that development of resilience is integral to the education of nursing students. Resilience allows individuals to adapt and persist in the 
face of adversities (Wolin \& Wolin, 1994), while being able to experience personal growth through their challenges (Richardson, 2002), and develop a sense of overcoming one situation and possible mastery over other situations (Dyer \& McGuinness, 1996). Resilience is also a dynamic process that helps mitigates the effects of stress (Tusaie \& Dyer, 2004).

The benefits of resilience in nursing students' academic lives are documented in a number of studies. For example, nursing students' resilience has been related, albeit weakly, to their academic success (Beauvais, Stewart, DeNisco, \& Beauvais, 2014; Taylor \& Reyes, 2012), psychological empowerment (Beauvais et al., 2014; Pines et al., 2012), and selfesteem and social support (Nishi, Uehara, Kondo, \& Matsuoka, 2010). Students use resilience to cope with faculty bullying (Mott, 2013) and to modify their coping to successfully adapt to stress (Peters, 2003). Resilience was perceived by nursing students to facilitate their academic success (Carroll, 2011; Crombie, Brindley, Harris, Marks-Maran, \& Thompson, 2013; Knight et al., 2012), while student support staff attributed students' resilience to their persistence to remain in the program (Williamson, Health, \& ProctorChilds, 2013). Students linked their assertiveness in dealing with aggression in their clinical placements to their resilience (Jackson et al., 2011). Intervention studies about educational programs designed to promote resilience revealed partial effects on resilience and conflict management styles of nursing students (Pines et al., 2014; Stephens, 2012). A more detailed description of the results of an integrative review of studies of nursing students' resilience is discussed elsewhere (Reyes, Andrusyszyn, Iwasiw, Forchuk, \& Babenko-Mould, in press).

Similar findings are also evident in resilience studies of university students within social care and other health-related fields. For example, medical students' resilience was found to be a mediator between positive personality traits and anxiety symptoms (Shi, Liu, Wang, \& Wang, 2015), negatively related to depression and other mental health problems 
(Dyrbye et al., 2010; Peng et al., 2012), and a factor in helping students adjust to the frequent changing of clinical faculty with different expectations (Seltz, Montgomery, Lane, Soep, \& Hanson, 2014). Social support was found to explain medical students' resilience to repeated exposure to traumatic events in their clinical rotations (Haglund et al., 2009) and was also significantly related to social care students' resilience (Wilks, 2008; Wilks \& Spivey, 2010). In a qualitative study, social care students described resilience as a reactive process of positive coping offering protection against negative situations (Grant \& Kinman, 2013). Additionally, the reflective abilities of social care and physical therapy students was found to be linked to their high levels of resilience (Grant \& Kinman, 2012; Hilliard, Rathsack, Brannigan, \& Sander, 2008). Resilience was also associated with dental students' commitment to their studies over time despite burnout (Montero-Marin, Piva Demarzo, Pereira, Olea, \& García-Campayo, 2014).

Investigations into the resilience of students within nursing, social care, and other health-related fields exist, however, there is a lack of description about how resilience is understood and enacted in students' academic lives. There is limited explication of particular processes that explain how nursing students overcome adversities, thrive in difficult academic situations, and develop positive adaptation despite challenging circumstances. Exploration of the processes that explain how resilience facilitates successful coping with stress can provide evidence-based understanding of effective strategies to support students. Hence, a study of nursing students' understanding and enactment of resilience is important to gain insights into the processes that contribute to resilience.

\section{Purpose of the Study}

The purpose of this study was to explore nursing students' understanding and enactment of resilience. 


\section{Design of the Study}

A constructivist, grounded theory study design (Charmaz, 2006) was used to guide data collection and analysis as there remains limited theoretical explication of nursing students' resilience. Grounded theory is appropriate in substantive areas where there are not enough theories to explain social processes and human behaviour (Hutchinson \& Wilson, 2001). Moreover, the constructivist approach was chosen for this particular study based on the complex nature of the grounded theory study design. The constructivist approach includes flexible yet rigorous analytic procedures that promote the reflexivity of the researcher (Charmaz, 2006), thereby allowing the exploration of the concept of resilience and the construction of a related theory, a theory which would be as resonant as possible with the realities of the participants.

\section{Participants of the Study}

Using purposive sampling, 38 students (4 males, 34 females) from a four-year, integrated baccalaureate nursing program of a university in Ontario, Canada were recruited for the study. Participants were 18 to 37 years of age, with a mean age of 21.7 years. Seven participants were in the first year, 13 in each of second and third years, and 5 in the fourth year. Eighteen participants had part-time employment. Five participants were married, two with children. Twenty-five students self-identified their cultural background as CanadianCaucasian, five as Asian, two as African, two as Portuguese, and one student each as Guyanese, Italian, Polish, and South Asian.

\section{Data Collection}

Face-to-face interviews were conducted from January to April 2012, which was the second semester of the academic year. The second semester was chosen because it was thought that participants would provide richer data through providing more examples and 
deeper insights about their experiences than would be possible at the beginning of a school year. A researcher-developed, semi-structured interview guide (Appendix A) was used and interviews, lasting from 30 to 60 minutes, were digitally recorded and transcribed. Sample questions from the interview guide included: 'Would you please share some of your experiences of stress, difficulties, and/or adversities as a nursing student?' and 'How were you able to resolve the issues around your stress, difficulties, and/or adversities as a nursing student?' Data collection and analysis occurred simultaneously; therefore, immediately after each interview, the electronically recorded interview was sent for transcription and transcribed data were analysed by coding and constant comparative methods. Member checking was implemented from December 2012 to April 2013 to verify whether the grounded theory resonated with their experiences. Participants reviewed emailed descriptions of conceptual categories, including the core category of pushing through, and the corresponding excerpts from their transcripts. They were offered a second telephone or faceto-face interview to comment on the materials sent. All 27 participants who responded to the member checking processes opted to comment through email, and they all confirmed that the conceptual propositions were representative of their experience.

\section{Ethical Considerations}

Ethics approval was obtained from Western University's Office of Research Ethics (Appendix B) and the site at which data were collected. Permission to conduct the study was also obtained from the Dean/Director of the School of Nursing study site (Appendix C). Additionally, letters of permission to inform students about the study were provided to selected course professors (Appendix D). A Letter of Information (Appendix E) about the study was given to each participant prior to the start of the interviews and written informed consent (Appendix F) was obtained from each participant. A unique identification number 
(alpha-numeric code) was assigned to each of the completed demographic data questionnaire (Appendix G) to protect participants' personal identifying information. To preserve anonymity, digital recordings and written transcripts of interviews were also assigned alphanumeric codes.

\section{Data Analysis}

Data were managed using NVivo 9 software and analysed through an iterative process of constant comparison of data from one participant to another and comparison of incidents within and among accounts (Glaser, 1978). The researchers used the three coding phases (initial, focused, and theoretical) of constructivist grounded theory methodology, as indicated by Charmaz (2006). Initial coding (line-by-line coding) was implemented after each interview. Focused coding, which involved synthesizing initial codes that made the most analytic sense to categorize the data followed thereafter. A few conceptual categories derived from focused coding of the initial interviews were used for theoretical sampling. For example, participants who failed a course, who were caregivers to sick family members, or who were dealing with their own physical or mental illness were asked to clarify conceptual categories of coping with failure and dealing with multiple commitments. More conceptual categories emerged in subsequent interviews. Therefore, theoretical sampling continued. Questions in the interview guide were modified and revised in subsequent interviews to clarify the emerging conceptual categories. In time, nine conceptual categories were clarified through theoretical sampling. After 38 interviews, theoretical saturation was achieved as no new properties of these conceptual categories were emerging. Theoretical coding was conducted thereafter. Moving to theoretical coding was not entirely a linear process: there were simultaneous memo-writing and constant comparisons between categories and memos and field notes. Further analysis through memo writing and constant comparative methods 
revealed that the concept of pushing through was the core category that both unified the other conceptual categories and exemplified nursing students' understanding and enactment of resilience.

\section{Rigour}

Charmaz's (2006) criteria of credibility, originality, resonance, and usefulness were used to evaluate the quality of the emerging substantive grounded theory. Credibility was achieved mainly by obtaining rich data through interviews, compiling detailed written transcripts of interviews, and making extensive field notes. Extensive and constant comparison procedures between observations and categories were also conducted to establish credibility. Originality was attained through reflexivity processes such as writing memos and reflective journals and by referring to the literature to explore whether the analysis provided a new conceptual rendering of the data. Resonance was realized through member checking to review how well participants agreed with emerging categories. Explication of the contribution of the emerging theory to the state of knowledge of resilience in nursing education accomplished the criterion of usefulness.

\section{Findings}

Pushing through was the basic social process that emerged from the data analysis. Pushing through is based on the competing demands of the nursing program and the student's extracurricular demands, including family commitments, social pressures and outlets, leisure pursuits, self-care and well-being, and so on. Students are faced with obstacles and challenges to achieving their academic goals. These obstacles include students' problems and risk factors, such as having a disease, caring for an ill family member, or being in a chaotic home environment. 
"Pushing through" was a phrase used by some participants to describe their experiences of resilience. They use the process of pushing through to withstand the challenges in their academic lives. One participant described:

Resilience is like pushing through or fighting your way, not letting things knock you down, kind of ploughing your way through.

The process of pushing through is also adopted in order to accomplish students' goals despite the setbacks and obstacles in their academic lives. Therefore, pushing through not only pertained to persevering and enduring hardships but also to taking action to achieve goals. One participant explained:

I just knew I had to keep going because I've never really given up on things. Resilience is like people who stick up for what they want and they don't give up in any situation. They just keep pushing until they get what they want.

The theory of pushing though has three main phases (see Figure 1): stepping into, staying the course, and acknowledging. In Figure 1, these three phases are depicted as spirals that are connected with each other. These spirals illustrate that the phases of pushing through are iterative wherein the person may go back and forth through these phases. Hence, the process of pushing through is not a linear one, but rather a dynamic and iterative process. The cylindrical bar inside these spirals includes an arrow at the right end of the bar to represent a progressive trajectory of pushing through. This means that the process of pushing through is not only enacted to deal with the here-and-now but to achieve a perceived goal, to move towards a resolution of a problem, or to realize a projected or envisioned future. There are sub-processes within each of the phases of pushing through which suggest as actions (responses, strategies, and approaches) of pushing through. The actions within each of the phases represent nursing students' enactment of resilience. The phases and the actions within 
each phase of the process of pushing through indicate that the students' experience of adversities in their academic life is a developmental process, and that there are actions (responses, strategies, and approaches) that are to be enacted to progress to subsequent phases of pushing through.

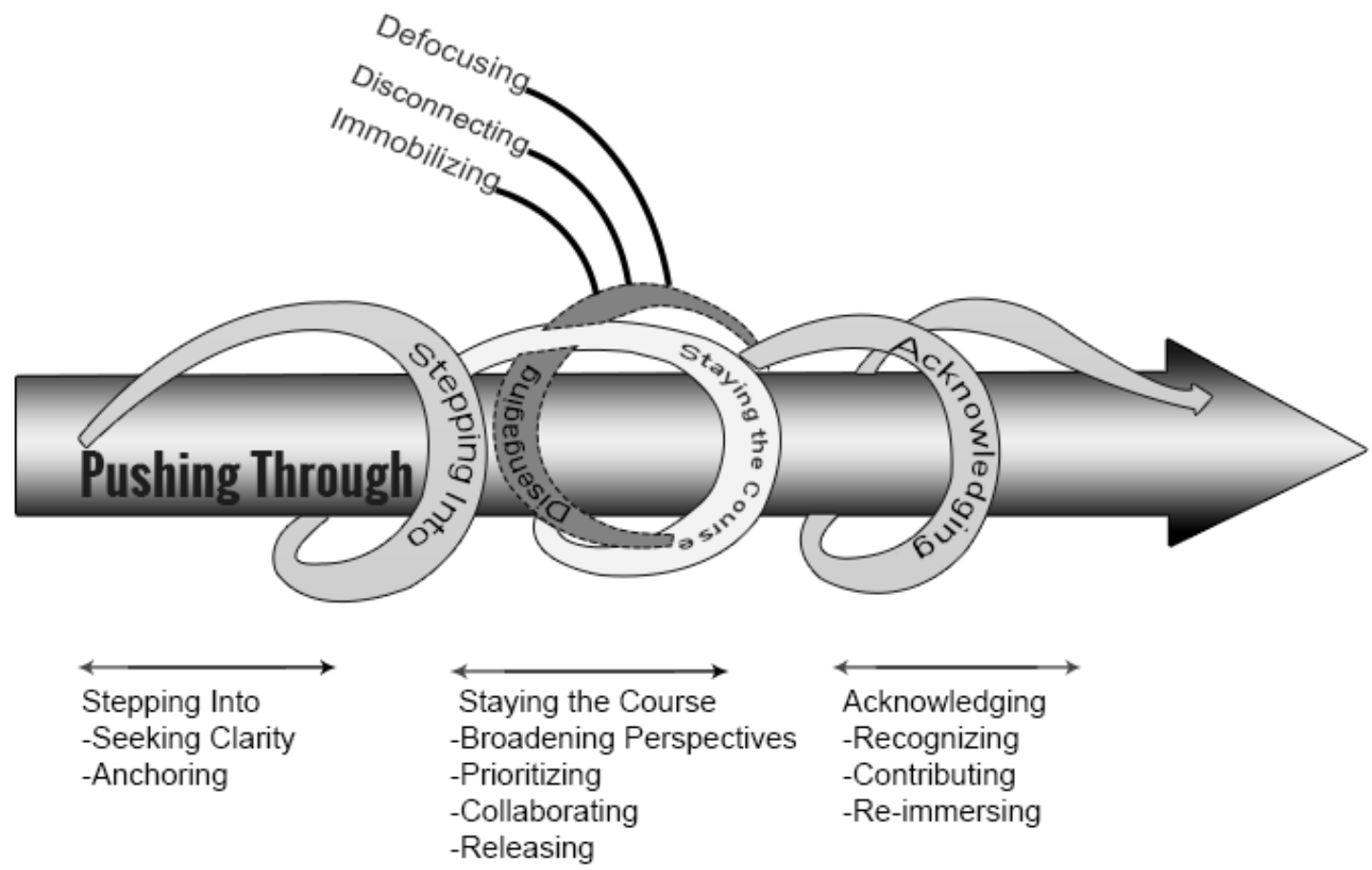

Figure 1: The grounded theory of pushing through. 


\section{First Phase of Pushing Through: Stepping Into}

The initial phase of pushing through is stepping into a difficult situation (Figure 1).

As students step into an adversity or challenging situation, they perceive that the challenging circumstance is a different or new experience, requiring a different set of skills or way of thinking, acting and being to cope successfully. There is anxiety and an overall sense of unfamiliarity in dealing with the situation and hence, certain responses are adopted to get through this stage of experiencing the adversity. There are two main responses that students employ when they step into a challenging life experience: seeking clarity and anchoring (Figure 1).

Students seek clarity by obtaining information that would assist them to effectively address their difficult situations. For example, students clarify expectations, ask questions of others, and explore causes and conditions of their adversities. An exemplar of seeking clarity in Table 3 illustrates how this particular participant was surprised to learn that she had failed a course and was afraid to tell her parents. She began to speak to different people (other than her parents) to explore why she had failed, and to figure out how to tell her parents and respond to their concerns. The second response to stepping into is anchoring which refers to holding on to certain belief systems and thought processes to feel safe and minimize anxiety. Students anchor to beliefs and values that are easily accessible to them in order to cope in the early phase of encountering adversity. An exemplar in Table 3 portrays an anchoring response by a student's emphasizing her parents' values about the importance of hard work and education. Other anchoring responses include using positive self-talk and considering the temporariness of one's situation. 
Table 3

Examples of Exemplars Supporting Sub-Processes of Pushing Through

\begin{tabular}{|c|c|c|}
\hline Phase & Sub-Processes & Exemplar \\
\hline \multirow[t]{2}{*}{ Stepping Into } & Seeking Clarity & $\begin{array}{l}\text { "I was trying to get it sorted before I had to tell my parents so that they won't have to say like } \\
\text { 'Oh well, what about this, this, and this? I could respond and say, 'Well I've already dealt with } \\
\text { this. This is what's going on."” }\end{array}$ \\
\hline & Anchoring & $\begin{array}{l}\text { "The demand was really hard and I was also dealing with being away from my family. I was } \\
\text { ready to quit. But my parents told me to be strong and they would give me examples of what } \\
\text { they went through because they had a hard life growing up." }\end{array}$ \\
\hline \multirow[t]{4}{*}{$\begin{array}{l}\text { Staying the } \\
\text { Course }\end{array}$} & Broadening Perspectives & $\begin{array}{l}\text { "All I have to think is two years and I'll be with him [referring to her boyfriend in another city]. } \\
\text { I'll be in a little apartment with a little weird dog. I'll have a job. I'll be happy." }\end{array}$ \\
\hline & Prioritizing & $\begin{array}{l}\text { "When I have a day off, if work calls and I plan to do schoolwork, I just say 'No, I can't take that } \\
\text { shift.' I only have to get eight shifts a month there and they're fine with that and then I } \\
\text { prioritize. When I have days off, that's when I do my schoolwork." }\end{array}$ \\
\hline & Collaborating & $\begin{array}{l}\text { "There have been days where he [her husband] just has to call in late in going to work because } \\
\text { we wouldn't be able to find somebody [to take care of the children]. My husband finds it } \\
\text { important that I don't miss out on anything. We had a long discussion, weighing the pros and } \\
\text { cons of me going back to school." }\end{array}$ \\
\hline & Releasing & $\begin{array}{l}\text { "I'll go out with friends and that's huge for me because it sort of reinvigorates me and I will have } \\
\text { more energy. It's sort of an escape, another release of energy." }\end{array}$ \\
\hline
\end{tabular}


Table 3 Continued

Examples of Exemplars Supporting Sub-Processes of Pushing Through

\begin{tabular}{|c|c|c|}
\hline Phase & Sub-Processes & Exemplar \\
\hline \multirow[t]{3}{*}{ Disengaging } & Defocusing & $\begin{array}{l}\text { "In two years, I lost three grandparents and two really good friends. I was distracted. It would be } \\
\text { so hard to try and focus and do all these readings. I'll start thinking about that (referring to the } \\
\text { death of her loved ones) but then it's affecting my schoolwork because by then ... my head's all } \\
\text { wrapped around thinking about that. I'm not paying attention and focusing as much as I should." }\end{array}$ \\
\hline & Disconnecting & $\begin{array}{l}\text { "I was really angry at myself for letting it happen again. I mean, being depressed. I had guilt, } \\
\text { anger, self-blame. I wallowed in it for a few days. You push everybody away." }\end{array}$ \\
\hline & Immobilizing & $\begin{array}{l}\text { "Last year, my boyfriend and I, we broke up and I was so upset. I spent the majority of my day } \\
\text { just in bed. School was - it didn't mean anything to me. I was just going through the motions of } \\
\text { everything. I didn't do a single reading that entire year. I was just in bed all day." }\end{array}$ \\
\hline \multirow[t]{3}{*}{ Acknowledging } & Recognizing & $\begin{array}{l}\text { "I have become confident in my ability to navigate the pitfalls and crap and everything else that } \\
\text { have shown up as I progressed. My time management skills have improved." }\end{array}$ \\
\hline & Contributing & $\begin{array}{l}\text { "He [her boyfriend] was a big help, too. He's really good at coaching me, like, 'You can do this. } \\
\text { Don't worry about it.' He was really good at calming me down when I'm stressing. He's } \\
\text { actually doing his exams right now so we're in reversal mode. And it's me saying, 'You can do } \\
\text { this.'” }\end{array}$ \\
\hline & Re-Immersing & $\begin{array}{l}\text { "I've always been someone who pushes myself. I just want to quit but my parents won't let me } \\
\text { quit. And now looking back, I'm so thankful that they pushed me to get those types of things } \\
\text { [referring to her extra-curricular activities]. And now that I realized that I'm thankful for those } \\
\text { things, I'm starting to push myself to do more." }\end{array}$ \\
\hline
\end{tabular}




\section{Second Phase of Pushing Through: Staying the Course}

Students progress to the second phase of pushing through when they develop an awareness that sustained or continuous actions are required to achieve their goals. Hence, this phase pertains to the actions that nursing students take in order to continue pursuing their goals despite obstacles. Students use the process of staying the course to prevent themselves from veering away from their plans or perceived path of achieving their academic aspirations. They implement strategies to withstand setbacks and to get through the challenges. There are four main strategies comprising the process of staying the course: broadening perspectives, prioritizing, collaborating, and releasing (Figure 1).

Broadening perspectives is a strategy that pertains to expanding and enriching students' understanding of the adversities they are experiencing. The purpose of broadening perspectives is to motivate oneself to continue pushing through. Many participants broaden perspectives by clarifying their goals and values in order to obtain unwavering reasons for continuing to push through. This strategy can also come in the form of making generalizations that their experience is not unique and that everybody goes through a generally similar encounter. By normalizing the experience, they feel validated and comforted. This strategy can also involve envisioning a bright picture of oneself in the future (exemplar in Table 3). Prioritizing is a strategy which involves exploring and selecting options that are useful in getting through a difficult or challenging situation. A prioritizing strategy is based on the perception that there are limited resources and time. Hence, students go through a decision-making process to consider which options are relevant, necessary and that will enable them to get through a challenging situation (exemplar in Table 3). Collaborating is another strategy which refers to connecting with another person or a group to vent feelings, to solve a problem, to get through the next stage of their academic lives, or 
to achieve a goal. The collaborating strategy is based on the premise that one has to take advantage of social resources (i.e., other individuals) in order to cope with a challenging situation (exemplar in Table 3). Finally, releasing is about engaging in different activities to create relief or a break from continued feelings of being burdened, overwhelmed or isolated. The nature of releasing is to involve oneself in different, yet temporary activities. Some participants describe releasing as an "escape." The outcome of releasing is a return to previous activities with a renewed sense of motivation or energy (exemplar in Table 3).

\section{Disengaging: An Intersecting Process in the Second Phase of Pushing Through}

The second phase of pushing through, which is staying the course, includes three reactions that deter students from pushing through: these are defocusing, disconnecting, and immobilizing (Figure 1). These reactions are collectively represented as the disengaging process of pushing through. These reactions are transient. Students re-engage in pushing through their challenges by employing the strategies of staying the course. Hence, in Figure 1, the spiral that depicts the disengaging process intersects with the process of staying the course. The intersecting of these two spirals depict that some participants experienced going back and forth between the disengaging process and staying the course.

Defocusing is a disengaging process which pertains to students' reactions to adversities that cause them to deviate from concentrating attention or energy on effectively managing adversities or achieving goals. Students are involved in extraneous activities that deter them from coping with their difficult situations or employing strategies that are critical to achieving their academic goals. They resort to activities that distract them from applying approaches that would workably address their challenges or even solve their problems. Examples of these activities are engaging in unhealthy recreational activities, working excessive hours in their part-time jobs, and brooding, all of which diffuses their attention 
from solving their problems (exemplar in Table 3). Disconnecting refers to reactions to adverse situations that keep students from seeking help and connecting with others. Students may create distance from people and resources that could potentially help them deal more effectively and realistically with their situations. They avoid sharing their concerns or asking for help, which creates more distance from others who could potentially offer assistance or support (exemplar in Table 3). Lastly, immobilizing is related to reactions that prevent students from taking the next steps in pushing through. Immobilizing is usually caused by exhaustion from the continued experience of adversities. As a result, students feel stuck and lose their sense of a forward trajectory in their academic lives (exemplar in Table 3). They temporarily lose a sense of hope and optimism; however, immobilizing is transient as with the other two disengaging processes.

\section{Third Phase of Pushing Through: Acknowledging}

The final phase of pushing through, which is acknowledging, begins when there is an awareness of one's self-transformation as a result of experiencing adversity. This phase refers to the students' reflections on their transformation from pushing through the challenges in their academic lives (Figure 1). Students evaluate the changes they have gone through, particularly changes in how they view themselves. There are three approaches to acknowledging: recognizing, contributing, and re-immersing.

Recognizing is an approach to acknowledging which mainly involves identifying, reflecting, and evaluating the sources and outcomes of students' transformations from pushing through (exemplar in Table 3). Contributing pertains to sharing the student's transformation with others. As students recognize the changes they experience, they in turn extend their transformations to others (exemplar in Table 3). Finally, re-immersing is an approach to acknowledging that mainly involves being prepared and ready to step into new 
challenges and being willing to continue to push through (exemplar in Table 3 ). There is an acknowledgement that adversity is part of life and that one must be willing to continue pushing through. The process of re-immersing is based on the premise that pushing through is an on-going process. It includes a commitment to continue pushing through and a willingness to engage, rather than avoid pushing through new or different challenges in life.

The third phase of pushing through, acknowledging, is a stage during which nursing students perceive themselves as ready for new challenges. They have a realistic perception that challenges are part of their academic lives and one continues to push through life challenges. Therefore, in Figure 1, there is an arrow at the right end of the acknowledging spiral, which symbolizes an anticipation of another opportunity to push through.

\section{Discussion}

The grounded theory of pushing through represents nursing students' understanding and enactment of resilience. This grounded theory adds evidence to the current state of knowledge about resilience. The explication of the process of pushing through suggests that resilience is a process, thereby contributing to the current literature of resilience as a process (Fletcher \& Sarkar, 2013; Ungar, 2013). More particularly, the iterative nature of the three phases of pushing through and the periods of disengagement and re-engagement within the second phase of pushing through demonstrate that resilience is not a linear, unhindered process. Additionally, participants' experiences of defocusing, disconnecting, and immobilizing were not necessarily indicative of lack of resilience but part of their resilience experience. Therefore, the process of pushing through supports the perspective that resilience is a dynamic process (Tusaie \& Dyer, 2004) because of the iterative interactions of the phases and the disengaging processes of pushing through. 
Ungar (2003) asserts that one of the results of conducting qualitative research about resilience is the discovery of unnamed protective processes of resilience. In this study, another process of resilience is discovered, the process of pushing through. More specifically, participants in the current study used the process of pushing through in order to withstand their challenges and achieve their academic goals. This is consistent with current conceptualizations of resilience, which denote competence to withstand or recover from adversities (Masten \& Powell, 2003) and actions to achieve positive outcomes despite adverse situations (Masten, 2001; Wyman, Sandler, Wolchik, \& Nelson, 2000). Therefore, the process of pushing through is yet another discovered process to describe the complex phenomenon of resilience.

The findings of the study also provide a further description of resilience as a process (Luthar \& Cicchetti, 2000). Results of this grounded theory study highlight that resilience is a process with temporally sequenced phases. Specifically, the process of pushing through is comprised of three iterative phases in which a nursing student steps into a challenging situation (stepping into), implements strategies for remaining in the nursing program or persisting through a challenge (staying the course), and acknowledges a personal transformation from the experience of challenging situations (acknowledging). This depiction of resilience as a phenomenon comprised of temporally sequenced phases is different from many conceptualizations of resilience. For example, this is different from Wagnild and Young's (1990) description of resilience as a phenomenon encompassing five essential characteristics, namely meaningful life, perseverance, self-reliance, equanimity, and existential aloneness as well as Benard's (1995) typology of resilience which includes capacities such as social competence, problem-solving, autonomy, and a sense of purpose and belief in a bright future. Wagnild and Young's and Benard's conceptualizations of 
resilience present more as structural dimensions than as temporal phases of resilience. Furthermore, conceptualizing resilience as a process with temporal phases suggests that resilience is an action-oriented process. This is also consistent with the description of resilience as a strategy to persevere and access valuable support systems (Kornhaber \& Wilson, 2011; Trusty-Smith, 2013). Additionally, this implies that resilience can be learned, developed, and enhanced (Edward, Welch, \& Chater, 2009).

The present study extends Stephens' (2013) concept of nursing student resilience, which is defined as "an individualized process of development that occurs through the use of personal protective factors to successfully navigate perceived stress and adversities.

Cumulative successes lead to enhanced coping/adaptive abilities and well-being" (p. 130). The explication of pushing through as an action-oriented process, and as a process comprised of temporally sequenced phases with actions indicating students' enactment of resilience highlights nuanced descriptions of resilience as a process. Therefore, the study findings provide an expanded view of Stephens' concept of resilience as a developmental process.

Furthermore, the results indicating resilience as a dynamic process are particularly relevant for nursing students. This view of resilience provides an alternative perspective for nursing students that resilience is not a static phenomenon nor it is only present in certain individuals. Instead, the explication of resilience as an action-oriented process provides a vantage point for students to recognize that resilience can be developed and further enhanced. For example, the processes and strategies within the theory of pushing through can be a resource for students in effectively addressing their adversities. The narratives and concepts within the theory also provide the validation that disengaging from and re-engaging with the process of pushing through are part of their experience of resilience. Therefore, the processes 
within the theory of pushing through are learning opportunities for students to enhance their resilience.

Furthermore, the representation of resilience through the process of pushing through provides nurse educators a strength-based perspective in supporting students with their challenges. The phases of pushing through allow teachers to identify their students' location on the trajectory of the process of pushing through and educate students to apply the appropriate strategies that will assist them to adapt to their adversities. Without this theory, teachers' support to students may be limited to problem-based or deficit-focused strategies applied in a haphazard fashion.

The findings also have implications for administrators of nursing programs. As previously explicated in the literature review, the continued stress of nursing students can lead to increased attrition whereas resilience can contribute to achievement of positive academic outcomes. Nursing programs can take advantage of integrating the concepts and processes within the theory of pushing through to new and existing programs within their schools in order to facilitate the development of resilience of nursing students.

The study findings can also be applied to the nursing practice context because of the conceptual rendering of the process of pushing through. Nurses around the world need to be resilient within their challenging practice environments while concurrently being compassionate, knowledgeable, competent, and ethical in their provision of care. The grounded theory can serve as a reflective practice tool to make sense of nurses' situations and realities (Boros, 2009; Oelofsen, 2012). The theory can be used as a tool for clinical supervision and ongoing professional support to nurses. For example, nurses can locate their experience in the trajectory of pushing through and identify the actions of pushing through which can help them move through their adversities and achieve transformation. Moreover, 
discussion and reflection of resilience is particularly useful in forging advanced nursing practice. This is because specialized and extensive clinical, research, and leadership competencies of advanced practice nurses evolve from complex healthcare needs of clients as well as rapidly changing healthcare delivery systems (Furlong \& Smith, 2005).

\section{Limitations of the Study}

A limitation of the study was that participants came from only one university. Most participants were second and third year students, females in their 20s and identified themselves at Canadian-Caucasian (83\%). Therefore, application and transferability of findings to larger populations of nursing students may be limited. Another limitation was the one-time data collection. A longitudinal, qualitative design (i.e., interviewing participants at multiple time points) could expand the substantive theory of pushing through.

\section{Conclusion}

The grounded theory of pushing through is the first theory that addresses nursing students' resilience. The concepts depicted in this theory offer foundational knowledge and preliminary evidence of nursing students' resilience as a dynamic process. The findings of the study provide a theoretical groundwork for future research of nursing students' resilience. Recommendations for further theory development include considering participants from different types of nursing education programs and from different cultural backgrounds, applying a critical social perspective such as exploring the impact of race, class, and gender on resilience, and using other data sources such as students' reflective journals written over an extended period of time.

The researcher's use of the constructivist grounded theory in this study allowed the exploration of resilience as the substantive area in nursing students' context, promoted the researchers' reflexivity in constructing a theory grounded in the data, and facilitated the use 
of flexible yet rigorous emergent processes to code and synthesize large amounts of data. The result was a theoretical rendering of the participants' realities. Furthermore, this grounded theory is interpretive in nature, which means that this theory assumes "emergent, multiple realities; indeterminacy; facts and values as linked; truth as provisional; and social life as processual" (Charmaz, 2006, p. 126). This theory provides "interpretive frames" (Charmaz 2006, p. 128), rather than deterministic explanations, from which to view resilience in a nuanced way.

The results of the study underscore the responsibility of nurse educators to develop and maintain an environment conducive to academic success. It is imperative for nurse educators to support students' coping with their challenges. Therefore, it is fitting for nurse educators to be committed to fostering resilience in their students. Finally, the findings highlight the significance of formally integrating the topic of student resilience into the nursing curriculum in order to create formal forums for students to learn how to thrive in their academic and practice environments. 


\section{References}

Al-Kandari, F., \& Vidal, V. (2007). Correlation of the health-promoting lifestyle, enrollment level, and academic performance of College of Nursing students in Kuwait. Nursing and Health Sciences, 9, 112-119. doi: 10.1111/j.1442-2018.2007.00311.x

Beauvais, A. M., Stewart, J. G., DeNisco, S., \& Beauvais, J. E. (2014). Factors related to academic success among nursing students: A descriptive correlational research study, Nurse Education Today, 34, 918-923. doi: 10.1016/j.nedt.2013.12.005

Benard, B. (1995). Fostering resilience in children. Urbana, IL: ERIC Clearing House on Elementary and Early Childhood Education. Retrieved from http://files.eric.ed.gov/ fulltext/ED386327.pdf

Boros, S. (2009). Exploring organisational dynamics. London: Sage.

Carroll, S. (2011). Resilience as a factor in the successful completion of a California community college based associate degree in nursing program (Doctoral dissertation). Retrieved from ProQuest Dissertations and Theses database. (UMI No. 3454870)

Charmaz, K. (2006). Constructing grounded theory: A practical guide through qualitative analysis. London: Sage.

Crombie, A., Brindley, J., Harris, D., Marks-Maran, D., \& Thompson, T. M. (2013). Factors than enhance rates of completion: What makes students stay? Nurse Education Today, 33, 1282-1287. doi: 10.1016/j.nedt.2013.03.020

Deary, I. J, Watson, R., \& Hogston, R. (2003). Longitudinal cohort study of burnout and attrition in nursing students. Journal of Advanced Nursing, 43, 71-81. doi: 10.1046/j.1365-2648.2003.02674.x

Dyer, J. G., \& McGuinness, T. M. (1996). Resilience: Analysis of the concept. Archives of Psychiatric Nursing, 5, 276-282. doi: 10.1016/S0883-9417(96)80036-7 
Dyrbye, L. N., Power, D. V., Massie, F. S., Eacker, A., Harper, W., Thomas, M. R., . . . Shanafelt, T. D. (2010). Factors associated with resilience to and recovery from burnout: A prospective, multi-institutional study of US medical students. Medical Education, 44, 1016-1026. doi: 10.1111/j.1365-2923.2010.03754.x

Edward, K., Welch, A., \& Chater, K. (2009). The phenomenon of resilience as described by adults who have experienced mental illness. Journal of Advanced Nursing, 65(3), 587595. doi: 10.1111/j.1365-2648.2008.04912.x

Fletcher, D., \& Sarkar, M. (2013). Psychological resilience: A review and critique of definitions, concepts, and theory. European Psychologist, 18, 12-23. doi: $10.1027 / 1016-9040 / \mathrm{a} 000124$

Freeburn, M., \& Sinclair, M. (2009). Mental health nursing students' experience of stress: Burdened by a heavy load. Journal of Psychiatric and Mental Health Nursing 16, 335-342. doi: 10.1111/j.1365-2850.2008.01376.x

Furlong, E., \& Smith, R. (2005). Advanced nursing practice: Policy, education, and role development. Journal of Clinical Nursing, 14, 1059-1066. doi: 10.1111/j.13652702.2005.01220.x

Glaser, B. G. (1978). Theoretical sensitivity. Mill Valley, CA: Sociology Press.

Glossop, C. (2002). Student nurse attrition: Use of an exit-interview procedure to determine students' leaving reasons. Nurse Education Today, 22, 375 - 386. doi: 10.1054/nedt.2001.0724

Grant, L., \& Kinman, G. (2012). Enhancing wellbeing in social work students: Building resilience in the next generation. Social Work Education: The International Journal, 31, 605-621. doi: 10.1080/02615479.2011.590931 
Grant, L., \& Kinman, G. (2013). 'Bouncing Back?' Personal representations of resilience of student and experienced social workers. Practice: Social Work in Action, 25, 349-366. doi: $10.1080 / 09503153.2013 .860092$

Hilliard, M. J., Rathsack, C., Brannigan, P., \& Sander, A. P. (2008). Exploring the cultural adaptability of doctoral entry-level physical therapist students during clinical education experiences. Journal of Allied Health, 37, e199-e220

Haglund, M. E. M., aan het Rot, M., Cooper, N. S., Nestadt, P. S., Muller, D., Southwick, S. M., \& Charney, D. S. (2009). Resilience in the third year of medical school: A prospective study of the Associations between stressful events occurring during clinical rotations and student well-being. Academic Medicine, 84, 258-268. doi:

10.1097/ACM.0b013e31819381b1

Hutchinson, S. A., \& Wilson, H. S. (2001). Grounded theory the method. In P. Munhall (Ed.), Nursing research: A qualitative perspective (3rd ed., pp. 209-244). Sudbury, MA: Jones \& Bartlett.

Jackson, D., Hutchinson, M., Everett, B., Mannix, J., Peters, K., Weaver, R., \& Salamonson, Y. (2011). Struggling for legitimacy: Nursing students' stories of organisational aggression, resilience, and resistance. Nursing Inquiry, 18, 102-110. doi: 10.1111/j.1440-1800.2011.00536.x

Jimenez, C., Navia-Osorio, P. M. \& Diaz, C. V. (2010) Stress and health in novice and experienced nursing students. Journal of Advanced Nursing, 66, 442-455. doi: 10.1111/j.1365-2648.2009.05183.x 
Kelley, T. M. (2004). Positive psychology and adolescent mental health: False Promise or True Breakthrough? Adolescence, 39, 257-277. Retrieved from http://www.threeprinciplesmovies.com/threeprinciplesmovies/cache/file/CE43362E1B07-4EE7-B67D1C5316A0AF75.pdf

Klainin-Yobas, P., Keawkerd, O., Pumpuang, W., Thunyadee, C., Thanoi, W., \& He, H. G. (2014). The mediating effects of coping on the stress and health relationships among nursing students: a structural equation modeling approach. Journal of Advanced Nursing 70, 1287-1298. doi: 10.1111/jan.12283

Knight, J., Corbett, A., Smith, C., Watkins, B., Hardy, R., \& Jones, G. (2012). What made me stay? A review of the reasons student nurses enrolled in a bachelor of nursing programme completed their studies: A descriptive phenomenological study. Nurse Education Today, 32, e62-e65. doi:10.1016/j.nedt.2012.03.007

Kornhaber, R. A., \& Wilson, A. (2011). Building resilience in burns nurses: A descriptive phenomenological inquiry. Journal of Burn Care \& Research, 32, 481-488. doi: 10.1097/BCR.0b013e3182223c89

Lee, E. Y., Mun, M. S., Lee, S. H., \& Cho, H. S. M. (2011). Perceived stress and gastrointestinal symptoms in nursing students in Korea: A cross-sectional survey. BMC Nursing, 10, Article 22. doi: 10.1186/1472-6955-10-22

Luthar, S. S., \& Cicchetti, D. (2000). The construct of resilience: Implications for interventions and social policies. Development and Psychopathology, 12, 857-885.

Magnussen, L., \& Amundson, M. J. (2003). Undergraduate nursing student experience. Nursing and Health Sciences, 5, 261-267. doi: 10.1046/j.1442-2018.2003.00158.x

Masten, A. S. (2001). Ordinary magic: Resilience processes in development. American Psychologist, 56, 227-238. doi: 10.1037/0003-066X.56.3.227 
Masten, A. S., \& Powell, J. L. (2003). A resilience framework for research, policy, and practice. In S. S. Luthar (Ed.), Resilience and vulnerability: Adaptation in the context of childhood adversities (pp. 1-25). New York: Cambridge University Press.

Mitchell, T., O’Sullivan, P. B., Smith, A., Burnett, A. F., Straker, L., Thornton, J., \& Rudd, C. J. (2009). Biopsychosocial factors are associated with low back pain in female nursing students: A cross-sectional study. International Journal of Nursing Studies, 46, 678-688. doi: 10.1016/j.ijnurstu.2008.11.004

Montero-Marin, J., Piva Demarzo, M. M., Pereira, J. P., Olea, M., García-Campayo, J. (2014) Reassessment of the psychometric characteristics and factor structure of the "Perceived Stress Questionnaire” (PSQ): Analysis in a sample of dental students. PLoS ONE 9(1), e87071. doi:10.1371/journal.pone.0087071

Mott, J. D. (2013). Undergraduate nursing student experiences with faculty bullying (Doctoral dissertation). Retrieved from ProQuest Dissertations and Theses database. (UMI No. 3565596)

Nishi, D., Uehara, R., Kondo, M., \& Matsuoka, Y. (2010). Reliability and validity of the Japanese version of the Resilience Scale and its short version. BMC Research Notes, 3, 310-315. doi: 10.1186/1756-0500-3-310

Oelofsen, N. (2012). Developing reflective practice: A guide for health and social care students and practitioners. Banbury: Lantern Publishing.

Peng, L., Zhang, J., Li, M., Li, P., Zhang, Y., Zuo, X., . . Xu, Y. (2012). Negative life events and mental health of Chinese medical students: The effect of resilience, personality, and social support. Psychiatry Research, 196, 138-141. doi:

10.1016/j.psychres.2011.12.006 
Peters, J. M. (2003). A qualitative study of registered nurses returning to school for a baccalaureate degree in nursing (Doctoral dissertation). Retrieved from ProQuest Dissertations and Theses database. (UMI No. 30282499)

Pines, E. W., Rauschhuber, M. L., Cook, J. L., Norgan, G. H., Canchola, L., Richardson, C., \& Jones, M. E. (2014). Enhancing resilience, empowerment, and conflict management among baccalaureate students. Nurse Educator, 39, 85-90. doi: 10.1097/NNE.0000000000000023

Pines, E. W., Rauschhuber, M. L., Norgan, G. H., Cook, J. D., Canchola, L., Richardson, C., \& Jones, M. E. (2012). Stress resiliency, psychological empowerment and conflict management style among baccalaureate nursing students. Journal of Advanced Nursing, 68, 1482-1493. doi: 10.1111/j.1365-2648.2011.05875.x

Reyes, A. T., Andrusyszyn, M. A., Iwasiw, C., Forchuk, C., \& Babenko-Mould, Y. (in press). Resilience in nursing education: An integrative review. Journal of Nursing Education.

Richardson, G. E. (2002). The metatheory of resilience and resiliency. Journal of Clinical Psychology, 58, 307-321.doi: 10.1002/jclp.10020

Ross, R., Zeller, R., Srisaeng, P., Yimmee, S., Somchid, S., \& Sawatphanit, W. (2005). Depression, stress, emotional support, and self-esteem among baccalaureate nursing students in Thailand. International Journal of Nursing Education Scholarship, 2, Article 25. doi: 10.2202/1548-923X.1165

Seltz, L. B., Montgomery, A., Lane, J. L., Soep, J., \& Hanson, J. L. (2014). Medical students' experiences working with frequently rotating pediatric inpatient attending physicians. Hospital Pediatrics, 4, 239-246. doi: 10.1542/hpeds.2014-0016 
Shi, M., Liu, L., Wang, Z. Y., \& Wang, L. (2015). The mediating role of resilience in the relationship between big five personality and anxiety among Chinese medical students: A cross-sectional study. PLoS ONE, 10(3), e0119916. doi:

10.1371/journal.pone.0119916

Shikai, N., Shono, M., \& Kitamura, T. (2009). Effects of coping styles and stressful life events on depression and anxiety in Japanese nursing students: A longitudinal study. International Journal of Nursing Practice, 15, 198-204. doi: 10.1111/j.1440172X.2009.01745.x

Stecker, T. (2004). Well-being in an academic environment. Medical Education, 38, 465-478. doi: 10.1046/j.1365-2929.2004.01812.x

Stephens, T. M. (2012). Increasing resilience in adolescent nursing students. (Doctoral dissertation). Retrieved from http://trace/tennessee.edu/utk_graddiss/1351

Stephens, T. M. (2013). Nursing student resilience: A concept clarification. Nursing Forum, 48, 125-133. doi: 10.1111/nuf.12015

Taylor, H., \& Reyes, H. (2012). Self-efficacy and resilience in baccalaureate nursing students. International Journal of Nursing Education Scholarship, 9, Article 2. doi: $10.1515 / 1548-923 X .2218$

Thomas, J., Jack, B. A., \& Jinks, A. M. (2012). Resilience to care: A systematic review and meta-synthesis of the qualitative literature concerning the experiences of student nurses in adult hospital settings in the UK. Nurse Education Today, 32, 657-664. doi:10.1016/j.nedt.2011.09.005 
Trusty-Smith, B. (2013). The optimism to overcome: Educational beliefs and strategies of resilience among African American college graduates who are former teenage mothers (Doctoral dissertation). Retrieved from ProQuest Dissertations and Theses database. (UMI No. 3563379)

Tully, A. (2004). Stress, sources of stress and ways of coping among psychiatric nursing students. Journal of Psychiatric and Mental Health Nursing, 11, 43-47. doi: 10.1111/j.1365-2850.2004.00682.x

Tusaie, K., \& Dyer, J. (2004). Resilience: A historical review of the construct. Holistic Nursing Practice, 18, 3-8.

Ungar, M. (2003). Qualitative contributions to resilience research. Qualitative Social Work, 2, 85-102. doi: 10.1177/1473325003002001123

Ungar, M. (2013). Resilience, trauma, context, and culture. Trauma, Violence, and Abuse. 14, 255-266. doi: 10.1177/1524838013487805

Wagnild, G., \& Young, H. M. (1990). Resilience among older women. Image: Journal of Nursing Scholarship, 22, 252-255. doi: 10.1111/j.1547-5069.1990.tb00224.x

Wells, M. I. (2007). Dreams deferred but not deterred: A qualitative study on undergraduate nursing student attrition. Journal of College Student Retention: Research, Theory, and Practice, 8, 439-456. doi: 10.2190/17K2-5847-6637-L70P

Williamson, G. R., Health, V., \& Proctor-Childs, T. (2013). Vocation, friendship, and resilience: A study exploring nursing student and staff views on retention and attrition. The Open Nursing Journal, 7, 149-156. doi: 10.2174/1874434601307010149

Wilks, S. E. (2008). Resilience amid academic stress: The moderating impact of social support among social work students. Advances in Social Work, 9, 106-125. 
Wilks, S. E., \& Spivey, C. A. (2010). Resilience in undergraduate social work students: Social support and adjustment to academic stress. Social Work Education, 29, 276-288. doi: 10.1080/02615470902912243

Wolin, S. J., \& Wolin, S. (1994). Survivor's pride: Building resilience in youth at risk. Verona, WI: Attainment Co.

Wyman, P. A., Sandler, I., Wolchik, S., \& Nelson, K. (2000). Resilience as cumulative competence promotion and stress protection: Theory and intervention. In D. Cicchetti, J. Rappaport, I. Sandler, \& R. P. Weissberg (Eds.), The promotion of wellness in children and adolescents (pp. 133-184). Washington, DC: CWLA Press. 


\section{Chapter Four - Exploring Nursing Student Resilience: Rationale, Challenges, and Advantages of Using Constructivist Grounded Theory}

Grounded theory is a qualitative research methodology originally developed by Glaser and Strauss (1967) within the field of sociology. Today, grounded theory is a widely used qualitative methodology in nursing education research. Grounded theory is particularly appropriate and useful in areas of inquiry where there are inadequate theories to explain social processes and human behaviour (Hutchinson \& Wilson, 2001). The knowledge which nurse educators apply to their teaching and curricular designs used to be largely based on tacit knowledge rather than research (Ferguson \& Day, 2004); hence, grounded theory methods have been increasingly used in areas of nursing education that have limited theoretical explanations to support the teaching base and curriculum development activities of nurse educators.

In this paper, a particular grounded theory approach called constructivist grounded theory (CGT) is discussed. This writer's experiences, drawn from using this methodology to explore nursing students' understanding and enactment of resilience are presented. Nurse education researchers who are planning to use grounded theory methodology in their research, more particularly those who are considering using CGT will find this work helpful. First, the background of CGT is provided, including the use of the methodology in previous nursing education studies. The rationale, challenges, and advantages of using the CGT are identified within the context of a study about nursing students' resilience. Finally, recommendations for using CGT in nursing education research are delineated.

\section{Constructivist Grounded Theory}

Charmaz's (2006) constructivist grounded theory (CGT) is a variation of the grounded theory approach originally developed by Glaser and Strauss (1967) and Glaser's (1992) 
classic grounded theory. In CGT, there is a shift from the objectivist paradigm of the classic grounded theory to a constructivist philosophy (Charmaz, 2006). Constructivism is based on the ontology of relativism, a belief that denies the existence of an objective reality but rather assumes that "realities are social constructions of the mind" (Guba \& Lincoln, 1989, p. 43). Constructivism is also based on the epistemology of subjectivism, a belief that knowledge is value laden because knowledge is "always filtered through the lenses of language, gender, social class, race, and ethnicity" (Denzin \& Lincoln, 2005, p. 21). Therefore, the philosophical underpinnings of CGT include attention to multiple social constructions of realities and assumption that the researcher is inseparable from the participants; hence, knowledge is shaped by the interaction between the researcher and the participants (Charmaz, 2006). As a result, in CGT, the emerging grounded theory is co-constructed between the researcher and the participants (Charmaz, 2006) as opposed to being discovered, which is a main tenet of the classic grounded theory (Glaser, 1992).

The constructivist approach is also different from classic grounded theory in the use of extant literature. In Glaser's (1998) classic grounded theory, literature review is delayed until data analysis is nearly completed in order to avoid contamination of the emerging theory from preexisting concepts. Conversely, CGT research starts with specific questions on a particular substantive area and a literature review is conducted to determine what is known in this substantive area (Hernandez \& Andrews, 2012). Use of extant literature is accepted in CGT because of its basis on the relativist epistemology in which the knower is inseparable from what can be known (Annells, 1996). In CGT, data are not only co-constructed by the researcher and the participants but also coloured by the researcher's perspectives (Charmaz, 2008a). Hence, extant literature and the researcher's preexisting theoretical perspectives are 
not abandoned but rather subjected to rigorous processes to ensure that these extant concepts "earn their way into the analysis" (Charmaz, 2005, p. 525).

The main tenets of classic grounded theory, such as constant comparative methods and theoretical sampling, are maintained in CGT; the philosophical basis of CGT, however, has been criticized by classic grounded theorists. One criticism is that constructivism in CGT is used to legitimize forcing data into preexisting concepts (Glaser, 2002). Another pertains to the identification of a particular substantive area at the beginning of some CGT studies. This is in contrast to classic grounded theory in which the research problem is not known or speculated about in advance, but rather the main concern of participants emerges as the research progresses (Glaser \& Holton, 2004). Glaser (2002) claims that in constructivism, the researcher discounts the participant's main concern and provides primacy to the professional concern of the researcher. These critiques are addressed and challenged in this paper.

\section{Literature Review of CGT Studies in Nursing Education}

Constructivist grounded theory (CGT) is not widely used in nursing education research. Grounded theory methods commonly used in nursing education research are those of the original or classic grounded theory (Glaser, 1992; Glaser \& Strauss, 1967) and the Straussian approach of grounded theory (Strauss \& Corbin, 1990, 1994). Examples of classic or Glaserian and Straussian grounded theory studies in nursing education are provided in Table 4. Very few CGT researchers in nursing education have examined general concerns of particular population groups without any identified phenomenon to be explored. For example, Drury, Francis, and Chapman (2008a, 20008b) investigated the general educational experience of mature-aged nursing students in two rural Australian universities. Results of this CGT study revealed that mature-aged nursing students follow a core trajectory called becoming a nurse. 
Table 4

Examples of Classic or Glaserian and Straussian Grounded Theory Studies in Nursing Education

\begin{tabular}{|c|c|}
\hline $\begin{array}{l}\text { Classic or Glaserian } \\
\text { (with purpose and findings of the study) }\end{array}$ & $\begin{array}{c}\text { Straussian } \\
\text { (with purpose and findings of the study) }\end{array}$ \\
\hline Cone \& Giske (2012) & Ashcroft \& Lutfiyya (2013) \\
\hline $\begin{array}{l}\text { Purpose: To investigate nursing teachers' } \\
\text { perspectives of spirituality and how they teach } \\
\text { students about spiritual care }\end{array}$ & $\begin{array}{l}\text { Purpose: To develop an understanding of } \\
\text { nursing teachers' perceptions of students with } \\
\text { disabilities }\end{array}$ \\
\hline $\begin{array}{l}\text { Findings: Basic social process of journeying } \\
\text { with students through their maturation }\end{array}$ & $\begin{array}{l}\text { Findings: Emerging theory of producing } \\
\text { competent graduates }\end{array}$ \\
\hline Cordeau (2012) & Cheraghi, Salasli, \& Ahı \\
\hline $\begin{array}{l}\text { Purpose; To explore the social psychological } \\
\text { process nursing students use in high-stakes } \\
\text { clinical simulation } \\
\text { Findings: Basic social psychological process: } \\
\text { linking (ability to interact with, assess, and } \\
\text { meet the needs of the simulator) }\end{array}$ & $\begin{array}{l}\text { Purpose: To explore factors affecting clinical } \\
\text { preparation of nursing student interns in Iran } \\
\text { Findings: Three mains factors: educator } \\
\text { incompetence, nursing staff's technical ability, } \\
\text { non-conducive learning environment }\end{array}$ \\
\hline $\begin{array}{l}\text { Giske \& Cone (2012) } \\
\text { Purpose: To explore nursing students' } \\
\text { understanding of spiritual care and how they } \\
\text { learn to provide spiritual care to patients } \\
\text { Findings: Basic social process of opening up to } \\
\text { learning spiritual care }\end{array}$ & $\begin{array}{l}\text { Goodolf (2013) } \\
\text { Purpose: To explore the experience of nursing } \\
\text { students as they progressed in the program and } \\
\text { to describe how they coped with stressors in } \\
\text { their academic lives } \\
\text { Findings: Substantive theory: growing a } \\
\text { professional identity }\end{array}$ \\
\hline $\begin{array}{l}\text { Kucirka (2013) } \\
\text { Purpose: To explore the basic social } \\
\text { psychological process in nursing faculty's } \\
\text { interactions with students suspected of having } \\
\text { mental health issues } \\
\text { Findings: Basic social psychological process of } \\
\text { navigating the faculty-student relationship }\end{array}$ & $\begin{array}{l}\text { Patterson (2012) } \\
\text { Purpose: To develop a grounded theory that } \\
\text { will help nursing faculty fulfill their educator } \\
\text { roles in an unfamiliar setting } \\
\text { Findings: Central category: preparing for an } \\
\text { unfamiliar setting }\end{array}$ \\
\hline $\begin{array}{l}\text { White-Williams (2012) } \\
\text { Purpose: To explore the process of connecting } \\
\text { in the student-patient relationship based on } \\
\text { student and clinical teacher's perspective } \\
\text { Findings: Core concept of connection: } \\
\text { mutuality }\end{array}$ & $\begin{array}{l}\text { Yaghoubinia, Heydari, \& Latifnejad Roudsari } \\
\text { (2014) } \\
\text { Purpose: To investigate the continuity of the } \\
\text { student-teacher relationship in clinical nursing } \\
\text { education in Iran } \\
\text { Findings: Core category: seeking a progressive } \\
\text { relationship for learning }\end{array}$ \\
\hline
\end{tabular}


Most of the CGT studies in the field of nursing education pertain to exploring a phenomenon of interest. For example, Dunnington (2012) explored the concept of presence by examining the nature of presence as experienced by nursing students involved in a simulation instructional modality called High-Fidelity-Human-Patient Simulation (HF-HPS). Dunnington used CGT, and as a result, constructed a model of HF-HPS, which depicts the determinants and nature of presence and the related learning outcomes of using HF-HPS. Mills (2012) used CGT to examine a concept called conceptual understanding. Mills particularly aimed to describe the process of conceptual understanding in a particular context of nursing students' learning of medication calculations. Other CGT studies involving exploration of a concept or an identified substantive area at the outset of the study include exploring the processes nurse educators follow when using reflective journaling as an assignment (Aaron, 2013); examining student actions and processes that impact student retention in the nursing program (Priode, 2013); and investigating information-seeking processes students use in searching a given topic (Duncan \& Holtslander, 2012). These studies were conducted because of limited theoretical explications of the substantive areas in nursing education. Therefore, in these studies, the use of grounded theory as a research methodology is justified based on Strauss and Corbin's (1990) claim that grounded theory is appropriate when "concepts pertaining to a given phenomenon have not yet been identified, at least not in this population or place; or if so, then the relationships between the concepts are poorly understood or conceptually underdeveloped" (p. 37).

\section{Summary of a CGT Study on Nursing Students' Resilience}

An overview of a CGT study in the field of nursing education is presented in this section. The purpose of this overview is to provide an example of the CGT processes applied in this study in order to demonstrate that the use of CGT was methodologically appropriate. 
The study purpose was to explore nursing students' understanding and enactment of resilience using constructivist grounded theory. Background, significance, and findings of the study are provided in detail elsewhere (Reyes, Andrusyszyn, Iwasiw, Forchuk, \& BabenkoMould, under review). The main reason for using grounded theory methodology in this study was the lack of research on the resilience of nursing students. Available theories were limited and did not directly address nursing students' experience of resilience in their academic lives. The state of available knowledge in this area makes the focus on theory development imperative.

Study participants were initially recruited using various methods such as informing students about the study immediately before or after a classroom lecture, posting notices on bulletin boards (Appendix $\mathrm{H}$ ), and sending an email message to students by an officially designated school staff member (Appendix I). Data were collected through in-depth, face-toface, individual interviews. A semi-structured interview guide (Appendix A) was used to collect data, beginning with broad questions such as, "Would you please share some of your experiences of stress, difficulties, and/or adversities as a nursing student?" and "How were you able to manage the issues around your stress, difficulties, and/or adversities as a nursing student?" Data were simultaneously collected, compared, and analyzed. The NVivo9 software was used to manage and synthesize large amounts of data, to facilitate the coding of data from descriptive to conceptual levels, and to implement the iterative process of constant comparative methods. Ongoing data analysis yielded emerging categories that led to revisions in follow-up and probing questions for succeeding participant interviews. These changes and revisions were implemented in accordance with the tenets of theoretical sampling. According to Charmaz (2006), theoretical sampling means "seeking and collecting pertinent data to elaborate and refine categories in [the] emerging theory" (p. 96). Along with 
revising the interview questions, participants were also asked, on a voluntary basis, to refer the study to their peers with particular issues. For example, some of the emerging themes during data analysis were coping with failure and dealing with competing commitments. Hence, some participants, who were recruited through the peer referral process, had issues such as coping with mental health illness, caring for a sick family member, and dealing with problems related to failing a course. As a result, the sample of the study included participants referred by their peers and those who responded through initial recruitment methods.

The three coding phases recommended by Charmaz (2006) were employed to analyze data. The first coding phase, initial coding, was conducted by going through interview transcripts line-by-line, labeling each segment of data in a manner that "simultaneously categorizes, summarizes, and accounts for each piece of data" (Charmaz, 2006, p. 43). In this phase, data were coded in the form of gerunds, reflecting actions. Glaser (1978) posits that coding in gerunds facilitates looking for processes and sticking to the data. Furthermore, Charmaz articulates that coding for actions rather than themes keeps the "analytic momentum" at a conceptual rather than a descriptive level. Focused coding, the second phase, involves sorting and integrating initial codes to "make the most analytic sense to categorize data incisively and completely" (Charmaz, 2006, p. 57). During this phase, gerunds were also used to keep the codes active and close to the data, as Charmaz recommends. The last phase involved specifying possible relationships between the coding categories developed during focused coding, and this theoretical coding moved the analysis in a theoretical direction, as Charmaz advocates.

The constant comparative method was used at every level of coding and data analysis. This particular method, which is a distinctive element of a grounded theory method, involves making comparisons between data, codes, and categories (Charmaz, 2006). Interview 
statements and incidents within the same interview and between interviews were compared. This method facilitated the development of conceptual understanding of the emerging theory as the analytic properties of the categories were defined and developed.

Numerous memos and personal journals were maintained to facilitate data analysis. Personal journals and some memos were about assumptions regarding the concept of resilience and reflections about the roles of the interviewer and participants during the interviews. Other memos were more specifically related to the emerging codes and categories. Memos comparing and contrasting personal preconceived theories with the emerging codes and categories were used in order to avoid forcing data into these extant concepts and theories.

Briefly, the grounded theory that emerged from this study is called the theory of pushing through, which is a process nursing students use to withstand their challenges and achieve academic goals. In this study, the process of pushing through is also represented as nursing students' understanding and enactment of resilience (Reyes, Andrusyszyn, Iwasiw, Forchuk, \& Babenko-Mould, under review).

\section{Rationale for Using CGT in Exploring Nursing Students' Resilience}

Compatibility of focus of the methodology and purpose of research. The first

rationale for using CGT was that the focus of the study was consistent with CGT's emphasis, which Charmaz (2000a) articulates as a "study of process, action, and meaning" (p. 512). The study aimed to explore nursing students' understanding (compatible with the meaning aspect of CGT) and enactment (compatible with the process and action aspects of CGT) of resilience.

Furthermore, the goal of the study was not merely to develop a theoretical explication of resilience in the context of nursing education in order to build new knowledge for 
cumulative theory development. Most importantly, the aim was to construct a theory that captures the unique aspects of nursing students' educational context and, in turn, renders the theory useful to the everyday lives of nursing students, teachers, and program leaders. Hence, the focus on process, action, and meaning of CGT highlights the value of the study's focus on understanding and enactment of resilience. To explain further, Charmaz (2008b) proposes that process, action, and meaning are fundamental to human existence. This assertion is based on Strauss's pragmatist heritage, a philosophical tradition embedded within CGT (Charmaz, 2008b). On the basis of pragmatism, Charmaz (2000b) further explains the primacy of process, action, and meaning:

Action always occurs within a context. Social life consists of processes. Everyday actions, negotiations, interpretations create stable social structures; they do not merely exist. Actions give rise to reconstructing meaning; in turn, meaning and symbol inform action (p. S172).

This pragmatist claim suggests that process, action, and meaning are a necessity, a sine qua non to everyday living. As a logical consequence, data analysis in CGT, which is focused on process, action, and meaning, renders the resulting interpretations useful to people's everyday lives (Charmaz, 2006). Hence, the study's focus on understanding and enactment, which implies an emphasis on meaning and action, suggests that the research outcome could also be useful to the everyday lives of nursing students.

\section{Coherence between methodology's philosophy and the use of extant concepts.}

The second rationale for using CGT was that the ontological and epistemological assumptions of the methodology support the use of broad, extant concepts (such as resilience) at the beginning of the study. Philosophical tenets of CGT include the assumptions that there are multiple social realities and multiple perspectives on these 
realities, and that the researcher and participants co-construct the data (Charmaz, 2008a). The constructivists believe that it is "impossible to separate the inquirer from the inquired into" (Guba \& Lincoln, 1989, p. 88). Hence, the constructivist grounded theorist can interact with the research field or with the participants and need not abandon his or her preconceived concepts. However, this comes with a caveat: the researcher must ensure that theoretical preconceptions are subjected to rigorous processes so that these preconceived notions are not forced into the emerging theory but rather scrutinized to determine whether they "earned their way into the analysis" (Charmaz, 2005, 2006, 2008a).

The researcher's implicit theoretical ideas must be made explicit in the research process. Consequently, the researcher recognizes the importance of constant reflexivity rather than denying these preexisting perspectives and pretending they are not there (Thornberg, 2012). Subsequently, grounded theory processes are implemented to work beyond the researcher's own assumptions and beliefs throughout the analysis (Schreiber, 2001).

Within the epistemology of CGT, it is also imperative to acknowledge the role of the participant in the co-construction of data, particularly when an identified substantive area is introduced into the data generation and co-construction setting (i.e., the interview). The inclusion of a phenomenon of interest in the data co-construction setting could be a factor in creating unequal sharing of power between the researcher and the participant, thereby affecting the reciprocal shaping of data between researcher and participant (Mills, Bonner, \& Francis, 2006a; Strauss \& Corbin, 1994). Therefore, "intimate familiarity” of the phenomenon of interest is required for the researcher to develop an "in-depth knowledge of [participants] who contend with the phenomenon" and a "level of understanding that pierces their experiences" (Charmaz, 2006, p. 68). The researcher's theoretical sensitivity to the phenomenon of interest can facilitate further exploring of participants' tacit meanings and 
assumptions.

In contrast, in classic grounded theory, the researcher has to be unbiased and objective in engaging with the data (Glaser, 1992, 1998). Thus, the classic grounded theory researcher collects data without any personal, professional, or literature-based preconceptions (Hernandez \& Andrews, 2012). However, the idea of conducting research without any $a$ priori knowledge is difficult, if not impossible (Charmaz, 2003). As the researcher interacts with the participants, s/he brings along personal theoretical lenses and conceptual networks (Kelle, 1995). The researcher's observation and engagement of the phenomenon under study is inevitably shaped by preconceptions (Kelle, 1995, 2005). Thornberg (2012) explains that observation in itself is already a "theoretically-laden undertaking" (p. 246). Therefore, the tabula rasa approach is logically impossible and fails to recognize the "embeddedness of the researcher within an historical, ideological, and socio-cultural context" (Thornberg, 2012, p. 246).

Charmaz (2008b) asserts that a constructivist grounded theorist uses broad concepts in conceptualizing research projects, brings these concepts into rigorous scrutiny, and implements emergent processes in developing theory. Therefore, identifying a particular substantive area, or research problem, at the beginning of a study is not a transgression of the philosophical and methodological assumptions of CGT.

\section{Challenges of Using CGT in Exploring Nursing Students' Resilience}

Risk of forcing data into preexisting concepts. One challenge of using CGT in the study of exploring nursing students' resilience was the risk of interpreting participant data to suit the researcher's preconceptions. For this study, the research field was approached with a particular focus on examining nursing students' resilience (or lack thereof) rather than exploring students' general experiences. Therefore, there was a real risk of forcing the data 
into the researcher's preconceptions about resilience rather having the concepts and categories emerge from the data.

Charmaz (2006) supports the use of preconceived perspectives in grounded theory work but provides a caveat that these concepts should serve as "points of departure for developing, rather than limiting, [the researcher's] ideas" (p. 17). Thus, the grounded theorist who explores a particular identified substantive area (such as resilience) must engage with the data with an open mind. The researcher must be receptive to whatever themes are emerging from the data. Charmaz (2006) recommends applying the stance of "theoretical agnosticism," a term originally coined by Henwood and Pidgeon (2003, p. 138). Charmaz explains that theoretical agnosticism means taking a critical perspective toward previous theories. Thornberg (2012) adds that this stance involves treating preexisting theories and concepts as "provisional, disputable, and modifiable conceptual proposals" (p. 250). Moreover, Schreiber (2001) asserts that the researcher must be willing to challenge his or her personal theoretical assumptions and biases to ensure that the emerging theory is grounded in the data.

In this study, basic grounded theory procedures were implemented to ensure that preconceived theoretical concepts (such as personal conceptualizations of resilience) were not forced into the analysis. These procedures were also executed to facilitate being openminded to whatever unfolded in the data collection and analysis, to ensure that the emergent nature of data analysis in grounded theory was followed, and to remain grounded in the data. For example, Charmaz's (2006) recommendation to code for actions and processes instead of static topics or nouns was followed, which allowed the analysis to be closely grounded in the data. For instance, some of the initial codes included: sticking it out, getting through, persevering, and persisting, rather than nouns such as hardships, problems, and difficult 
emotions. Coding for actions "preserves the fluidity" of the participants' experience since ignoring participants' meaning and actions may “reflect an outsider's, rather than an insider's view" (Charmaz, 2006, p. 49).

Constant comparative methods were used rigorously, which Charmaz (2006) posits as a strategy to prevent the researcher from forcing processes, codes, and categories into a preconceived theoretical framework. Moreover, Charmaz recommends writing memos as a way of making preconceived ideas or sensitizing concepts explicit rather than them remaining unconscious or subliminal. Hence, memos were written about preconceived thoughts regarding resilience, experiences of adversities, the research process itself, and about the emerging codes and categories. Reflective memos, as recommended by Mills et al. (2006a), were also written; these memos were reflections on the data generation (interview) setting, particularly highlighting the interviewer's self-examination of the reciprocal shaping of data between the interviewer and the participant. Memos were also constantly considered in light of preconceived notions of resilience, determining whether the emerging data had "earned their way into the analysis" or not. Lastly, Charmaz also recommends member checking, which pertains to seeking feedback about the emerging analytic categories in order to confirm and refine interpretations of the data. Hence, member checking was implemented in the study by returning to the participants to determine if the emerging categories resonated with their realities and to explore areas for further theory refinement.

Therefore, procedures such as coding for actions and processes, rigorous constant comparative processes, memo writing, and meetings with dissertation committee members were executed to address the risk of forcing the data into preexisting theoretical concepts. Most importantly, participants' confirmation of the theory through member checking was a strong indication that the challenge had been overcome. 
Risk of obtaining insufficient data. The other methodological challenge

encountered in this study was related to the risk of recruiting participants who would not be able to provide rich data, hence, the risk of obtaining insufficient data. This concern arose after ensuring that recruitment processes should align with the philosophical assumptions of CGT. In the early phase of the study, the researcher questioned whether attempting to determine the level of resilience of nursing students, interviewing only those participants who considered themselves "resilient" was inconsistent with the ontological bases of constructivism. Upon closer examination, this act of screening participants as resilient or not does not consider the philosophy of the relativism of multiple constructions of social realities. Rather, it reifies the conceptualization of resilience as that of an individual's characteristic, and potentially ignores other possible constructions of resilience. Therefore, recruitment criteria in the early phase of the study were broad. Students were recruited to participate in the study by sharing their challenges and adversities and how they coped with them. Potential participants were recruited without regard to their degree of resilience or lack thereof. Hence, the criterion of recruiting participants without considering their degree or level of resilience induced concerns about how these might have assisted recruitment of participants who could provide rich information about resilience. A concern was raised whether initial participants who would be recruited might turn out to be "non-resilient," hence collecting thin data about resilience.

This challenge was addressed by reexamining this concern in light of the constructivist philosophy. From a constructivist stance, the researcher must recognize that individuals make multiple meanings of their experience; he or she does not have to judge if students' experiences are indicative of resilience or not. Therefore, the initial interviews were conducted and data analysis was concurrently implemented. As initial participants were 
interviewed and their data coded and analyzed, analytic categories were emerging that required further theoretical sampling. Hence, recruitment processes were not based on the degree of participants' level of resilience, but on the emerging categories and themes to refine the emerging theory further.

\section{Advantages of Using CGT in Exploring Nursing Students’ Resilience}

The study was started with a concept of interest, which was the resilience of nursing students. Use of CGT (as opposed to Glaserian classic grounded theory) allowed the researcher to explore the concept, learn participants' views of the concept and its enactment, and then construct the resulting theory. The advantage of using CGT in this study is that the final theory has resonance for participants and reflects accurately their understanding of their experiences. Therefore, authenticity is assured. The theory's resonance is a result of implementing rigorous procedures mentioned earlier in this paper.

Another advantage of using CGT in exploring the concept of nursing students' resilience is that the emerging theory may be useful for further theory development and to the everyday lives of nursing students. The use of literature review before the study was conducted provided information on the current state of knowledge on the substantive area, thereby helping the researcher avoid conceptual and methodological pitfalls and focus on particular areas and contexts for cumulative theory development (Dunne, 2011; Goldkuhl \& Cronholm, 2010). Therefore, the emerging theory from the study adds evidence to the current knowledge of resilience in the context of nursing education. Additionally, the rendering of the emerging theory as processes and actions (for example, concepts in the theory were stated as gerund phrases) makes the theory useful and accessible to the intended readership (in this case, nursing students, educators, and program leaders). Lastly, study participants who were involved in the member checking process may have developed a heightened understanding of 
their experience and gained more self-awareness about their resilience; thereby making the emerging theory helpful with their own challenges.

\section{Recommendations for Using CGT in Nursing Education Research}

Many teaching-learning innovations in nursing education are based on experiential knowledge rather than on research (Ferguson \& Day, 2005; Schmitt, 2002). Additionally, contextual factors (e.g., student demographics, teaching-learning technology, clinical practice settings, community and global political and economic events, etc.) affecting the development and delivery of these pedagogical innovations are rapidly changing. In many instances, unique aspects of these contextual factors may have major impacts on the effectiveness of these innovations and programs. Therefore, grounded theories particularly arising from nursing education research may be uniquely suited as theoretical bases of these innovations.

In this section, three main recommendations are outlined for nursing education researchers interested in using CGT methodology. The first recommendation is for the researcher to examine if there is a need for theory development in the identified research area. Grounded theory is appropriate in areas where there is no theory developed or there are inadequate theories to explain human behaviour (Hutchinson \& Wilson, 2001). Charmaz (2005) adds that grounded theory pertains to seeking a deeper contextualization and theoretical understanding around a phenomenon of concern. Hence, if the researcher aims to understand the process by which individuals make meaning out of their experience in specific contexts that have been minimally explored in the literature, then theory development through grounded theory methods may best suit gaining such deeper understanding (Suddaby, 2006). However, following on Suddaby's claim, if a researcher aims to generalize and make knowledge claims about an objective reality rather than seeking 
to understand how individuals interpret reality, grounded theory method may not be appropriate.

The second recommendation is to examine whether the identified research problem or substantive area is related to a concept that may have some theoretical underpinnings. Other examples of concepts that may have theoretical bases in nursing education are reflective thinking, empowerment, critical thinking, and stress and coping of nursing students. If the research area pertains to a concept, the researcher must take extra steps to choose the version of grounded theory to be used carefully. Breckenridge, Jones, Elliott, and Nicol (2012) recommend that given the significant differences between versions of grounded theory, researchers must be certain of their choice rather than mixing up methodologies. Based on earlier discussion, a CGT methodology may be considered if the research is undertaken with a previously established theoretical substantive area. This is because the fit between the philosophical assumptions of CGT methodology and of the researcher, who inevitably enters the research field with preconceived theoretical ideas, support the use of exploring a concept or substantive area at the outset of the study.

The third recommendation is to exercise consistent reflexivity. Reflexivity pertains to the critical examination of the influence of the researcher on the research process (Charmaz, 2006; Reay, 1996). Constant reflexivity is required because the researcher always brings his or her preconceived theoretical lenses to the research scene (Thornberg, 2012). Reflexivity allows researchers to bring their unconscious, preconceived notions into conscious awareness and helps researchers implement rigorous processes to prevent these preconceived ideas from forcing their way into the emerging theory (Charmaz, 2006; Thornberg, 2012). As a result, the theory is grounded in the data rather than imposed by researcher's preexisting theoretical frameworks. 
In the process of reflexivity, one area to examine is the researcher's ontological and epistemological positions towards the research process in general and his or her study in particular. The purpose of this introspection is to examine a fit between the research methodology and the researcher. This fit will also impact how research questions will be formulated and how a research project will be conceptualized and implemented. Mills, Bonner, and Francis (2006b) posit that exploring and choosing a research paradigm that is congruent with one's ontological assumption facilitates the choice of appropriate epistemological and methodological approaches, hence ensuring a stronger research design. Another area for the researcher to identify and examine is his or her particular preexisting theoretical ideas that may affect the construction of the emerging theory. Thornberg (2012) asserts that it is more appropriate to identify and acknowledge one's theoretical preconceptions than claiming neutrality or objectivity, which may mask forcing preconceptions into the analysis. Lastly, the researcher must also be reflexive on his or her influence in the data generation, such as during interviews. It is recommended that the researcher examine processes affecting the reciprocal shaping of data between the participant and researcher, such as reflecting upon whether strategies to elicit tacit meanings and assumptions were adequately implemented (Charmaz, 2006; Mills et al., 2006a).

In using grounded theory in resilience research or in research in which a particular substantive area is already identified at the outset of the study, reflexivity is required. Charmaz (2006) insists that researchers are "obligated to be reflexive" (p. 15). The obligation of the researcher to be constantly reflexive implies that reflexivity must not only be regularly practiced, but more importantly, implemented at every stage of the research process. 


\section{Conclusion}

In this paper, an overview of the constructivist grounded theory (CGT) methodology, a summary of some landmark CGT studies in nursing education, and a brief background of a research study about nursing students' resilience were provided to outline a context that would facilitate a better understanding of using CGT in nursing education research. The rationales, challenges, and advantages of using CGT methodology in exploring nursing students' understanding and enactment of resilience were presented. The rationales for using CGT were the compatibility of focus between the methodology and the purpose of the research, and the coherence between the ontological and epistemological assumptions of the methodology and the use of extant concepts. The challenges encountered in applying CGT in this study included the risk of forcing data into the researcher's preexisting theoretical concepts and the risk of obtaining insufficient data. The benefits of using CGT were resonance of the final theory with participants' experience, usefulness of the theory in furthering research, and usefulness to the everyday lives of nursing students, nurse educators, and nursing program leaders.

Also included in this paper are recommendations for researchers interested in using grounded theory to explore resilience. These recommendations are also applicable for grounded theorists starting their research with identified broad concepts or substantive areas at the beginning of their studies in nursing education research. These recommendations include the following: explore the need for theory development in the identified research area, examine whether the research problem is related to a concept with theoretical underpinnings, and practice constant reflexivity.

The practice of constant reflexivity is crucial. Reflexivity is particularly relevant to those researchers who view the mutual construction of data between the researcher and the 
researched and to those who are interested in using grounded theory methods in further expanding a particular substantive area. Arguments to challenge the implausibility of a neutral and unbiased researcher were presented. Therefore, it is imperative for the researcher to engage in constant reflexivity at every stage of the research process to construct a grounded theory that not only resonates with participants' realities but is also useful for practical situations. 


\section{References}

Aaron, C. D. (2013). The process of using reflective journaling in nursing education (Doctoral dissertation). Retrieved from ProQuest Dissertations and Theses database. (UMI No. 3562390)

Annells, M. (1996). Grounded theory method: Philosophical perspectives, paradigm of inquiry, and postmodernism. Qualitative Health Research, 6, 379-393. doi:

\section{$10.1177 / 104973239600600306$}

Ashcroft, T. J., \& Lutfiyya, Z. M. (2013). Nursing educators' perspectives of students with disabilities: A grounded theory study. Nurse Education Today, 33, 1316-1321. doi: 10.1016/j.nedt.2013.02.018

Breckenridge, J. P., Jones, D., Elliott, I., \& Nicol, M. (2012). Choosing a methodological path: Reflections on the constructivist turn. The Grounded Theory Review, 11, 64-71. Retrieved from http://groundedtheoryreview.com/2012/06/01/choosing-amethodological-path-reflections-on-the-constructivist-turn/

Charmaz, K. (2000a). Grounded theory: Objectivist and constructivist methods. In N. K. Denzin \& Y. S. Lincoln (Eds.), Handbook of qualitative research (2nd ed., pp. 509535). Thousand Oaks, CA: Sage.

Charmaz, K. (2000b). Teachings of Anselm Strauss: Remembrances and reflections. Sociological Perspectives, 43, S163-74

Charmaz, K. (2003). Grounded theory-Objectivist and constructivist methods. In N. K. Denzin \& Y. S. Lincoln (Eds.), Strategies of qualitative inquiry (pp. 249-291). London: Sage. 
Charmaz, K. (2005). Grounded theory in the 21st century: Applications for advancing social justice studies. In N. K. Denzin \& Y. S. Lincoln (Eds.), Handbook of qualitative research (3rd ed., pp. 507-535). Thousand Oaks, CA: Sage.

Charmaz, K. (2006). Constructing grounded theory: A practical guide through qualitative analysis. Thousand Oaks, CA: Sage.

Charmaz, K. (2008a). Constructionism and the grounded theory. In J. A. Holstein \& J. F. Gubrium (Eds.), Handbook of constructionist research (pp. 397-412). New York: The Guilford Press.

Charmaz, K. (2008b). The legacy of Anselm Strauss in constructivist grounded theory. Studies in Symbolic Interaction, 32, 127-41.

Cheraghi, M. A., Salasli, M., \& Ahmadi, F. (2008). Factors influencing the clinical preparation of BS nursing student interns in Iran. International Journal of Nursing Practice, 14, 26-33. doi: 10.1111/j.1440-172X.2007.00664.x

Cone, P. H., \& Giske, T. (2012). Teaching spiritual care - A grounded theory study among undergraduate nursing educators. Journal of Clinical Nursing, 22, 1951-1960. doi: 10.1111/j.1365-2702.2012.04203.x

Cordeau, M. A. (2012). Linking the transition: A substantive theory of high-stakes clinical simulation. Advances in Nursing Science, 35(3), E90-E102. doi:

10.1097/ANS.0b013e318262614f

Denzin, N., \& Lincoln. Y. (2005). Introduction. In N. Denzin \& Y. Lincoln (Eds.) The Sage handbook of qualitative research (pp. 1-32). Thousand Oaks, CA: Sage Publications.

Drury, V., Francis, K., \& Chapman, Y. (2008a). Letting go and moving on: A grounded theory analysis of disengaging from university and becoming a registered nurse. Nurse Education Today, 28, 783-789. doi: 10.1016/j.nedt.2008.05.006 
Drury, V., Francis, K., \& Chapman, Y. (2008b). Mature learners becoming registered nurses: A grounded theory model. Australian Journal of Advanced Nursing, 26(2) 3945. Retrieved from http://www.ajan.com.au/Vol26/26-2_Drury.pdf

Duncan, V., \& Holtslander, L. (2012). Utilizing grounded theory to explore the informationseeking behavior of senior nursing students. Journal of the Medical Library Association, 100, 20-27. doi: 10.3163/1536-5050.100.1.005

Dunne, C. (2011). The place of literature review in grounded theory research. International Journal of Social Research Methodology, 14, 111-124. doi:

$10.1080 / 13645579.2010 .494930$

Dunnington, R. M. (2012). The nature and determinants of presence among nursing students participating in high fidelity human patient simulation (Doctoral dissertation). Retrieved from ProQuest Dissertations and Theses database. (UMI No. 3520557)

Ferguson, L., \& Day, R. A. (2005). Evidence-based nursing education: Myth or reality? Journal of Nursing Education, 44, 107-115.

Giske, T., \& Cone, P. H. (2012). Opening up to learning spiritual care of patients: A grounded theory study of nursing students. Journal of Clinical Nursing, 21, 20062015. doi: 10.1111/j.1365-2702.2011.04054.x

Glaser, B. G. (1978). Theoretical sensitivity: Advances in the meaning of grounded theory. Mill Valley, CA: Sociology Press.

Glaser, B. G. (1992). Basics of grounded theory analysis. Mill Valley, CA: Sociology Press.

Glaser, B. G. (1998). Doing grounded theory: Issues and discussions. Mill Valley, CA: Sociology Press.

Glaser, B. G. (2002). Constructivist grounded theory? Forum: Qualitative Social Research, 3, Article 12. Retrieved from http://nbn-resolving.de/urn:nbn:de:0114-fqs0203125 
Glaser, B. G., \& Holton, J. (2004). Remodeling grounded theory. Forum: Qualitative Social Research, 5, Article 4. Retrieved from http://nbn-resolving.de/urn:nbn:de:0114fqs040245

Glaser, B. G. \& Strauss, A. L. (1967). The discovery of grounded theory: Strategies for qualitative research. Chicago: Aldine.

Goldkuhl, G., \& Cronholm, S. (2010). Adding theoretical grounding to grounded theory: Toward multi-grounded theory. International Journal of Qualitative Methods, 9, 187205. Retrieved from http://ejournals.library.ualberta.ca/index.php/IJQM/article/ view/6784/7027

Goodolf, D. M. (2013). Growing a professional identity: A grounded theory of the educational experience of baccalaureate nursing students (Doctoral dissertation). Retrieved from Proquest Dissertations and Theses database. (UMI No. 3570584).

Guba, E., \& Lincoln, Y. (1989). Fourth generation evaluation. Newbury Park, CA: Sage. Henwood, K., \& Pidgeon, N. (2003). Grounded theory in psychological research. In P. M. Camic, J. E. Rhodes, \& L. Yardley (Eds.), Qualitative research in psychology: Expanding perspectives in methodology and design (pp. 131-155). Washington, DC: American Psychological Association.

Hernandez, C. A., \& Andrews, T. (2012). Commentary on "Constructing new theory for identifying students with emotional disturbance." The Grounded Theory Review, 11, 59-63. Retrieved from http://groundedtheoryreview.com/2012/06/01/commentary-onconstructing-new-theory-for-identifying-students-with-emotional-disturbance/

Hutchinson, S. A., \& Wilson, H. S. (2001). Grounded theory the method. In P. Munhall (Ed.), Nursing research: A qualitative perspective (3rd ed., pp. 209-244). Sudbury, MA: Jones \& Bartlett. 
Kelle, U. (1995). Theories as heuristic tools in qualitative research. In I. Maso, P. A. Atkinson, S. Delamont, \& J. C. Verhoeven (Eds.), Openness in research: The tension between self and others (pp. 33-50). Assen: van Gorcum.

Kelle, U. (2005). 'Emergence' vs. 'forcing' of empirical data? A crucial problem of 'grounded theory' reconsidered. Forum: Qualitative Social Research, 6, Article 27. Retrieved from http://nbn-resolving.de/urn:nbn:de:0114-fqs0502275

Kucirka, B. G. (2013). Navigating the faculty-student relationship: A grounded theory of interacting with nursing students with mental health issues (Doctoral dissertation). Retrieved from Proquest Dissertations and Theses database. (UMI No. 3570583).

Mills, S. (2012). A grounded theory of the process of conceptual understanding in baccalaureate nursing students learning medication calculations (Doctoral dissertation). Retrieved from ProQuest Dissertations and Theses database. (UMI No. 3515684)

Mills, J., Bonner, A., \& Francis, K.. (2006a). Adopting a constructivist approach to grounded theory: Implications for research design. International Journal of Nursing Practice, 12, 8-13. doi: 10.1111/j.1440-172X.2006.00543.x

Mills, J., Bonner, A., \& Francis, K.. (2006b). The development of constructivist grounded theory. International Journal of Qualitative Methods, 5, 25-35. Retrieved from http://ejournals.library.ualberta.ca/index.php/IJQM/article/view/4402/3795

Patterson, R. B. (2012). Using grounded theory to reveal tacit knowledge for nurse educators in an unfamiliar African setting (Doctoral dissertation). Retrieved from Proquest Dissertations and Theses database. (UMI No. 3548728). 
Priode, K. S. (2013). The use of grounded theory to develop a framework for understanding student retention in community college nursing programs (Doctoral dissertation). Retrieved from ProQuest Dissertations and Theses database. (UMI No. 3593714)

Reay, D. (1996). Dealing with difficult differences: Reflexivity and social class in feminist research. Feminism \& Psychology, 6, 445-56. doi: 10.1177/0959353596063007

Reyes, A. T., Andrusyszyn, M. A., Iwasiw, C., Forchuk, C., \& Babenko-Mould, Y. (under review). Nursing students' understanding and enactment of resilience: A grounded theory study. Journal of Advanced Nursing.

Schmitt, M. H. (2002). It's time to revalue nursing education research. Research in Nursing and Health, 25, 423-424. doi: 10.1002/nur.10064

Schreiber, R. S. (2001). The 'how to' of grounded theory: Avoiding the pitfalls. In R. S. Schreiber \& P. N. Stern (Eds.), Using grounded theory in nursing (pp. 55-83). New York: Springer Publishing.

Strauss, A., \& Corbin, J. (1990). Basics of qualitative research: Grounded theory procedures and techniques. Newbury Park, CA: Sage.

Strauss, A., \& Corbin, J. (1994). Grounded theory methodology: An overview. In N. K. Denzin \& Y. S. Lincoln (Eds.), Handbook of qualitative research (pp. 273-285). Thousand Oaks, CA: Sage.

Suddaby, R. (2006). From the editors: What grounded theory is not. Academy of Management Journal, 49, 633-642. doi: 10.5465/AMJ.2006.22083020

Thornberg, R. (2012). Informed grounded theory. Scandinavian Journal of Educational Research, 56, 243-59. doi: 10.1080/00313831.2011.581686 
White-Williams, H. K. R. (2012). The process of senior nursing student-patient connection: Student and clinical nursing faculty perceptions (Doctoral dissertation). Retrieved from Proquest Dissertations and Theses database. (UMI No. NR89306).

Yaghoubinia, F., Heydari, A., \& Latifnejad Roudsari, R. (2014). Seeking a progressive relationship for learning: A theoretical scheme about the continuity of the studenteducator relationship in clinical nursing education. Japan Journal of Nursing Science, 11, 65-77. doi: 10.1111/jjns.12005 


\section{Chapter Five - Conclusion}

In this chapter, a summary of the study exploring the resilience of nursing students is provided. Limitations of the current study are noted and discussed. Key findings are presented and discussed. The implications of the study for nursing students, nurse educators, and nursing program administrators are delineated and recommendations are made based on these implications. Implications and recommendations for theory development are deduced from the findings. Finally, conclusions arising from the results of the study are drawn.

\section{Summary of the Study}

The purpose of this study was to explore nursing students' understanding and enactment of resilience. The core outcome of the study was the generation of a grounded theory of pushing through. The process of pushing through was the emerging representation of nursing students' understanding and enactment of resilience. More details about the findings of the study are in Chapter Three.

Permission to conduct this research study was obtained from the research ethics boards of the Western University (Appendix B) and the University at which data were collected, and from the Dean/Director of the School of Nursing study site (Appendix C). Informed consent (Appendix F) to participate was obtained from all participants prior to conducting the interviews. To preserve anonymity, digital recordings and written transcripts of participant interviews were assigned alpha-numeric codes.

The constructivist grounded theory methodology by Charmaz (2006) was used to explore nursing students' understanding and enactment of resilience. Through a purposive sampling method, a total of 38 students (4 males, 34 females) from a four-year baccalaureate nursing program at a university in Ontario, Canada were included in the study. Data were collected through face-to-face interviews using a semi-structured interview guide (Appendix 
A). The three coding phases (initial, focused, and theoretical ) from the constructivist grounded theory methodology (Charmaz, 2006) were used as the specific method of data analysis. Theoretical sampling, also recommended by Charmaz, was employed in order to address gaps noted in the analysis. Therefore, the interview guide was adapted as the study progressed in order to add areas that required further exploration to clarify gaps in the emerging theory. Charmaz's four criteria for evaluating the quality of a grounded theory credibility, originality, resonance, and usefulness - were applied to the emerging substantive grounded theory. More details regarding the way in which each criterion was applied are provided in Chapter Three.

In addition to the research study, an integrative review of past research studies and theoretical papers about resilience in nursing education was conducted to evaluate the current state of knowledge of resilience in nursing education. The conclusion of the integrative review revealed a need for further studies of resilience in nursing education, particularly exploring the resilience of nursing students. The review also included implications and recommendations for nurse educators to effectively foster resilience in their students and for nursing education researchers to further examine the concept of resilience. Details of the results of this integrative review are in Chapter Two.

An in-depth exploration of constructivist grounded theory as the methodology of choice for examining the resilience of nursing students was conducted and discussed in Chapter Four. More particularly, the rationales, challenges, and advantages of using constructivist grounded theory in examining nursing students' resilience are articulated in this chapter. Recommendations for using the methodology in nursing education research are also provided. The overall purpose of Chapter Four is to illuminate readers, particularly 
nursing education researchers, as to what constructivist grounded theory offers as a research methodology in nursing education research.

\section{Limitations}

Three study limitations were identified. One was related to the sample. Participants came from one Canadian university and the majority were from the second and third years of the undergraduate program. Although there was a wide range of cultural backgrounds of participants, $83 \%$ identified themselves as Canadian/Caucasian. Hence, most participants were white, female undergraduate students in their 20s. This limited diversity resulted in some limitations of the emerging theory, such as lack of articulation of themes such as culture, family structure, power structure and dynamics, and significant historical events. It is important to note, however, that the cultural backgrounds of the sample closely reflected the nursing program's student population.

Another limitation was related to the theoretical sampling of resilience as a dynamic process that changes over time. Participants were interviewed only once. Therefore, theorizing resilience as a basic social process characterized by stages was mainly based on participants' accounts of past experiences, namely, from the time they started the nursing program to the day of the interview. A greater variation of the theory may have emerged had the research used a longitudinal study design such as interviewing participants periodically during their nursing education. Although this strategy was considered, it was deemed unrealistic due to the resources and time it would require.

Finally, the study was limited to participant interviews as the primary data source. The grounded theory of pushing through was based mainly on data analysis of the interviews of participants, field notes written immediately after each interview, reflective journals about the interview settings, and memos about the emerging categories and concepts and personal 
preexisting beliefs about resilience. The emerging grounded theory might have yielded richer data, categories, and concepts if other sources of data had been used, such as student journals written over time and researcher observations of selected participants as they went about their activities in their nursing education.

\section{Key Study Findings and Discussion}

Results of the constructivist grounded theory study revealed three notable findings. First, nursing students' understanding and enactment of resilience is represented as the process of pushing through. Second, the process of pushing through is comprised of three main iterative phases: stepping into, staying the course, and acknowledging. Third, there are periods in the process of pushing through during which students disengage from and reengage with this process. Each of these main findings is discussed in the proceeding section.

\section{The Process of Pushing Through.}

The first key finding of the study is that nursing students' understanding and enactment of resilience is represented as the process of pushing through. Pushing through is an action-oriented process used by nursing students to withstand the challenges in their academic lives and to achieve goals. This finding means that the resilience of nursing students extends beyond merely coping with significant challenges; it also pertains to achieving positive outcomes despite difficulties or setbacks. Hence, studies about the resilience of nursing students include examples of students' behaviours of persevering with their challenges, resulting in remaining in their programs and in many cases, completion of their degrees (Carroll, 2011; Crombie, Brindley, Harris, Marks-Maran, \& Thompson, 2013; Knight et al., 2012; Peters, 2003; Williamson, Health, \& Proctor-Childs, 2013). The findings of the current study extend current knowledge of resilience in the nursing education literature 
by providing an explicit portrayal of the two-fold nature of resilience - the presence of a risk or challenge and a positive outcome such as successful adaptation or achievement of goals (Masten, 1999). Also, the research makes a significant contribution to nursing education literature by focusing on the theme of achieving goals as not only a positive outcome of resilience but also as a purpose of resilience.

Additionally, a process called moving forward emerged from the finding to portray the trajectory of pushing though. Moving forward is further explained as students having the sense of progressing in their academic lives such as achieving certain milestones. This theme is also evident in studies of nursing students' resilience. In Caroll's (2011) and Mott's (2013) studies, moving forward was related to perseverance, which was an evident aspect of resilience in these two studies. Moving forward in these two studies was illustrated through narratives of participants of being unhindered, being unstoppable, and not giving up. However, descriptions of moving forward in these two studies were sparse. Therefore, findings from the current grounded theory study further expand the limited description of the theme of moving forward in the nursing education literature. More particularly, the illustration of moving forward as a trajectory of pushing through suggests the primacy of this theme in understanding the phenomenon of resilience.

Another aspect of the study that affirms the conceptualization of resilience in the literature is the nature of pushing through as an action-oriented process. This particular finding suggests that resilience is not merely a characteristic or trait of a person, but that resilience is also a dynamic process involving actions. This observation helps further explain what is already known about resilience as a process. Rutter (1985) articulates that resilience not only pertains to one's strength or weakness, but also includes taking action to deal with a stressful situation. Kornhaber and Wilson (2011) concur that resilience is a strategy for 
coping with adversity. Similarly, the conclusions of Trusty-Smith's (2013) qualitative study of the resilience of African-American undergraduate students demonstrate that resilience is a strategy used to overcome challenges in academic life and to access valuable support systems.

\section{Three Main Phases of Pushing Through}

The second key finding of the study is that pushing through is comprised of three main phases (stepping into, staying the course, and acknowledging), which indicate that resilience is a process consisting of unfolding temporal sequences. These three phases are iterative, which means that pushing through is not a linear process, but rather, one in which students may go back and forth through these phases.

In the first phase, stepping into, students are beginning to encounter a challenging circumstance and perceive that they may require a different set of skills or way of thinking, acting, and being to cope successfully with this situation. This phase consists of two main responses: seeking clarity and anchoring. This initial phase of pushing through is similar to Rutter's (1985) description of the processes involved in resilience. Rutter explains that as individuals are faced with adversity, they begin to appraise their situation, ascribe meaning to it, and integrate it into their belief systems.

Staying the course, which is the second phase, refers to the actions nursing students take in order to continue pursuing their goals despite perceived obstacles. They also employ this process to withstand their challenges and get through their adversities. There are four main strategies students use in this phase: broadening perspectives, prioritizing, collaborating, and releasing. This second phase, staying the course, is consistent with the construct of perseverance as an aspect of resilience (Wagnild \& Young, 1990). Perseverance is described as "the act of persistence despite adversity or discouragement, connoting a 
willingness to continue the struggle to reconstruct one's life and remain involved in the midst of adversity" (Wagnild, 2009, p. 106). Similarly, staying the course pertains to the actions used to continue pursuing academic goals despite obstacles and setbacks. Staying the course is also conceptually resonant with themes of perseverance in studies about nursing students' resilience. Peters (2003) demonstrated that nursing students' resilience is based on their perseverance and persistence to remain in their programs, and as a result, 14 out of the 15 participants completed their nursing degrees. Carroll (2011) found perseverance to be an intrinsic factor related to resilience and further described perseverance as students' ability to remain in the program despite overwhelming challenges in their education. Therefore, the current grounded theory study extends the findings about perseverance in studies about nursing students' resilience. More particularly, the explication of the theme of staying the course represents more an action of persevering and persisting than an ability or characteristic. The four strategies of staying the course suggest specific actions students can take to persevere in their programs.

The last phase of the process of pushing through is called acknowledging, which refers to the students' reflections on their transformation from pushing through the challenges in their academic lives. There are three approaches to acknowledging: recognizing, contributing, and re-immersing. This phase of pushing though, acknowledging, suggests that transformation and growth experience are consequences of resilience. This finding affirms descriptions of positive outcomes of resilience in the literature. For example, Smith (2006) defined resilience as a process that provides an awareness of one's strength while Richardson (2002) conceptualized resilience as a "process of coping with adversity, change, or opportunity in a manner that results in the identification, fortification, and enrichment of resilient qualities or protective factors" (p. 308). There is very limited 
description of personal growth and transformation as consequences of resilience in studies about nursing students' resilience. In Peters' (2003) work on nursing students' resilience, students reported changes they experienced because of resilient experiences with challenging situations. They found themselves to be more open-minded and inquisitive and more aware of and sensitive to cultural differences. The explication of transformation and personal growth as consequences of resilience is sparse in nursing education literature. Therefore, the current grounded theory study extends current knowledge of resilience in the nursing education literature by focusing more on the different forms of transformation and personal growth as consequences of resilience.

\section{Disengaging Processes of Pushing Through}

The third key finding of the study is that there are periods in the process of pushing through when students disengage from this process. This period of disengagement usually occurs during the second phase of pushing through, namely, staying the course. Students disengage by defocusing, disconnecting, or immobilizing. They reengage with the process of pushing through by applying the strategies of the staying the course process (i.e., broadening perspectives, prioritizing, collaborating, and releasing). This spiraling from pushing through to disengagement and back to pushing through represents a dynamic perspective of resilience. This spiraling process of disengaging-reengaging of pushing through provides data to support Richardson's (2002) explication of resilience as a dynamic process in his The Resiliency Model. Resilience in this model is depicted as a process in which a person passes through stages of biopsychospiritual homeostasis, disruption (experiencing an adversity) and reintegration (adapting from the adversity and gaining learning and growth from the experience). Richardson provides a caveat that his model is depicted as a linear model for educational and counseling purposes. However, he further elucidates that in actuality, a 
person may experience multiple and frequent disruptions as well as several opportunities to reintegrate. Similarly, spiraling from pushing through to disengagement and back to pushing through suggests that resilience is a dynamic process, not a linear one.

These particular findings of the current study provide additional evidence of resilience in nursing education literature by portraying the dynamic nature of resilience through the theoretical rendering of the disengaging-reengaging processes and the iterative phases of pushing through. Resilience as enacted in the lives of nursing students is not a straightforward, unidirectional process.

\section{Implications for Nursing Education}

In this section, implications of the study findings for nursing students, nurse educators, and nursing school administrators are delineated with a view to making recommendations based upon these implications. This section also includes a discussion of the possible consequences for students, educators, and administrators if the phases within the process of pushing through were to continue without progress to the next phase.

When students are in the stepping into phase of pushing through, they experience lack of clarity of their school expectations and ways to effectively deal with their challenging situations. Students also experience anxiety in this phase. If they do not use responses such as seeking clarity and anchoring, they may continue to remain unclear about what is expected of them and unable to take the actions necessary to manage their adversities and address their anxiety. They might not progress into the next phases of the process of pushing through. Consequently, their anxiety may escalate and they may develop physical, mental, and psychological symptoms of stress. They might also avoid further perceived adversities, rather than viewing them as potential opportunities for personal and professional development. Their academic performance may suffer further because of lack clarity of what is expected of 
them and the necessary steps to be successful. Evidence has shown that when nursing students are unclear about their roles and school expectations and when they continue to exhibit symptoms of anxiety, they have poor academic performance and develop physical, mental, and psychological symptoms of distress (Dzurec, Allchin, \& Engler, 2007; Freeburn \& Sinclair, 2009; Klainin-Yobas et al., 2014; Portoghese et al., 2014; Watson, Deary, Thompson, \& Li, 2008; Watson et al., 2009; Wu \& Norman, 2006).

Students who find themselves in the second phase of pushing through, staying the course, are actively using strategies to withstand their challenges and achieve their goals. However, at times, they may disengage from the process of pushing through and may be involved in any of the disengaging processes, namely defocusing, disconnecting, and immobilizing. If students do not reengage in the process of pushing through and remain disengaged, they may delay seeking help, avoid solving their problems, and eventually may withdraw from the nursing program. Evidence has shown that disengaged students spend less time and effort on learning activities, thereby significantly and negatively affecting academic performance (Curtis \& Williams, 2002; Krause, Hartley, James, \& McInnis, 2005; Salamonson, Andrew, \& Everett, 2009).

Students may not able to reach the acknowledging phase of pushing through because they fail to acknowledge their transformation. Students may be able to solve their problems but may not have gained any insight or maturity of perspective from their experience. Hence, these students may remain in the second phase of pushing through, attempting to address every problem that comes on their way without developing insight or transformation. At this point, students may also disengage from the process of pushing through. If this situation persists, students may view adversities as threatening and fail to perceive them as opportunities for personal growth and development. These outcomes are similar to 
Richardson's (2002) description of individuals who cling to their "comfort zones" and "turn down opportunities for growth to avoid disruption" (p. 311). Consequently, when they inevitably encounter further disruptions, they may revert to the stepping into phase. At this point, students may focus their efforts on seeking clarity of new challenges and minimizing anxiety. Hence, outcomes for students who are not progressing to the acknowledging phase may include a perception of being in a constant flux of adversities, a sense of being overwhelmed, and application of repeated, ineffective coping strategies.

When students do not ask for help to seek clarity and address their anxiety, nurse educators may fail to identify students who need their help. Teachers may find struggling students in the later stages of students' experience of stress when students have already developed complications of anxiety from poor and ineffective coping with adversities. Therefore, teachers, at this point, may focus their efforts more on addressing risks and problems rather than employing health-promoting strategies such as fostering resilience.

Teachers may have difficulty contacting disengaged students in an effort to support their academic success. Teachers are already pressured by their academic and administrative workloads; efforts to contact disengaged students in the hopes of fostering resilience may not be a priority. Teachers may also conveniently attribute students' disengagement to students' poor intellectual abilities and lack of critical thinking skills rather than first exploring students' contextual factors affecting their disengagement.

When students are not reaching the phase of acknowledging in the process of pushing through, they may lack the sense of fulfillment and personal growth for withstanding their challenges and achieving related goals. As a result, they may also lack a sense of accountability for their situations. Hence, they may blame their teachers for their poor academic outcomes. Teachers may be accused of being incompetent at creating meaningful 
and interactive learning environments, insensitive to students' needs and situations, and unavailable to provide support. Lack of accountability may also result into problematic student-faculty relationships. Problematic relationships may cause hindrances in further delivering meaningful and interactive teaching strategies, and eventually may adversely affect teacher performance evaluations.

Nursing school administrators may also find these circumstances problematic, particularly when compromised students' health and academic performance become pervasive across the student population. Students' inability to cope with academic demands may result in overall poor academic performance, negatively affecting the quality of graduates and, in the long term, adversely affecting the program's reputation and hence student recruitment efforts. Nursing school administrators may also focus a significant amount of their leadership responsibilities on alleviating the pervasive negative consequences of poor academic performance and health of disengaged learners. Administrative activities may be more reactive as administrators increasingly take corrective actions to fix students' problems. Moreover, administrators may also place more attention on rectifying issues related to problematic relationships between teachers and students because of students' poor academic performance. Consequently, nursing program leaders may devote less time to their broader responsibilities of their leadership role such as implementing strategic directions to raise the profile of research and the academic excellence of the school.

The above illustrated possible outcomes of the students' lack of application of the process of pushing through reinforce the value of (1) nursing students' self-awareness, (2) nurse educators' active engagement with the students, and (3) nursing school administrators' leadership in implementing school-wide programs that impact students' resilience and academic success. First, nursing students' self-awareness can be considered an underlying 
force of students' application, ability, and motivation to use of the processes and strategies embedded within the theory of pushing through. For example, when students are aware of their confusion and lack of information required to cope successfully with their challenges, they may, as a result, seek clarity. When students are aware of their triggers of disengaging from the process of pushing through, they may consciously apply some of the strategies of staying the course. When they are reflective of their transformation, they may perceive adversities as opportunities for personal and professional growth. As a result, negative outcomes associated with disengaging may be minimized significantly. Hence, students may value the importance of their engagement in learning, and therefore implement actions to increase such engagement. Participants in the current study reported that many of the reasons for disengaging were due to non-academic concerns such as part-time jobs, relationships, death of a family member, caregiving responsibilities, and maintaining their own physical and mental health.

It is, therefore, imperative that students increase their academic engagement. Salamonson, Andrew, and Everett (2009) posit that the amount of time students spend on learning-related activities directly influences their academic engagement. Students' interactions with fellow students and faculty have been shown to increase academic success (Shelton, 2003). Students persist to remain in the program when they are engaged with and included in learning communities in the school (Pike \& Kuh, 2005).

Second, nurse educators' engagement with students is a key facilitating factor for teachers to effectively foster resilience in students. When nurse educators are actively engaged with students, they create meaningful interactions with students. Consequently, students may positively respond to teachers' assistance in supporting them with their challenges. Students will likely see the benefits of asking others for help rather than trying to 
solve problems on their own. Students' reflections of their transformation from pushing through challenges may include the acknowledgement of faculty support. When nurse educators are interacting with students with a caring approach, they are able to explore and recommend relevant and applicable solutions and approaches that effectively address student problems and issues. Close interactions between teachers and the students may also allow teachers to identify, at an early stage, students who are struggling with their education. Therefore, active engagement is an important vehicle in influencing students to apply processes and strategies of pushing through consistently. Similarly, Hodges, Keeley, and Grier (2005) and Chen (2011) posit that supportive and highly engaging relationships between teachers and students promote the development of student resilience.

Third, nursing school administrators' leadership is also an essential contributing factor in the development of the resilience of nursing students. It is imperative that nursing school administrators are supportive to the design, implementation, and evaluation of school-wide programs and activities aimed at developing the resilience of students. Administrators' leadership and influence are required in implementing programs that will keep students well informed about resilience-enhancing resources. Their leadership also has a significant impact on the development of teachers' competence at supporting and fostering student resilience. Their role in tracking school performance indicators (i.e., attrition rates, success rates of nursing licensure examinations, enrollment rates) is crucial in obtaining a broader understanding of the impact of resilience-fostering programs.

\section{Implications for Theory Development}

There is a lack of theoretical explanation of nursing students' resilience in the nursing education literature. The findings of the current study offer a foundational theoretical perspective about the resilience of nursing students. The main finding of the study, which is 
the grounded theory of pushing through, provides additional evidence about nursing students' resilience. Hence, the theory of pushing through offers a conceptual framework that can be used to guide further development of theory about the resilience of nursing students.

The first implication of the study findings for further theory development about resilience particularly pertains to the use of the key study findings as sensitizing concepts. According to Charmaz (2003), sensitizing concepts are the researcher's perspectives and notions that "offer ways of seeing, organizing, and understanding experience; they are embedded in our disciplinary emphases and perspectival proclivities ... they provide starting points for building analysis, not ending points for evading it" (p. 259). Therefore, sensitizing concepts need to be made visible within the researcher's awareness and used only as starting points for analysis, rather than as means to limiting ideas or completing data analysis (Charmaz, 2006). The latter point is particularly relevant to the current study's findings. Findings that are particularly critical in exercising purposeful awareness in further theory development about resilience are the characteristics of pushing through as a process: pushing through is (1) an action-oriented process, (2) comprised of temporally sequenced phases, and (3) a dynamic, iterative process rather than a linear, straightforward one. These three characteristics of pushing through as a process are conceptual or abstract enough to be covertly forced into the data analysis. A lack of conscious awareness of how a researcher's pre-existing theoretical notions influence data analysis could result in "a constructed theory, supporting what was already known, rather than an emergent theory providing new insights" (Heath, 2006, p. 520). Although the findings of the current study, such as the theory of pushing through, can provide a foundational basis for furthering theoretical understanding of nursing students' resilience, it is imperative that these findings are not forced into an emerging theory when using grounded theory methods for further theory development. 
The second implication of the study findings for further theory development relates to the complex nature of resilience. This complexity is exemplified in the study findings. For example, the iterative nature of the three main phases of pushing through is a demonstration that resilience is not a simple, linear process. Nursing students vacillated within these phases, and narratives within the study revealed that going back and forth between phases did not necessarily indicate that the students were not resilient, but rather, were part of their experience of resilience. Within the second phase of pushing through, which is the staying the course phase, there are disengaging processes that intersect this phase. This is also a representation that resilience is a complex process. Similarly, these moments of disruptions and disengagement were aspects of the process of pushing through. Additionally, these periods of disengaging from the process of pushing through and the iterative nature of the phases of pushing through are not simply brought about by internal factors such as students' thought processes, feelings, and emotions. As noted within the narratives, the process of pushing through was also influenced by environmental or external factors. Although particular interactions of environmental factors affecting the process of pushing through were not delved into within this grounded theory study, the phases and processes within the theory of pushing through demonstrate that environmental factors play a significant role within the process of pushing through. For example, the processes of seeking clarity (within the first phase of pushing through), collaborating (within the second phase), and contributing (within the third phase) are some of the more overt processes indicating that environmental factors impact the process of pushing through. These implications highlight that further theory development of resilience of nursing students should consider the complexity and multidimensionality of resilience. For example, Ungar (2011) recommends that future theory development on resilience should not be limited to the study of individuals or individual 
factors but also consider the interactions of ecological factors. Ungar proposes four key principles in further theory development of resilience: decentrality (delimiting study of resilience beyond the individual to ecological factors), complexity (considering variability of responses between contexts and through time), atypicality (shifting perspective on adaptive responses as not necessarily positive or "good" behaviour), and cultural relativity (including the influence of culture on the study of resilience).

In summary, it is imperative that theory development about resilience be grounded in the voices of the participants; hence, the emerging theory should reflect participants' experiences rather than forcing researcher's pre-existing theoretical notions into the theory. Furthermore, theory development in resilience should consider a broader conceptual ground. This means that expanding theoretical understanding of nursing students' resilience should highlight the complex nature of resilience including the interaction between individual and environmental factors influencing resilience. Specific recommendations for theory development are delineated in the latter section of this chapter.

\section{Recommendations for Nursing Students}

As noted in the findings and implications of the study, nursing students will inevitably face challenges in their academic lives. Some of these challenges may be perceived by students as significantly threatening to their achievement of their academic goals. Therefore, the following recommendations are provided for nursing students to enable them to thrive in their nursing education programs. Recommendations include that nursing students:

- Ask questions of teachers to clarify expectations of course objectives, assignments, and other course requirements. 
- Establish a consistent practice of reflection of their school life, such as writing personal journals.

- Use the theory of pushing through to locate themselves in the process and test out processes and strategies within the theory by applying them in their everyday lives.

- Recognize that resilience is a process and apply the theory of pushing through to validate their experience of struggling and successful coping. For example, students are recommended to acknowledge their occasional disengagement from pushing through as part of their resilience experience rather than invalidating themselves as "not resilient."

- Determine aspects of their (academic as well as non-academic) problems that require assistance from others, and seek help for those aspects rather than attempting to solve them on their own.

- Seek support early on when they first sense a challenging situation rather than waiting until circumstances get worse.

- Debunk stigma about seeking help from school and external counselors and other forms of support (i.e., psychological and mental health) by considering alternative perspectives such as perceiving help-seeking behaviour as a health promotion strategy.

- Explore alternative coping strategies to replace common ones that do not work. For example, students can clarify ambiguities directly with the teacher as opposed to the common habit of asking peers.

- Set up an accountability partner (e.g., a peer, family member, counselor, personal development or life coach) to whom students can promise goals to achieve, establish negative consequences for not meeting the goals and rewards for achieving them, 
identify activities required to meet the goals, and set up consistent follow-up meetings or calls.

- Take advantage of promptly completing and submitting formative assessment requirements such as submitting an outline of a paper early or before the deadline.

- Set goals that they can control. For example, rather than aiming for a $90 \%$ test grade, students can create targets such as ensuring they study at least 2 hours a day, working a maximum of 2 shifts a week (if employed), and reading one research article per day.

- Set high expectations for themselves to increase their motivation to perform well in school. Examples of expectations that exceed basic requirements include submitting essays one week before the deadline, completing all chapter readings covered in a test one week before the exam, and providing a supernumerary patient case analysis to the clinical teacher.

- Participate in available mentoring programs (such as those in which a student is paired with an upperclassman or faculty providing mentoring to selected students).

\section{Recommendations for Nurse Educators}

Nurse educators are a vital support to nursing students' development and enhancement of resilience. Nursing students also recognize that their relationships with their teachers significantly affect their academic success. Therefore, the following recommendations are made to nurse educators to help foster resilience in their students. Recommendations include that nurse educators:

- Recognize that students' academic success is a result of multiple and interacting factors, including resilience. Additionally, nurse educators are reminded that students' poor academic performance is seldom affected simply by one factor. 
- Articulate to students their overall purpose of teaching at the beginning of the semester. Examples of these purposes are to support students' academic success and to give opportunities for consistent reflective thinking.

- Communicate to students that teachers understand that many students have other commitments and obligations (such as family, part-time jobs, etc.) and at the same time, that students are expected to meet their academic requirements and encouraged to set high standards for themselves.

- Emphasize to students that their (the teacher's) primary role is teaching, not counseling, but that they are available to explore students' concerns and ways to address them.

- Discuss the theory of pushing through during the first or second meeting of the course and offer a discussion among students to explore how they could use the theory to promote successful adaptation in their academic lives.

- Implement formative assessments to monitor student performance, to identify where students are struggling, and to address problems promptly. Examples of formative assessments are asking students to submit a learning plan, a brief summary of the main points of a lecture, an outline of a paper, and a concept map representing understanding of a topic or concept.

- Use the theory of pushing through as a teaching tool when assisting students to cope with their challenges. Nurse educators can ask questions rather than providing advice. For example, teachers can say, "Where do you see yourself in this process of pushing through? What can you do or practice to move through the next phase of pushing through? Which of these processes can you start applying now?" It is also recommended that teachers establish follow-up meetings with students to determine 
benefits and challenges of applying concepts of the theory to practical aspects of students' lives.

- Encourage students to reflect on their protective factors and explore how they could improve these protective factors to help enhance their resilience. Examples of protective factors include hope, optimism, supportive relationships, self-esteem, and self-confidence.

- Set high expectations for students. For example, teachers can provide bonus marks (i.e., an additional 5\% mark to their total grade) for completing assignments above and beyond basic expectations.

- Create frequent, open discussions to clarify expectations of student assignments and other course requirements.

- Obtain information about available counseling programs, writing support and tutoring services, medical and psychological support services, and other related programs in the school. Teachers are also recommended to examine how these services and programs could be relevant and applicable to particular concerns of their students.

- Explore the personal and educational contexts of students who appear to be struggling in a course rather than making premature conclusions such as that students have poor critical thinking skills, have low intellect, or are not studying hard enough. It is recommended that nurse educators consider these factors on an individual basis.

- Use broad, open-ended questions and offer to work together (rather than giving advice) when exploring students' situations. For example, teachers can say, "Would you like to share what's going on so we can explore ideas about how you might improve your test grades?" 
- Apply the theory of pushing through as a map to guide their assessment of students who are both struggling and thriving in their education. It is recommended that nurse educators examine how students are using the processes within the theory of pushing through.

- Ask students what their typical ways of coping with difficulties are and encourage them to try out alternative coping strategies. For example, teachers can say, "Now you told me that you used to avoid conflicts; what would be possible if you experiment on more assertive ways of dealing with conflicts?"

- Integrate other skills in their individual interactions with students, such as time management, priority setting, self-assessment of stress, and stress reduction.

- Establish a consistent practice of recognizing students' achievements in class or among clinical group members. These student achievements are not limited to excellent test grades, consistent attendance, and awards and scholarships received. Achievements may also include recognizing students' academic performance while doing other commitments and addressing significant milestones in students' personal and academic lives. For example, teachers can say, "I know you had been very busy volunteering at a community nursing home, and yet you still managed to get $90 \%$ on your midterm. Well done!"

- Schedule meetings with students who are thriving in both classroom and clinical courses to explore with them factors and processes that impact their individual success. Use insights learned from these interactions in helping students who are having difficulty with their courses. 
- Model resilience. For example, teachers can share their personal experiences as a learner, their encounters of professional and personal setbacks and the lessons from these experiences, and stories of successfully pushing through to achieve their goals.

- Participate in curriculum development activities and advocate for integrating concepts of resilience into the curriculum, including concepts from the theory of pushing through.

- Serve as a mentor in available formal student mentoring programs (such as a program involving a teacher providing mentoring to a maximum of 3 students).

\section{Recommendations for Nursing School Administrators}

Based on the implications of the findings of this study, it is apparent that nursing program administrators and leaders have a responsibility to foster the resilience of nursing students in their programs. Although their effect on students' resilience is not as direct as that of faculty members, administrators can significantly influence students' positive adaptation to academic challenges through their leadership. Therefore, the following recommendations are provided for nursing program administrators to contribute to the development of resilience of nursing students. Recommendations include that nursing program administrators:

- Ascertain that information about support services offered by the school, which may facilitate nursing students' academic success, is included in student orientation programs. These services include different counseling programs, writing support and tutoring services, medical and psychological support services, and other related programs in the school.

- Ensure that concepts of resilience and ways to develop and enhance resilience are integrated in student and faculty orientation programs. 
- Arrange faculty development programs aimed at improving faculty members' sensitivity to students' challenges. These educational sessions could include discussions on key literature of resilience, practical examples from the findings of the study, and action plans to improve nurse educator skills in fostering the resilience of students. The theory of pushing through should be included in these faculty development programs.

- Support faculty and other key stakeholders who are advocating for integrating concepts of resilience into the curriculum.

- Establish consistent practices that recognize the contributions of teachers to the success of students. This may include consistently acknowledging teachers in faculty meetings, nominating faculty for appropriate teacher awards, and recognizing teacher efforts during performance appraisal or review.

- Enhance selection and hiring of tenure track and contract faculty by examining the teaching philosophies of applicants to determine how applicants support resilience and academic success of students. Interview questions that assess applicants' sensitivity to nursing student stress, resilience, and coping could be added.

- Monitor school performance indicators that reflect the resilience, academic success, and overall health status of students on a regular basis. Some of these indicators may include the success rate of nursing licensure examination of graduates, changes in recruitment and retention efforts, rate of student absenteeism, results from student and teacher satisfaction surveys, and attrition rates.

\section{Recommendations for Theory Development}

Future research studies may yield critical concepts about the resilience of nursing students that have not emerged from the current grounded theory study. Qualitative studies 
need to be conducted to refine and expand the concepts and themes within the grounded theory of pushing though. Therefore, researchers are recommended to:

- Expand the sample to include students from other programs such as post-RN diploma programs, second-degree entry programs, associate degree programs, bridging programs for licensed practical nurses to become registered nurses, and baccalaureate programs for internationally educated nurses.

- Consider students from different cultural backgrounds in the sample.

- Interview participants at different times during students' education.

- Include (in addition to participant interviews) students' reflective journals written over a determined period as a data source.

- Use an ethnographic approach to determine the impact of culture on the resilience of nursing students.

- Apply a critical social perspective to understand the impact of broader social, economic, and historical factors on resilience.

The grounded theory of pushing through has great potential to be a conceptual foundation for developing a resilience-measuring instrument that captures the unique aspects of nursing students' educational context. Therefore, more qualitative studies must be conducted to expand the concepts and categories within the grounded theory further, and be more applicable to different types of nursing student populations. Researchers interested in developing such instruments are recommended to consider the concepts in the grounded theory during the conceptualization and psychometric development of the construct.

Furthermore, concepts from the grounded theory of pushing through can be integrated into educational interventions aimed at enhancing nursing students' resilience. 
Pines et al. (2014) and Stephens (2012) determined the effectiveness of existing educational interventions among nursing students. Likewise, it is recommended that researchers consider integrating concepts from the grounded theory into the design and testing of educational interventions.

\section{Conclusion}

The grounded theory of pushing through that emerged from the study is the first theory that addresses nursing students' resilience. The concepts and processes depicted in this theory offer additional evidence to the current state of knowledge of the resilience of nursing students. The findings of the study provide a theoretical groundwork for future research of nursing students' resilience. A unique contribution of the grounded theory of pushing through is its illustration of various processes in response to experiencing adversity. These processes are also depicted as strategies nursing students use in order to withstand the challenges they are experiencing as well as to achieve their academic goals. Examples of these processes include stepping into, staying the course, and acknowledging. The study findings also indicate that resilience is a dynamic, multidimensional, and contextual process. The findings imply that resilience is a process and a strategy that can be learned, developed, and enhanced. Moreover, this conceptualization of resilience as a process that can be taught and learned highlights the imperative for nurse educators, administrators, and researchers alike to implement interventions or produce new knowledge that will support students' coping with stress, enhancement of resilience, and achievement of academic goals. 


\section{References}

Carroll, S. (2011). Resilience as a factor in the successful completion of a California community college based associate degree in nursing program (Doctoral dissertation). Retrieved from ProQuest Dissertations and Theses database. (UMI No. 3454870)

Charmaz, K. (2003). Grounded theory-Objectivist and constructivist methods. In N. K. Denzin \& Y. S. Lincoln (Eds.), Strategies of qualitative inquiry (pp. 249-291). London: Sage.

Charmaz, K. (2006). Constructing grounded theory: A practical guide through qualitative analysis. London: Sage.

Chen, J. Y. (2011). Problem-based learning: Developing resilience in nursing students. Kaohsiung Journal of Medical Sciences, 27, 230-233. doi:10.1016/j.kjms.2010.11.005

Crombie, A., Brindley, J., Harris, D., Marks-Maran, D., \& Thompson, T. M. (2013). Factors than enhance rates of completion: What makes students stay? Nurse Education Today, 33, 1282-1287. doi: 10.1016/j.nedt.2013.03.020

Curtis, S., \& Williams, J. (2002). The reluctant workforce: Undergraduates' part-time employment. Education and Training, 44, 5-10. doi: 10.1108/00400910210416192

Dzurec, L. C., Allchin, L., \& Engler, A. J. (2007). First-year nursing students' accounts of reasons for student depression. Journal of Nursing Education, 46, 545-451.

Freeburn, M., \& Sinclair, M. (2009). Mental health nursing students' experience of stress: Burdened by a heavy load. Journal of Psychiatric and Mental Health Nursing 16, 335-342. doi: 10.1111/j.1365-2850.2008.01376.x

Heath, H. (2006). Exploring the influences and use of the literature during a grounded theory study. Journal of Research in Nursing, 11, 519-528. doi: 10.1177/1744987106069338 
Hodges, H. F., Keeley, A. C., \& Grier, E. C. (2005). Professional resilience, practice longevity, and Parse's theory for baccalaureate education. Journal of Nursing Education, 44, 548-554.

Hodges, H. F., Keeley, A. C., \& Troyan, P. J. (2008). Professional resilience in baccalaureate- prepared acute care nurses: First steps. Nursing Education Perspectives, 29, 80-89. doi: 10.1043/1094-2831(2008)29[80:PRIBAC]2.0.CO;2

Klainin-Yobas, P., Keawkerd, O., Pumpuang, W., Thunyadee, C., Thanoi, W., \& He, H. G. (2014). The mediating effects of coping on the stress and health relationships among nursing students: a structural equation modeling approach. Journal of Advanced Nursing 70, 1287-1298. doi: 10.1111/jan.12283

Knight, J., Corbett, A., Smith, C., Watkins, B., Hardy, R., \& Jones, G. (2012). What made me stay? A review of the reasons student nurses enrolled in a bachelor of nursing programme completed their studies: A descriptive phenomenological study. Nurse Education Today, 32, e62-e65. doi: 10.1016/j.nedt.2012.03.007

Kornhaber, R. A., \& Wilson, A. (2011). Building resilience in burns nurses: A descriptive phenomenological inquiry. Journal of Burn Care \& Research, 32, 481-488. doi: 10.1097/BCR.0b013e3182223c89

Krause, K. L., Hartley, R., James, R., \& McInnis, C. (2005). The first year experience in Australian universities: Finding from a decade of national studies. Retrieved from http://www.griffith.edu.au/_data/assets/pdf_file/0006/37491/FYEReport05.pdf

Masten, A. S. (1999). Resilience comes of age: Reflections on the past and outlook for the next generation of research. In M. D. Glantz \& J. L. Johnson (Eds.), Resilience and development: Positive life adaptations (pp. 282-296). New York: Plenum. 
Mott, J. D. (2013). Undergraduate nursing student experiences with faculty bullying

(Doctoral dissertation). Retrieved from ProQuest Dissertations and Theses database. (UMI No. 3565596)

Peters, J. M. (2003). A qualitative study of registered nurses returning to school for a baccalaureate degree in nursing (Doctoral dissertation). Retrieved from ProQuest Dissertations and Theses database. (UMI No. 30282499)

Pike, G. R., \& Kuh, G. D. (2005). A typology of student engagement for American colleges and universities. Research in Higher Education, 46, 185-209. doi: 10.1007/s 11162004-1599-0

Pines, E. W., Rauschhuber, M. L., Cook, J. L., Norgan, G. H., Canchola, L., Richardson, C., \& Jones, M. E. (2014). Enhancing resilience, empowerment, and conflict management among baccalaureate students. Nurse Educator, 39, 85-90. doi: 10.1097/ NNE.0000000000000023

Portoghese, I., Galleta, M., Sardu, C., Mereu, A., Contu, P., \& Campagna, M. (2014). Community of practice in healthcare: An investigation on nursing students' perceived respect. Nurse Education in Practice, 14, 417-421. doi:10.1016/j.nepr.2014.01.002

Richardson, G. E. (2002). The metatheory of resilience and resiliency. Journal of Clinical Psychology, 58, 307-321. doi: 10.1002/jclp.10020

Rutter, M. (1985). Resilience in the face of adversity: Protective and resistance to psychiatric disorder. British Journal of Psychiatry, 147, 598-611.

Salamonson, Y., Andrew, S., \& Everett, B. (2009). Academic engagement and disengagement as predictors of performance in pathophysiology among nursing students. Contemporary Nurse, 32, 123-132. doi: 10.5172/conu.32.1-2.123 
Shelton, E. N. (2003). Faculty support and student retention. Journal of Nursing Education, $42,68-76$.

Smith, E. J. (2006). The strength-based counseling model. The Counseling Psychologist, 34, 13-79. doi: 10.1177/0011000005277018

Stephens, T. M. (2012). Increasing resilience in adolescent nursing students (Doctoral dissertation, University of Tennessee, Knoxville, TN). Retrieved from http://trace/tennessee.edu/utk_graddiss/1351

Trusty-Smith, B. (2013). The optimism to overcome: Educational beliefs and strategies of resilience among African American college graduates who are former teenage mothers (Doctoral dissertation). Retrieved from ProQuest Dissertations and Theses database. (UMI No. 3563379)

Ungar, M. (2011). The social ecology of resilience: Addressing contextual and cultural ambiguity of a nascent construct. American Journal of Orthopsychiatry, 81, 1-17. doi: 10.1111/j.1939-0025.2010.01067.x

Wagnild, G. (2009). A review of the Resilience Scale. Journal of Nursing Measurement, 17, 105-113. doi: 10.1891/1061-3749.17.2.105

Wagnild, G., \& Young, H. M. (1990). Resilience among older women. Image: Journal of Nursing Scholarship, 22, 252-255. doi: 10.1111/j.1547-5069.1990.tb00224.x

Watson, R., Deary, I., Thompson, D., \& Li, G. (2008). A study of stress and burnout in nursing students in Hong Kong: A questionnaire survey. International Journal of Nursing Studies, 45, 1534-1542. doi: 10.1016/j.ijnurstu.2007.11.003 
Watson, R., Gardiner, E., Hogston, R., Gibson, H., Stimpson, A., Wrate, R., \& Deary, I. (2009). A longitudinal study of stress and psychological distress in nurses and nursing students. Journal of Clinical Nursing, 18, 270-278. doi: 10.1111/j.13652702.2008.02555.x

Williamson, G. R., Health, V., \& Proctor-Childs, T. (2013). Vocation, friendship, and resilience: A study exploring nursing student and staff views on retention and attrition. The Open Nursing Journal, 7, 149-156. doi: 10.2174/1874434601307010149

Wu, L., \& Norman, I. J. (2006). An investigation of job satisfaction, organizational commitment and role conflict and ambiguity in a sample of Chinese undergraduate nursing students. Nurse Education Today, 26, 304-314. doi:

10.1016/j.nedt.2005.10.011 


\title{
Appendix A: Semi-Structured Interview Guide for Participants
}

\author{
Nursing Students' Understanding and Enactment of Resilience: \\ A Grounded Theory Study \\ Semi-Structured Interview Guide for Participants
}

Introduction:

I would like to thank you for participating in this interview to explore how nursing students manage stress, adversities, and challenges within their academic life. Today, I plan to explore with you how you have managed stress, adversities, and challenges within your academic life.

Before we begin, do you have any questions pertaining to the study?

- Ensure participant has signed consent form

- Restate permission to tape the interview

\section{Questions:}

1. Would you please share some of your experiences of stress, difficulties, and/or adversities as a nursing student?

2. How were you able to manage the issues around your stress, difficulties, and/or adversities as a nursing student?

3. Please share some of your experiences in overcoming your stress, difficulties, and/or adversities as a nursing student?

Probes:

a.) How did you overcome your stress, difficulties, and/or adversities?

b.) What did you do to overcome them?

4. What is your understanding of resilience?

Probe:

a.) What comes up to your mind when you hear this word?

b.) If you are to explain resilience to someone else, how would you explain it?

5. What academic experiences helped you develop resilience?

Probe:

a.) What academic experiences hindered you in developing resilience? 
6. If you were talking with your friends in your nursing class or someone interested in the nursing program, what would you tell them about what has helped you in developing resilience?

Probes:

a.) Would there be things you would want them to know about what has hindered you in developing resilience?

b.) Do you have ideas about how the nursing program could support students in developing resilience?

7. Based on your experience, what factors within your school and outside school helped you develop resilience?

Probes:

a.) How about personal factors and personality characteristics about yourself that helped you develop resilience?

8. How did these factors you mentioned help you develop resilience?

Probes:

a.) How did these factors you mentioned hinder you from developing resilience?

(Question \#9: This question is for Third and Fourth Year Level Students only):

9. Please compare your ability to manage adversities and challenges within your academic life to how you managed challenges earlier in the nursing program.

Probes:

a.) How similar are your ways of managing your adversities and challenges within your academic life from now compared to when you were in your first and/or second years?

b.) In what ways do you manage adversities and challenges within your academic life differently than when you were in your first and/or second years?

\section{Final Questions:}

10. Is there anything else that you would like to tell me about your experiences of stress, difficulties, and/or adversities as a nursing student?

11. Is there anything else that you would like to tell me about your resilience as a nursing student? 


\title{
Appendix B: Ethics Approvals
}

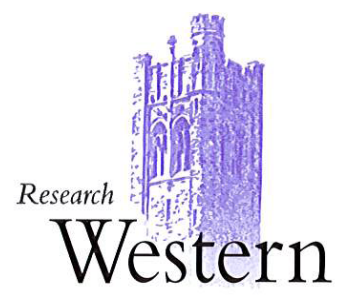

Use of Human Participants - Ethics Approval Notice

Principal Investigator: Dr. Mary Anne Andrusyszyn

Review Number: $18589 E$

Review Level: Delegated

Approved Local Adult Participants: 50

Approved Local Minor Participants: 0

Protocol Title: Nursing Students' Understanding and Enactment of Resilience: A Grounded Theory Study

Department \& Institution: Nursing, University of Western Ontario

Sponsor: Sigma Theta Tau International Nursing Honor Society

Ethics Approval Date: December 06, 2011

Expiry Date: December 31, 2012

Documents Reviewed \& Approved \& Documents Received for Information:
Document Name
Comments
Version Date

UWO Protocol

Flyer, Email, Poster

Advertisement

Letter of Information
Letter of Information

Director

Letter of Information Professor

\begin{abstract}
This is to notify you that The University of Western Ontario Research Ethics Board for Health Sciences Research Involving Human Subjects (HSREB) which is organized and operates according to the Tri-Council Policy Statement: Ethical Conduct of Research Involving Humans and the Health Canada/ICH Good Clinical Practice Practices: Consolidated Guidelines; and the applicable laws and regulations of Ontario has reviewed and granted Canada/ICH Good Clinical Practice Practices: Consolidated Guidelines; and the applicable laws and regulations of Ontario has reviewed and granted
approval to the above referenced revision(s) or amendment(s) on the approval date noted above. The membership of this REB also complies with the membership requirements for REB's as defined in Division 5 of the Food and Drug Regulations.

The ethics approval for this study shall remain valid until the expiry date noted above assuming timely and acceptable responses to the HSREB's periodic requests for surveillance and monitoring information. If you require an updated approval notice prior to that time you must request it using the UWO Updated Approval Request Form.

Members of the HSREB who are named as investigators in research studies, or declare a conflict of interest, do not participate in discussion related to, nor vote on, such studies when they are presented to the HSREB.



UWO HSREB is registered with the U.S. Department of Health \& Human Services under the IRB

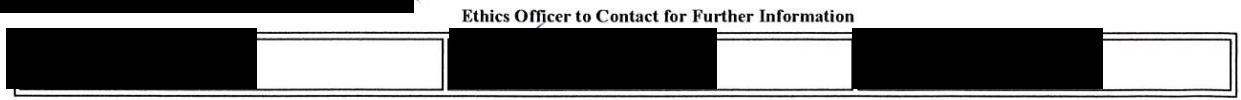

This is an official document. Please retain the original in your files.

The University of Western Ontario Office of Research Ethics 
Review Level:Delegated

Approved Local Adult Participants:50

Approved Local Minor Participants:0

Protocol Title:Nursing Students' Understanding and Enactment of Resilience: A Grounded Theory Study -18589E

Department \& Institution:Health SciencesiNursing,Western University

Sponsor:Sigma Theta Tau International Nursing Honor Society

Ethics Approval Date:February 28, 2013 Expiry Date:December 31, 2013

Documents Reviewed \& Approved \& Documents Received for Information:

Document Name Comments

Revised Study End The study end date has been extended to December 31, 2013

Date

to allow for project completion.

This is to notify you that The University of Western Ontario Research Ethics Board for Health Sciences Research Involving Human Subjects (HSREB) which is organized and operates according to the Tri-Council Policy Statement: Ethical Conduct of Research Involving Humans and the Health Canada/lCH Good Clinical Practice Practices: Consolidated Guidelines; and the applicable laws and regulations of Ontario has reviewed and granted approval to the above referenced revision(s) or amendment(s) on the approval date noted above. The membership of this REB also complies with the membership requirements for REB's as defined in Division 5 of the Food and Drug Regulations.

The ethics approval for this study shall remain valid until the expiry date noted above assuming timely and acceptable responses to the HSREB's periodic requests for surveillance and monitoring information. If you require an updated approval notice prior to that time you must request it using the University of Western Ontario Updated Approval Request Form.

Members of the HSREB who are named as investigators in research studies, or declare a conflict of interest, do not participate in discussion related to nor vote on, such studies when they are presented to the HSREB.

The Chair of the HSREB is under the IRB registration number IRB 00000940

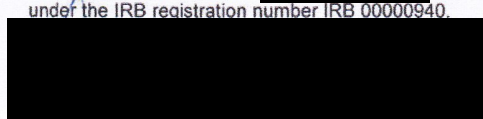

HSREB is registered with the U.S. Department of Health \& Human Service

Ethics Officer to Contact for Further Informatio

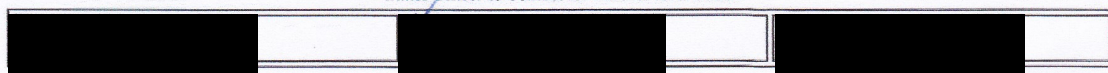

This is an official document. Please retain the original in your fites 


\section{Appendix C: Letter of Permission to Conduct the Study}

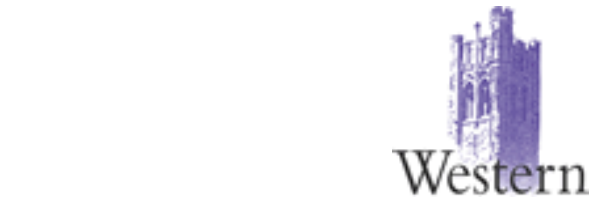

Nursing Students' Understanding and Enactment of Resilience:

A Grounded Theory Study

Date:

Dear Dean or Director,

I am a doctoral student in the Arthur Labatt Family School of Nursing, The University of Western Ontario. I am conducting a qualitative research study to generate insights about how nursing students manage the demands and challenges in their academic lives. The title of the research study is "Nursing Students' Understanding and Enactment of Resilience: A Grounded Theory."

I am seeking volunteers to participate in interviews related to their experience of stress, adversities, and challenges within their academic life. About 40-50 nursing students enrolled in your Bachelor of Science in Nursing Program will be able participate in individual interviews. Each individual interview will last about 1 to 1 1/2 hours. There will also be follow-up individual interviews with the participants in order to verify with the participants whether emerging findings are consistent with their experience.

I would like to ask that one of your staff members be the designated person to contact potential study participants by e-mailing students and informing them about the study. I also would like to arrange a time in which I can explain the study to the students in selected classroom sessions. This will also include providing the students a letter of information and flyer about the study and answering questions they may have. This process will last about 1015 minutes and may happen before, during, or after the selected classroom sessions. If possible, I would also like to ask for your permission to use some of the available rooms within the school where I can hold interviews.

It will be emphasized that participation in the study is voluntary. Students may refuse to participate in the study. Students who initially participated in the study may withdraw their data at any time up until all data analysis is complete, at which point they cannot withdraw their data. Their responses will remain anonymous and confidential. Their study participation or non-participation will have no academic consequence on their courses or program. Study participants will be provided a $\$ 10$ coffee voucher as a token of appreciation for participating the study. The complete explanation of the study is provided in the attached Letter of Information. 
If you have questions about the conduct of this study or the rights of the research participants, you may contact the Director of the Office of Research Ethics at the University of Western Ontario at Xxx-Xxx-Xxxx or email at

I thank you in advance for your time and consideration of my request. If you have any questions regarding this study, please do not hesitate to contact me. My contact information is indicated below. You can also contact my thesis supervisor, Dr. Mary-Anne Andrusyszyn, and her contact information is indicated below.

Sincerely,

Andrew Reyes, RN, MScN

PhD Candidate

Arthur Labatt Family School of Nursing

University of Western Ontario

(email, phone)

Thesis Supervisor:

Mary-Anne Andrusyszyn, RN, EdD

Professor and Director

Arthur Labatt Family School of Nursing

University of Western Ontario

(email) 


\title{
Appendix D: Letter of Permission to Promote the Study in a Classroom Session
}

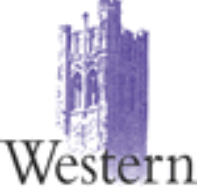 \\ Nursing Students' Understanding and Enactment of Resilience: \\ A Grounded Theory Study
}

Date:

Dear Course Professor,

I am a doctoral student in the Arthur Labatt Family School of Nursing, The University of Western Ontario. I am conducting a qualitative research study to generate insights about how nursing students manage the demands and challenges in their academic lives. The title of the research study is "Nursing Students' Understanding and Enactment of Resilience: A Grounded Theory."

In this study, I will be asking at least 40-50 nursing students enrolled in the Bachelor of Science in Nursing Program to participate in individual interviews. This individual interview will last about 1 to $1 \frac{1 / 2}{2}$ hours. They will be asked questions about their experience of stress, adversities, and challenges within their academic life. There will also be follow-up individual interviews with the participants in order to verify with the participants whether the emerging findings are consistent with their experience.

I have received approval from the Research Ethics Board of the University as well as the Dean/Director of the school of nursing to promote the study in selected classroom sessions. For this matter, I have chosen your particular classroom session (name of the course) on (day of the week of the course) at (time period of the class). The process of promoting the study will last for 10-15 minutes and it can be done at either before, during, or after your classroom session. If you allow me to promote the study, I would like to arrange a time with you when we could set up the specific details of when I could attend one of your classes.

In class, students will be provided with information about the study. Also during this time, it will be emphasized that participation in the study is voluntary. Students may refuse to participate in the study. Students who initially participated in the study may withdraw their data at any time up until all data analysis is complete, at which point they cannot withdraw their data. Their responses will remain anonymous and confidential. Their study participation or non-participation will have no academic consequence on their courses or program. Study participants will be provided a $\$ 10$ coffee voucher as a token of appreciation for participating the study. 
If you have questions about the conduct of this study or the rights of the research participants, you may contact the Director of the Office of Research Ethics at the University of Western Ontario at Xxx-Xxx-xxxx or email at

I thank you in advance for your time and consideration of my request. If you have any questions regarding this study, please do not hesitate to contact me. My contact information is indicated below. You can also contact my thesis supervisor, Dr. Mary-Anne Andrusyszyn, and her contact information is indicated below.

Sincerely,

Andrew Reyes, RN, MScN

PhD Candidate

Arthur Labatt Family School of Nursing

University of Western Ontario

(phone, email)

Thesis Supervisor:

Mary-Anne Andrusyszyn, RN, EdD

Professor and Director

Arthur Labatt Family School of Nursing

University of Western Ontario

(email) 


\title{
Appendix E: Letter of Information to Participants
}

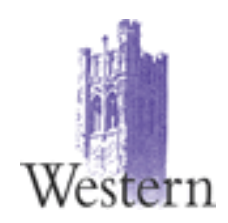

\author{
Letter of Information \\ Nursing Students' Understanding and Enactment of Resilience: \\ A Grounded Theory Study \\ Study Investigator: Andrew Reyes, RN, MScN, $\mathrm{PhD}(\mathrm{c})$ \\ Doctoral Candidate, Arthur Labatt Family School of Nursing, \\ University of Western Ontario \\ Telephone Number: $\mathrm{xxx}-\mathrm{xxx}-\mathrm{xxxx}$ \\ Thesis Supervisor: Mary-Anne Andrusyszyn, RN, EdD
}

Date:

Dear Nursing Student,

I would like to invite you to participate in a research study. I am a Registered Nurse completing my Doctor of Philosophy degree in Nursing at the Arthur Labatt Family School of Nursing, The University of Western Ontario under the supervision of Dr. Mary-Anne Andrusyszyn. The purpose of this study is to generate insights about how nursing students manage the demands and challenges within their academic lives. It is my hope that the results of this study will contribute to the development of programs and policies that will support nursing students to effectively cope and manage the demands, stress, and adversities within their academic life. It is estimated that there will be about 40-50 nursing students that will participate in the study.

If you take part in this study, you will participate in an interview with me. Before the interview, you will be given information about the study; then, an informed written consent to participate the study will be obtained. The interview will last about 1 to $1 \frac{1 / 2}{2}$ hours. You will be asked questions about your experience of stress, adversities, and challenges within your academic life. Following completion of all interviews, you will be invited to take part in a follow-up interview to discuss whether the emerging findings are consistent with your experience. This follow-up interview may last for 30 minutes to 1 hour. The interviews will take place at a location of your choice. We can meet at a room in your school, a community centre, or a place of your choice that is quiet and comfortable for you. Telephone interviews may be conducted if face-to-face interviews are not feasible for you. The interviews will be digitally recorded so that I may be able to pay careful attention to what you are saying. The interview will also be transcribed into written format.

During the interview, it is possible that you may experience physical and/or psychological discomfort and may not want to continue our interview. To the best of our knowledge, there is minimal risk associated with participating in this study. If you should require 
supplementary emotional support after the interview, I can provide you a list of counseling and other support services both offered by the university and other community agencies. On the other hand, having a chance to talk about important experiences may be helpful for you. It is possible that by talking about your experiences, you will begin to understand them in new or different ways. Most likely, the issues we will talk about are ones you have thought about before, but may not have had an opportunity to talk about with others. Potential benefits for participating in the study include increased insight and understanding about your own resilience and/or and lack of resilience in your academic life.

Participation in this study is voluntary. You are free to stop the interview at any time, and for any reason. You do not have to answer any questions that you do not want to answer. If you change your mind and decide that you do not want to take part in this research, you may do this at any time up until all data analysis is complete. When all data analysis is complete, withdrawal of your data is no longer an option. Your participation or non-participation will have no academic consequence on any of your course or your program. You will receive a $\$ 10$ coffee-shop voucher as a token of appreciation for participating in the study.

Anything you tell me will be strictly confidential and no real names will be used in reports of the study. To ensure your anonymity, no real names or identifying information will be included on the transcripts, nor in the analyzed data, or manuscripts. A code-number will be used to identify your data, but this code-number will not be shared with anyone else. When the results of this study are published, your name, any information disclosing your identity or that of your organization will not be released or published. All information that you provide about yourself will be encrypted and/or stored in a locked cabinet. A summary of what we have learned from this research will be given to you when the study is over. If you have any questions, please feel free to contact Dr. Mary-Anne Andrusyszyn who is my research supervisor, or me. We can be reached at the addresses/phone numbers listed below.

If you have questions about the conduct of this study or your rights as a research participant, you may contact the Director of the Office of Research Ethics at the University of Western Ontario at Xxx-Xxx-Xxxx or email at This letter is yours to keep for future reference. Thank you for your interest.

Sincerely,

Andrew Reyes, RN, MScN, PhD (candidate)

Arthur Labatt Family School of Nursing

University of Western Ontario

(email, phone)

Mary-Anne Andrusyszyn, RN, EdD

Thesis Supervisor, Professor, and Director

Arthur Labatt Family School of Nursing,

University of Western Ontario

(email) 


\section{Appendix F: Participant Consent Form}

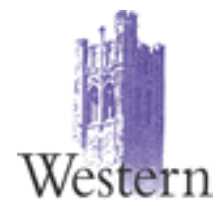

Participant Consent Form

Nursing Students' Understanding and Enactment of Resilience:

A Grounded Theory Study

I have read the Letter of Information. I have had the nature of the study explained to me. All questions have been answered to my satisfaction. I agree to participate in the study.

Printed name of participant:

Signature of participant:

Date:

Printed name of person obtaining informed consent:

Signature of person obtaining informed consent:

Date: 


\section{Appendix G: Demographic Data Questionnaire}

Nursing Students' Understanding and Enactment of Resilience:

A Grounded Theory Study

Demographic Data Questionnaire

\section{Participant Information:}

Unique Identification Number:

Age:

Year Level in the Nursing Program:

Gender:

\section{Living Accommodations:}

With whom do you live right now?

Do you live in the city or outside the city?

What kind of living accommodations are you in right now (dormitory, rooming house, shared apartment, etc.)?

\section{Commute to School:}

How often do you come to school?

How do you commute to school?

\section{Employment Information:}

Are you working at this time?

How many hours per week do you work?

What kind of work do you do?

Are you doing any volunteer work right now?

If so, what kind of volunteer work do you do?

\section{Family Information:}

Are you single, married, divorced, separated, etc.?

Do you have children?

How many children do you have?

How old are your children?

Do your children live with you?

Do you financially support your children?

Do you have siblings?

Do your siblings live with you?

\section{Academic Performance:}

What was your latest grade point average? 


\section{Within-School Extra-Curricular Activities:}

Are you involved in extra-curricular activities within the school?

What kind of extra-curricular activities within the school are you participating or involved right now?

\section{Out-of-School Extra-Curricular Activities:}

Are you involved in extra-curricular activities outside the school?

What kind of extra-curricular activities outside the school are you participating or involved right now?

\section{Cultural and Religious Background:}

What is your cultural or ethnic background?

What is your religious or spiritual background? 


\section{Appendix H: Recruitment Poster/Flyer for Students}

Nursing Students' Understanding and Enactment of Resilience:

A Ground Theory Study

\section{Attention: Nursing Students}

\section{Would you like to participate in a study about how you manage the demands and challenges within your academic life?}

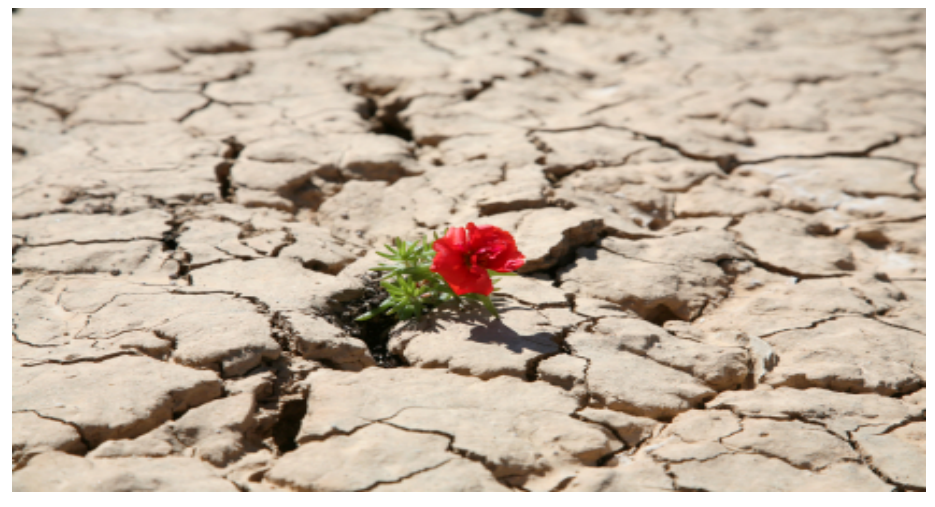

Volunteers will participate in:

- An interview for 1 to 1.5 hours

- Follow-up interview for 30 minutes to 1 hour

In the interview, I will ask you about:

- Your academic challenges, demands, and stressors

- How you cope with your stress

- How you overcome some of your difficulties in school and life

If you'd like to participate or receive more information about this study, contact:

Andrew Reyes, RN, MScN, PhD (candidate)

Arthur Labatt Family School of Nursing

University of Western Ontario

(email, phone) 


\section{Appendix I: Email Communication to Students Forwarded by the Designated School Staff Member}

To: Group E-mail Address of Nursing students enrolled in the four-year baccalaureate nursing program

Subject: UWO PhD Nursing Student Seeking Research Study Participants

Nursing Students' Understanding and Enactment of Resilience: A Grounded Theory Study

Dear Nursing Student,

I would like to invite you to participate in a research study about how nursing students manage the demands and challenges within their academic life. The findings of this study will contribute to the development of programs and policies that will support nursing students to effectively cope and manage the demands, stress, and adversities within their academic life.

In this research study, you will be asked to participate in an interview that will last for 1 to 1 $1 / 2$ hours. You will be asked questions about your experience of stress, adversities, and challenges within your academic life. You will also be asked to participate in a follow-up interview to discuss whether the emerging findings are consistent with your experience. The complete explanation of the study is provided in the attached Letter of Information.

Participation in this study is voluntary and confidential. If you are interested in participating in the study, please directly e-mail or call me. My contact information is indicated below.

Sincerely,

Andrew Reyes, RN, MScN, PhD (candidate)

Arthur Labatt Family School of Nursing

University of Western Ontario

(email, phone) 


\section{Curriculum Vitae}

Name:

Post-secondary Education and Degrees:

Honours and Awards:

Related Work Experience:
Andrew Thomas Reyes

Remedios Trinidad Romualdez Medical Foundation

College of Nursing

Tacloban City, Philippines

1987-1992 BScN

D'Youville College

Buffalo, New York, USA

2001-2003 MScN

Western University

London, Ontario, Canada

2006-2015 Ph.D.

Sigma Theta Tau International Honor Society of Nursing Iota Omicron Chapter Research Grant

2007

Registered Nurses Foundation of Ontario

Provincial Nurse Educators Interest Group Research Award 2007

Irene E. Nordwich Foundation Scholarship Award 2007

Registered Nurse

Schizophrenia and Forensic Mental Health

Centre for Addiction and Mental Health, Toronto, Ontario

1996-2001; 2008-current

Registered Nurse

St. Michael's Hospital, Toronto, Ontario

2002-2004

Manager of Nursing Education

Centre for Addiction and Mental Health, Toronto, Ontario 2004-2006

Clinical Instructor

School of Nursing, Faculty of Health

York University, Toronto, Ontario

2011-current 